Distribution Limited to Recipients Indicated ORNL

Central Files Number $58-7-4$

\title{
ANALYTICAL STUDY OF SOME ASPECTS \\ OF VORTEX TUBES FOR GAS-PHASE \\ FISSION HEATING
}

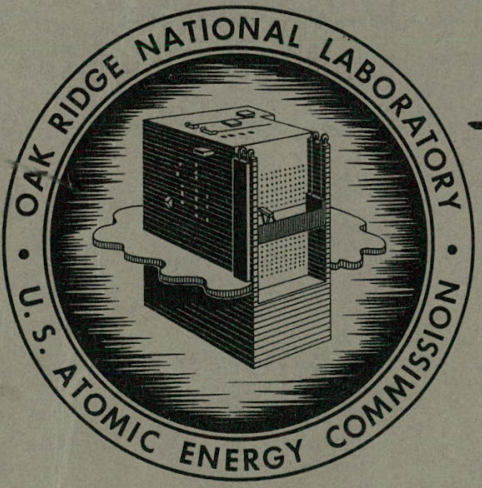

NOTICE

This document contains information of a preliminary nature and was prepared primarily for internal use at the Oak Ridge National Laboratory. It is subject to revision or correction and therefore does not represent a final report. The information is not to be abstracted, reprinted or otherwise given public dissemination without the approval of the ORNL patent branch, Legal and Information Control Department.

OAK RIDGE NATIONAL LABORATORY operated by

UNION CARBIDE CORPORATION

for the

U.S. ATOMIC ENERGY COMMISSION 


\section{DISCLAIMER}

This report was prepared as an account of work sponsored by an agency of the United States Government. Neither the United States Government nor any agency Thereof, nor any of their employees, makes any warranty, express or implied, or assumes any legal liability or responsibility for the accuracy, completeness, or usefulness of any information, apparatus, product, or process disclosed, or represents that its use would not infringe privately owned rights. Reference herein to any specific commercial product, process, or service by trade name, trademark, manufacturer, or otherwise does not necessarily constitute or imply its endorsement, recommendation, or favoring by the United States Government or any agency thereof. The views and opinions of authors expressed herein do not necessarily state or reflect those of the United States Government or any agency thereof. 


\section{DISCLAIMER}

Portions of this document may be illegible in electronic image products. Images are produced from the best available original document. 


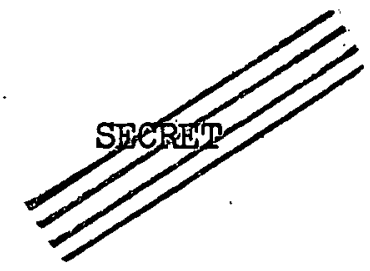

\section{UNCLASSIFHED}

C-86 NUCLEAR ROCKET ENGTNES

External Transmittal Authorized Distribution Iimited to Recipients Inäicated

ORNL

Central Files Number $58-7-4$

This document consists of 84 pages. Copy 75 of 109 copies. Series A.

Analytical Study of Some Aspects of

Vortex Tubes for Gas-Phase Fission Heating

J. L. Kerrebrock:

P. G. Lafyatis

July 21, 1958

Classification canceiled (oo clianged to UNCLASSIFIED

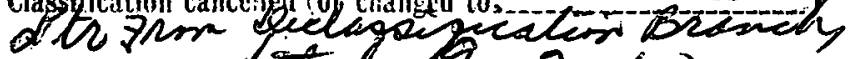
by authority of dited $2-2=60$ by Gillemos 2 TIE, date $10-7-60$

OAK RIDGE NATIONAL IABORATORY

Oak Ridge, Tennessee

operated by

UNION CARBIDE CORPORATION

for the

U.S. ATOMIC ENERGY COMMISSION

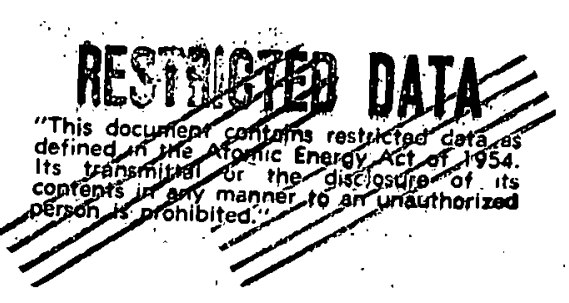


Internal Distribution

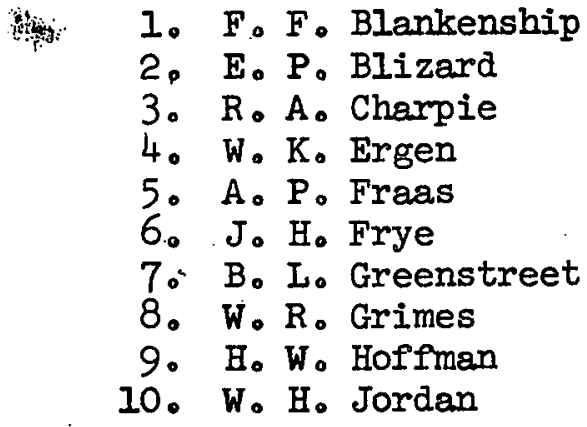

11. J. L. Kerrebroak

12. J. J. Keys

13. W. D. Manly

14-16: R. V. Meghreblian

17. R. F. Newton

18. J. A. Swartout

19. A. M. Weinberg

20. E. P.Wigner

Extèrnal Distribution

21. A. Ho Flagg, Aerojet-General Corp.

22. AFPR, Douglas, Long Beach

23. AFPR, North American Conoga Park

24. AFPR, North American Downey

25. Air Research and Development Command (RDGN)

26. Air Research and Development Command (RDZPSP)

27. Air Technical Intelligence Center

28. ANP Project Office, Convair, Fort Worth

29. Albuquerque Operations office

30. Armed Forces Special Weapons Project, Sandia

31. Armed Forces Special Weapons Project, Washington

32. Army Ballistic Missile Agency

33. Assistant Secretary of Defense, Rand (WSEG)

34.-37. Atomic Energy. Commission, Washington

38. Bureau of Aeronautics

39. C. D. Pengelley, BAR, Glenn I. Martin, Baltimore

40. Bureau of Ordnance

41. Bureau of Ordnance (SP-209)

42. Bureau of "Ships

43. General Electric Company (ANPD)

44. Headquarters, Air Force Special Weapons Center

45. J. B. Robinson, III, Headquarters, USAF; Washington

46...47. F. Goddard, Jet Propulsion Iaboratory

48. H. J. Stewart, Jet Propulsion Laboratory

49. P. Wegener, Jet Propulsion Laboratory

50.-51. J. Todd, Los Alamos Scientific Laboratory

52. Marquardt Aircraft Company

53.-54. F。 E。 Rom, National Advisory Comittee for Aeronautics, Cleveland

55. National Advisory Committee for Aeronautics, Washington

56. Office of Naval Research

57. Office of the Chief of Naval Operations (Op-361)

58. Office of the Chief of Ordnance

59. Patent Branch, Washington

60. Redstone Arsenal

61. San Francisco Operations Office

62.-63. G. Safanov, USAF Project RAND

64. U. S. Naval Ordnance Test Station

65. 66. University of California Radiation Laboratory, Livermore

67.-68. Western Development Division

69.-74. Wright Air Development Center. (WCOSI-3)

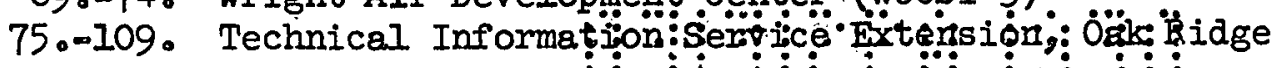


Several problems connected with vortex cavity reactors have been strdied analytically. They include: the generation of high strength vortices by utilization of bleed through a porous tube wall to stabilize the shear layer on the wall: the nuclear criticality problem; the suitibility of varlous compounds of plutonium as gaseouis fissionable materials; the problem of retaining the fission fragments within the vortex tube.

It is concluded that the shear layer on the vortex tube wall can be stabilized if a mass flow greater than or equal to the vortex through flow is bled through the porous wall, and that the tangential Mach numbers which can be obtained are then slightiy more than one half the imaligid values.

Beryllium oxide or graphite moderated reactors of reasonable size and weight can attain criticality if the product of the hydrogen pressure in the vortex core and the maximum value of the ratio of fissionable gas density to hydrogen density in the tube is greater than about 100 atmospheres. The re= actor weights are then in the order of 50,000 pounds or less.

Of the several compounds of plutonium considered as gaseous fuel carriers, plutonium trifluoride and plutonium tribromide appear to be the most promising. It is probable that they can be held in gaseous form in hydrogen, under the desired concentrations.

The rate of loss of fission fragments from the vortex tube can be reduced to a small fraction of the rate of their generation by making the vortex tubes about twice the minimum size which is:allowable for satisfactory retention of the fissionable materiai. 


\section{Table of Contents}

Summary

Page

General Introduction

Section I a Vortex Recirculation

Influence of wall bleed on the vortex

Effectivenews of vortex formation

Stabilization of the shear layer

13

Effect of wall bleed on the separation process

Recirculation systems

21

Gas turbine cycle

22

Fropellant turbine cycle

28

Conclusions

Section II - Criticality

Derivation of nucleas contacts from separation calculations

Reactor code.

40

Resurts

4.1

Conclusions

Section III - Gaseous Fissionable Compounds for Vortex Reactors 48

Possible fuel carriers

Volacility

50

Chemical equilibxium

50

Calculation of free energies

53

Requirements imposed by vapor pressure and equilibrium

60

Conclusions

60

Section IV - Fission Product Retention

62

Nomenclature 64

Differential equations 66

Boundary conditions 70

Leakage rate 71

Numerical examele

Conclusions 
INTRODUCTION

A method was proposed in Ref. I for holding gaseous fissionable material in a vortex tube, against the radial flow of a fluid which was to be heated to a high temperature. The process of diffusion of a low molecular weight gas through the high molecular weight fissioning gas was considered in some detail. It was concluded that if laminar vortices of the required strength could be generated with the radial mass flow rates required by the diffusion process, then the vartex tube held promise as a device for producing very high temperature gases, for example for rocket propulsion.

In the first section of this report; a method for producing laminar vortices of the required strength will be suggested. It consists of a recirculatory system in which the mass flow through the tangential vortex driving nozzles is increased beyond the amount allowed by the radial diffusion process: the excess mass flow is bled off through a porous vortex tube wall. The bled fluid must be returned to the nozzle entrance conditions, and some methods for doing this will be proposed. Bleeding of the fluid through the porous wall is equivalent to sucking a boundary layer: the shear layer on the vortex tube wall is thinned and its Reynolds ${ }^{8}$ number reduced. Thus, there seems to be some possibility that the shear layer may be stabilized and a laminar vortex produced. The scheme has the additional advantage that the porous tube wall will be effectively cooled by the bled fluid:

Although the diffusionobeating process considered in Ref。 1 is evidently the key problem to be solved in applying the vortex tube to rocket propulsion, the high temperatures envisioned, and the gaseous state of the fissionable material, give rise to other problems which must be studied before the application of the vortex tube to rocket propulsion can be seriously considered. Some of these problems will be indicated, and the progress made to date in studying them will be surmarized.

Because of the gaseous form of the fissionable material, and the limitations imposed by the vortex aseparation process ${ }^{(1)}$, it seems that 
the fuel concentration in a reactor composed of vortex. tubes must be rather low. The available fuel concentrations are about one tenth of the usual values for small, highly poisoned reactors. The critical sizes (and weights). of the vortex reactors thus tend to be large. A series of criticality calculations has therefore been done, with the emphasis on minimizing the reactor weight for a given fuel concentration. These calculations have been carried out by P.G. Lafyatis, and will be dis. cussed in section II.

It was implicitly assumed in Ref. I that some compound of plutonium, or uranium, could be found, which could be held in gaseous form under the desired conditions. Rather high concentrations of fissionable material must be held at very high temperatures and under reducing conditions, if bydrogen is to be used as propellant. There is some doubt as to whether any material can be found which will satisfy these requirements, since the compounds of uranium and plutonium which are stable at high temperatures are neither very volatile nor very resistant to reduction by hydrogen. This problem will be considered in section III.

The fissioning of uranium or plutonium in the vortex tubes will prom duce rather large quantities of very radioactive fission products. If these fission products are discharged to the atmosphere contamination will result. However, since the fission products will in general have rather high molecular weights, there is some possibility that a considerable fraction of those produced will be held in the vortex tubes along with the fissionable material. A calculation of the rate of loss of the fission fragments from the vortex tube has been carried out by the methods used in Ref. 1, and will be discussed in section IV. 
STrop rom

$-7 \infty$

?

SECTION I

Vortex Recirculation 


\section{Introduction:}

In the analysis of vortex heating-separation tubes presented in Ref. 1 , it was assumed that the flow in the vortex tube was laminar and inviscid. It was demonstrated that, for laminar flow, viscous effects would not prevent the formation of vortices of sufficient strength to give the desired separation. It was also pointed out that even though the Reynolds " number (based on tube diameter and tangential velocity) of the flow is very large, there is a possibility of obtaining laminar flow because of the large den sity gradients produced by the action of the vortex field on the heavy fissionable gas. However, if this stabilizing effect is not sufficient to maintain laminar flow, there seems to be little possibility of obtaining vortices of adequate strength in the simple tube described in Ref. 1.

Accordingly, a method of improving the effectlveness of vortex forma tion has been considered. The essential idea is to reduce the Reynolds" number of the wall shear layer, by bleeding fluid through a porous wall, to the extent that it will remain laminar. The viscous effects on the vortex strength will then be predictable, and much smaller than they would be if the shear layer were turbulent.

All of the fluid which is bled from the vortex tube through its porous wall must be returned to the conditions at the entrance to the inlet nozzles, and recycled, at least for rocket propulsion applications. It seems possible to do this by means of a gas turbine cycle operating between the reactor as a heat source and the fresh propellant as a heat sink.

It is logical to divide the following discussion into two parts. In the first, the influence of the porous wall bleed on the velocity profile, vortex strength, and radial diffusion, is considered. In the second, some methods of recycling the bled fluid are discussed.

Influence of wall bleed on the vortex:

It was shown in Ref。 I that the tangential momentum equation for the vortex flow may be written as follows, if the flow is laminar:

$$
\frac{d\left(v_{0} / v_{j}\right)}{d r^{8}}+\frac{\left(v_{0} / v_{j}\right)}{r^{i}}=-\frac{2 \pi j}{m} \cdot r^{0}\left\{\frac{d^{2}\left(v_{0} / v_{j}\right)}{d r^{02}}+\frac{1}{r^{1}} \frac{d\left(v_{0} / v_{j}\right)}{d r^{0}}-\frac{\left(v_{0} / v_{j}\right)}{r^{12}}\right\} . \quad I-(I)
$$


The tangential velocity, $v_{0}$, is referred to the exit velocity from the inlet nozzles; $v_{j}$, and the radius has been made dimensionless by division by the radius at which the jets enter the tube (see Fig. 1 )。 Mis the radial mass flow rate, and is positive for inward flow. It has been assumed in writing Eq. (1) that $\mu$ is constant. Inclusion of the variation of $\mu$ would complicate the following analysis greatly, and would not change the results significantly.

From Eq. (1), it is clear that the quantity $2 \pi \mu / m_{\text {g }}$ which will be denoted by $K$, measures the importance of viscous effects in the vortex. If the absolute value of $\mathrm{K}$ is large, viscous forces predominate; if it is small, inertial forces predominate. The solution of Eq. (1) may be written as

$$
\frac{v_{0}}{v_{j}}=A_{1}\left(r^{i}\right)^{-\frac{1-K}{K}}+A_{2}\left(r^{i}\right)^{-1} .
$$

The flow consists of two regions. In the inner region $\left(r^{P}<1\right), K$ is positive, while in the outer region $\left(r^{*}>1\right), K$ is negative. Appropriate boundary conditions are as follows:

1. The velocity must be continuous at $r^{\prime}=1$.

2. The torque exerted on the exterior region by the interior region, at $r^{1}=1$, must be zero.

3. The velocity must be zero at the tube wall.

4. The torque exerted on the fluid in the tube, by the entering jets of fluid, must equal that due to viscous shear at the tube wa.11.

The last two conditions are sufficient to specify the flow in the outer region, since the last condition effectively determines $v_{0}$ at $r^{\prime}=1$. The first two conditions would then determine the flow in the inner region, but this in formation w1ll not be needed in the following analysis. Applying the third boundary condition. we find,

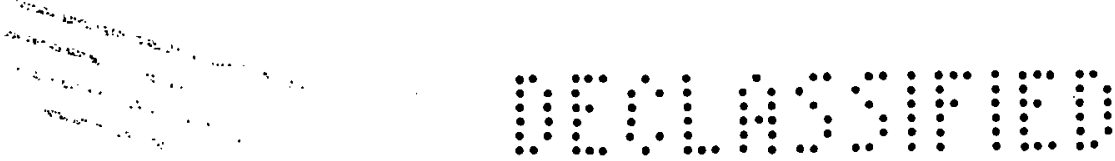




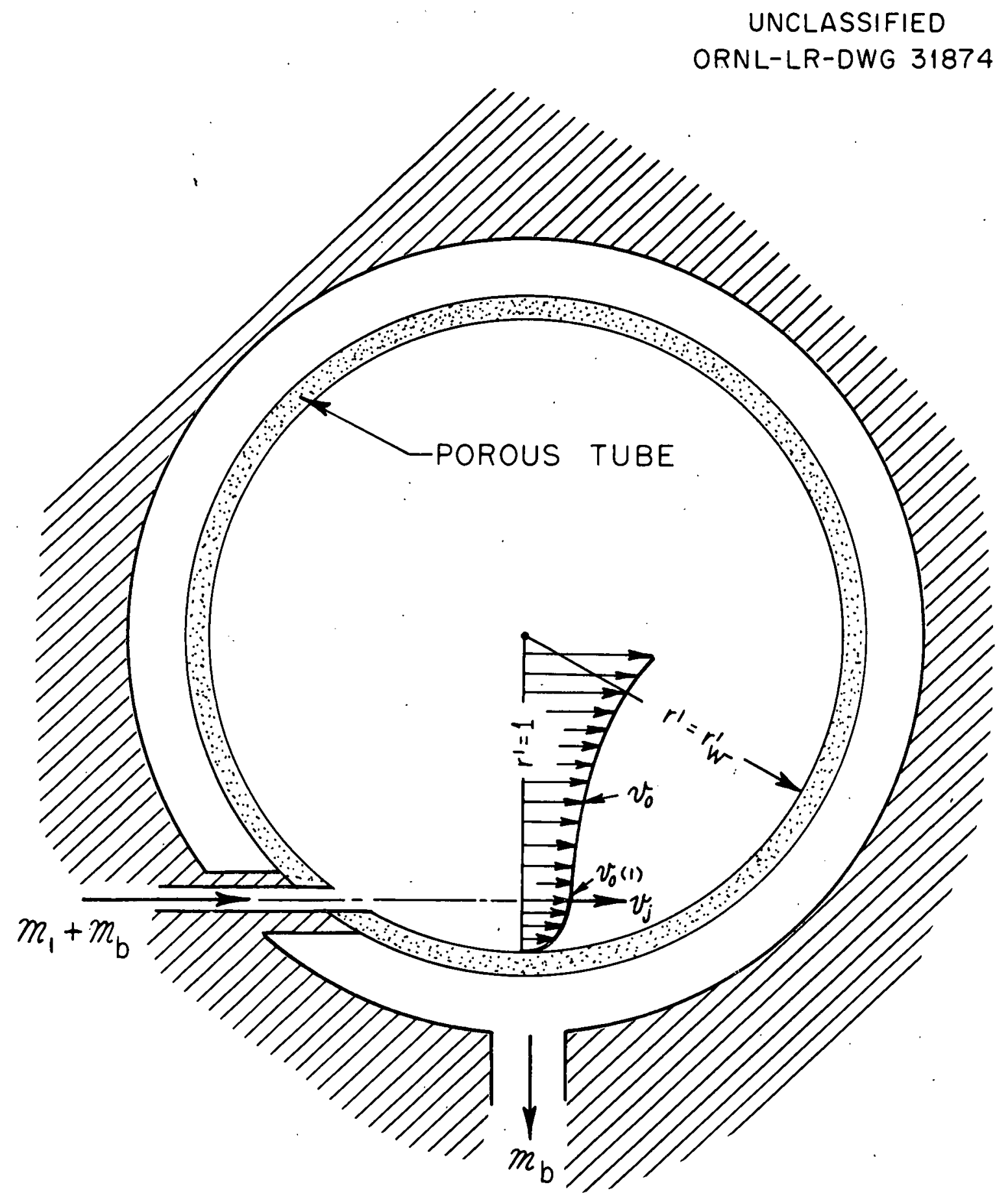

Fig. 1. Withdrawal of fluid through Porous Wall. 


$$
A_{2}=-A_{1}\left(r_{w}^{0}\right)^{2-\frac{1}{K}}
$$

where $r_{\mathrm{w}}^{\prime}$ is the value of $r^{\prime}$ corresponding to the tube radius. The fourth condition gives

$$
\left(m_{1}-m_{b}^{\prime}\right)\left[1-\frac{v_{o}(1)}{v_{j}}\right]=-\left.\mu \frac{d}{d r^{i}}\left(\frac{v_{0}}{v_{j}}\right)\right|_{r_{w}^{i}} 2 \pi\left(r_{w}^{i}\right)^{2},
$$

where $m_{1}$ and $m_{b}$ are the radial and bled mass flows.

We then have,

$$
\frac{v_{i o}}{v_{0}(1)}=\left(x^{\prime}\right)^{-1}\left\{\frac{\left(r^{\prime}\right)^{2-\frac{1}{K}}-\left(r_{w}^{8}\right)^{2-\frac{1}{\bar{K}}}}{1-\left(x_{w}^{8}\right)^{2-\frac{1}{K}}}\right\} .
$$

where

$$
\frac{v_{0}(I)}{v_{j}}=\frac{1}{1+\frac{1-2 \mathrm{~K}}{\left(1-\frac{m_{1}}{m_{b}}\right) \cdot\left[1-\left(r_{\mathrm{w}}^{0}\right)^{\frac{1}{\mathrm{~K}}-2}\right]}} .
$$

Effectiveness of vortex formation:

The effectiveness of vortex formation is indicated directly by the ratio $v_{0}(1) / v_{j}$, from Eq. (4). This ratio is plotted in Fig. 2 , for a range of $m_{b} / m_{I}$, for $2 \pi \mu / m_{I}=0.02$. The values indicated in Fig. 2 for $m_{\mathrm{b}} / m_{I}=0$ are somewhat smaller than were given in Ref. I, Fig. 23. 
UNCLASSIFIED

ORNL-LR-DWG 30565

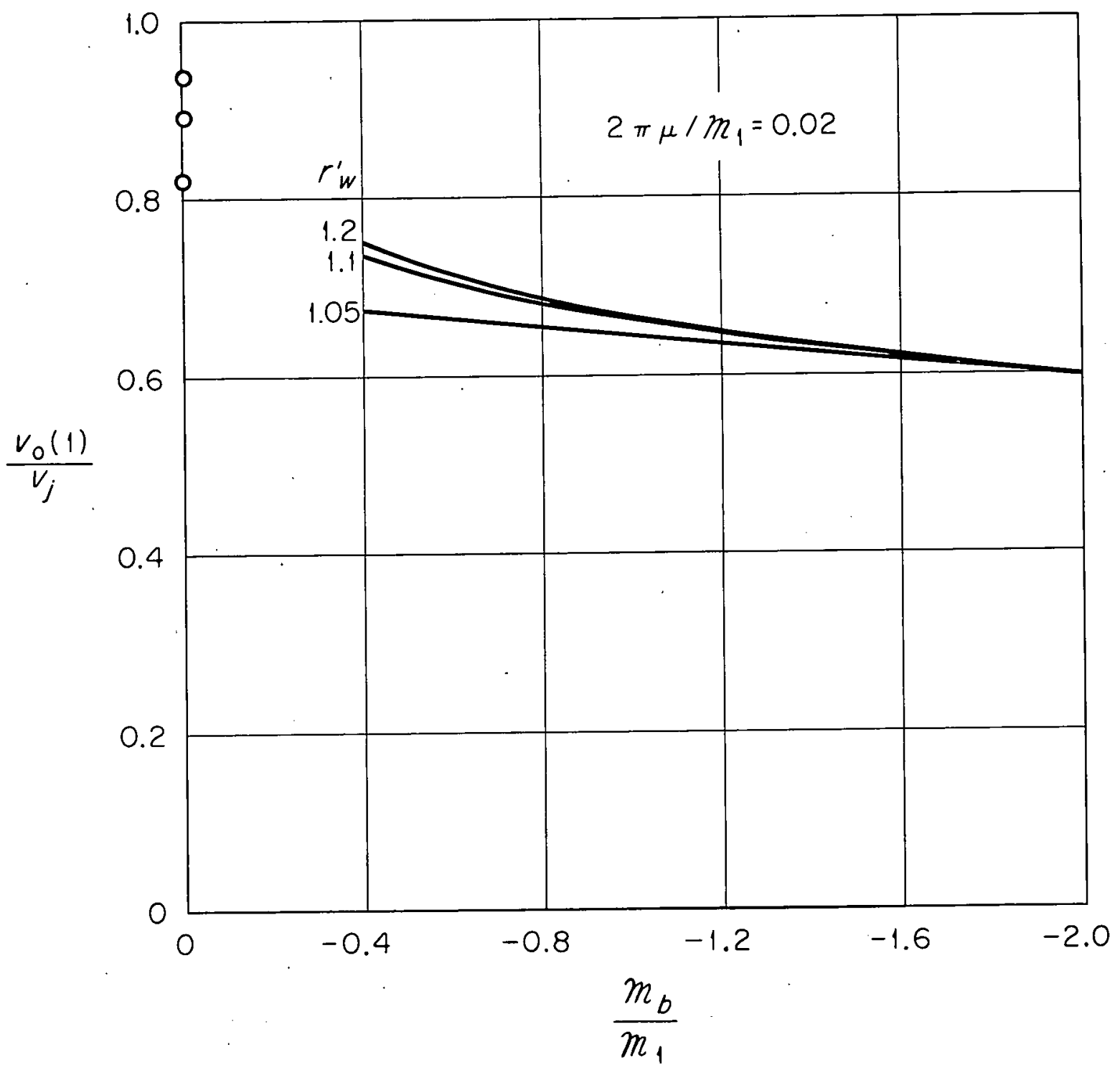

Fig. 2. Variation of Effectiveness of Vortex Formation, $v_{0}(1) / v_{j}$, with Bleed to Radial Mass Flow Ratio, $m_{b} / m_{1}$, and Dimensionless Tube Radius $r_{w}$. 
A. Pactor of two: : was!' omittedif from the second : term in the denominator of

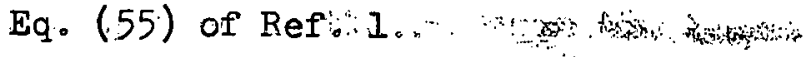

It is clear that bleeding through the wall reduces the strength of a laminar vortex, but not to a very large extent. As - $\mathrm{K} \rightarrow 0$ for fixed M $_{1}$, Eq. (4) gives $v_{0}(1) / v_{j}=1 / 2$ as a limiting value. Thus, if the vortex can be kept laminar by bleeding through a porous wall, it seems that tangeno tial velocities greater than one half the inviscid values will be obtained.

\section{Stabilization of the shear layer:}

Calculations of the stability of laminar shear flows result in curves giving the Reynolds" number for which the shear layer is neutrally stable to excitation of a specified wave length. For each such curve there is some Reynolds number below which the shear layer is stable to excitation of all wave lengths. This value is usually termed the critical Reynolds' number, $\mathrm{Re}_{\mathrm{cr}}$.

The critical Reynolds number is defined in terms of the stream velocity at infinity, and the displacement thickness of the shear layer. Its value depends rather strongly on the velocity profile in the shear layer, ranging from about 420 for a Blasius profile on a flat plate to 70,000 for an asymptotic suction profile on a flat plate ${ }^{(2)}$.

For the shear layer on the vortex tube wall we may define a displacement thickness, $\delta^{*}$, by:

$$
\delta^{*}=r_{w} \int_{1}^{r^{8}}\left\{1-\frac{v_{0}}{v_{0}(1)}\right\} d r^{8}
$$

Using Eq. (3), we find:

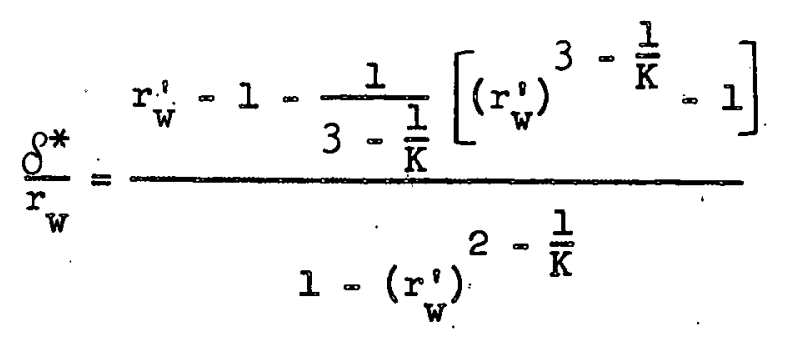


Now the velocity ratio, $v_{0} / v_{0}(I)$ may be given as a function of $\left(r_{w}-r\right) / \delta^{*}=$ $\left(r_{\mathrm{w}}^{\prime}-r^{\prime}\right) r_{\mathrm{w}} / \delta^{*}$. A typical vortex tube shear layer profile is compared to the Blasius and asymptotic suction profiles in this fashion in Fig. 3 . It appears that the vortex tube profile is very close to the plate suction profile, apart from a scale factor which results from the finite limit in the above definition of $\delta^{*}$. Thus, if the density were constant through the shear layer, its critical Reynolds' number would be slightly greater than $0.7 \times 10^{5}$. It will be shown in the next section that the influence of the wall bleed on the heavy gas is such as to produce an appreciable positive density gradient in the direction of increasing $r^{\prime}$. Such a density gradient, in combination with the radial force field produced by the vortex, will tend to stabilize the shear layer, hence it is concluded that the critical Reynolds' number will be somewhat greater than $10^{5}$.

Ratios of $\delta^{*}$ to the tube radius, computed from Eq. (6), are shown in Fig. 4. It is clear that bleeding reduces the displacement thickness markedly, för fixed $r_{w^{*}}^{\prime}$ In fact, for $K$ sufficiently small, and $r_{w}^{\prime}$ not too near unity, $\delta^{*} / r_{W}$ is very nearly equal to $-K r_{w^{\prime}}^{\circ}$

The significance of the above values will be best illustrated by an example. From Table I, p. 6l, Ref. 1 , the Reynolds' number for case 2 is found to be: $\operatorname{Re}=7.38 \times 10^{6}\left(8^{*} / r_{W}\right)$, for a tube radius of one inch. Thus, we find the following values:

\begin{tabular}{l|ccccc}
\hline$m_{0} m_{1}$ & -0.17 & -0.33 & -0.67 & -1.35 & -6.7 \\
\hline$K$ & 0.0 .04 & -0.02 & -0.01 & -0.005 & -0.001 \\
\hline $\operatorname{Re}$ & $2.0 \times 10^{5}$ & $1.4 \times 10^{5}$ & $0.96 \times 10^{5}$ & $0.38 \times 10^{5}$ & $0.74 \times 10^{4}$ \\
\hline
\end{tabular}

If the above estimate of $10^{5}$ for $R_{c r}$ is valid, the shear layer should be stabilized by a mass flow ratio (bleed to radial) of about unity. 


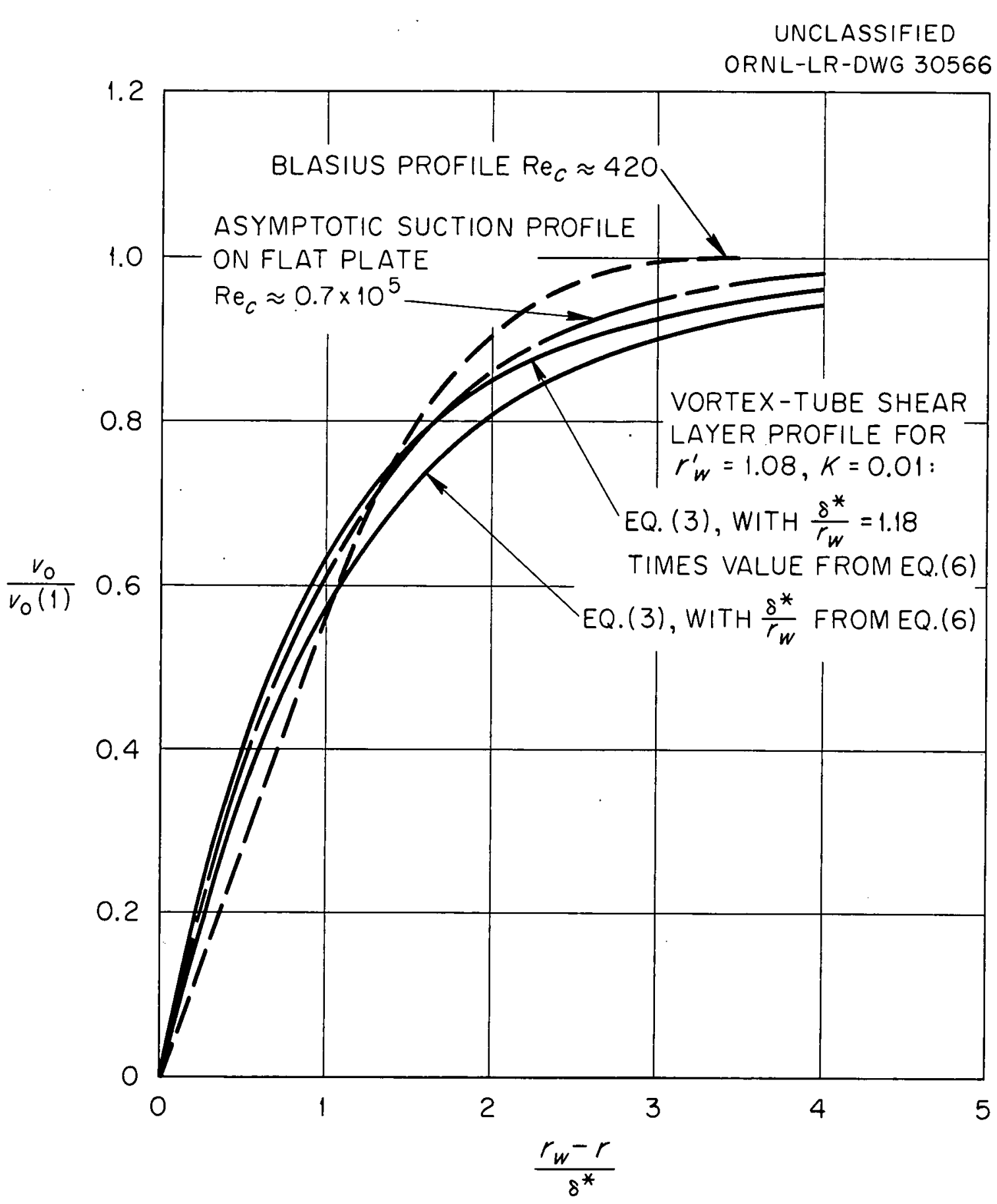

Fig. 3. Comparison of Vortex Tube Shear Layer Velocity Profile with Blasius and Asymptotic Flat Plate Suction Profiles.

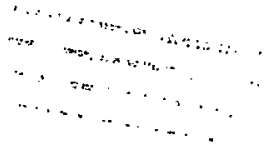




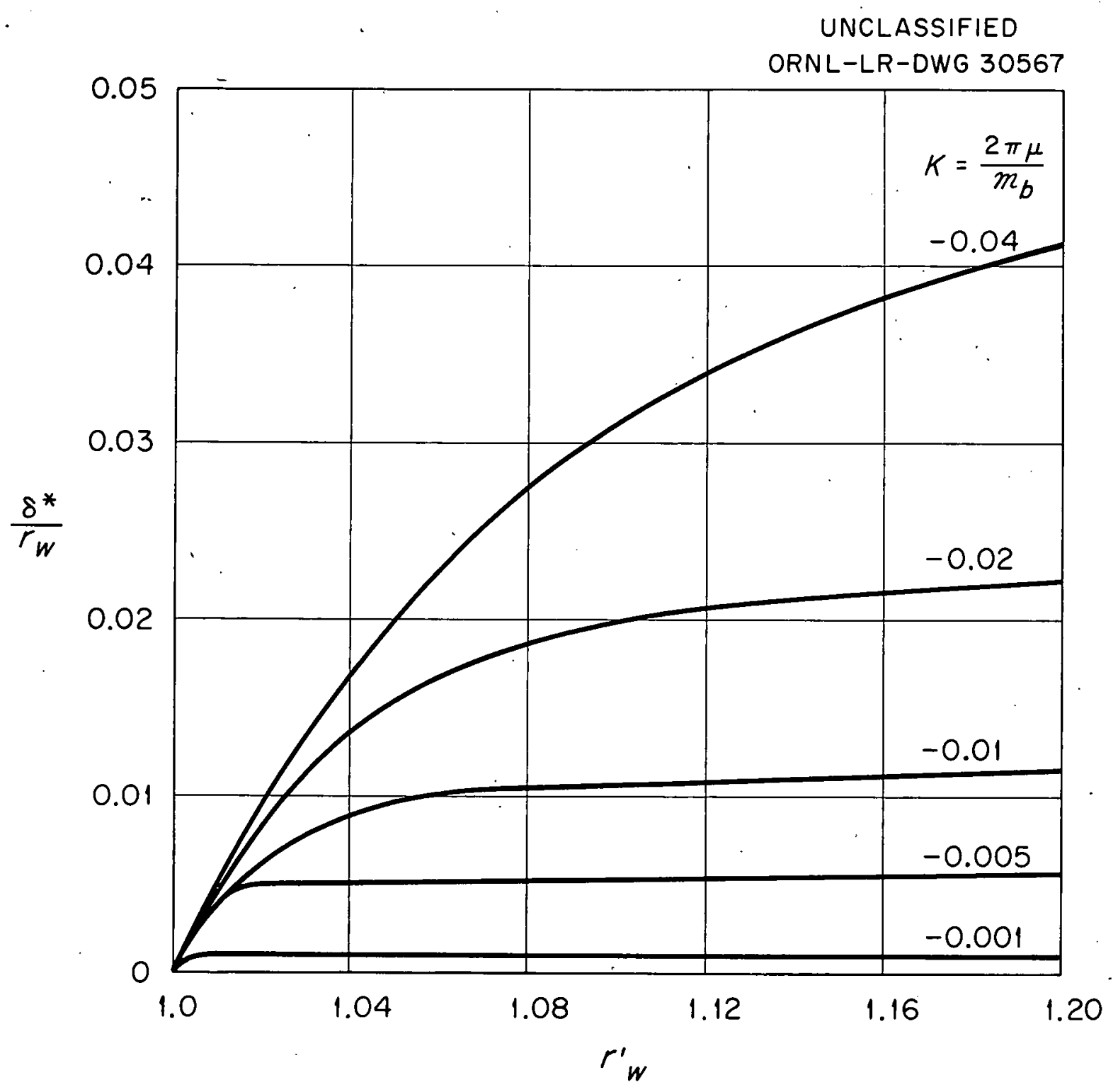

Fig. 4. Variation of Ratio of Shear Layer Displace ment Thickness to Tube Radius, $\delta^{*} / r_{w}$ with Bleed Mass Flow Rate and Dimensionless Tube Radius. 
Effect of wall bleed on the separation process:

The analysis of Ref. I considered a free vortex with radial flow, bounded on the outside by a solid tube wall. It is now proposed that a region with radial outflow be interposed between the free vortex core and the tube wall. The influence of this region of reversed mass flow on the separation effect wili be estimated in this section, by the methods of Ref。I.

A model for the flow is shown in Fig. 5. It is assumed that fluid is introduced with an effective tangential Mach number $M_{t p}$ of total amount $m_{1}\left(1+w_{c}\right)=m_{b}\left(1+w_{b}\right)$ per unit of tube length, uniformly over the cylindrical surface of radius $r^{\prime}=1$. Of this total amounits $m_{I}\left(1+w_{c}\right)$ then flows inward; while $=m_{b}\left(1+w_{b}\right)$ flows outward. The mass flows of light gas are $M_{1}$ and $M_{b}$ ? while $w_{c}$ and $w_{b}$ are the ratios of heavy gas density to light gas density at the vortex exit and in the gas bled through the wall.

It is readily seen from Eq. (22a) of Ref. I that the ratio of heavy gas density to light gas density, $w_{0}$ is governed by the following equation:

$$
1-\frac{w_{b}}{w}=D_{p} \frac{1+w_{b}}{1+w_{p}} T^{i \frac{1}{2}}\left\{\left(\frac{m_{2}}{m_{1}}-1\right) \frac{\gamma M_{t p}^{2}}{T^{\prime}} v_{0}^{02}-\frac{r^{\prime}}{w} \frac{d w}{d r^{\prime}}\right\},
$$

where the primes indicate values divided by their respective values at $r=r_{p}$, the jet entry radius. The quantity $D_{p}$ is given by Eq. (24) of Ref。I as,

$$
D_{p}=\frac{3(2 \pi)^{\frac{1}{2}}}{8}\left(\frac{k^{\frac{1}{2}} m_{1}^{\frac{1}{2}}}{d_{12}^{2}}\right)\left(1+\frac{m_{1}}{m_{2}}\right)^{\frac{1}{2}}\left(\frac{1+w_{p}}{1+w_{b}}\right) \frac{T_{p}^{\frac{1}{2}}}{m_{b}}
$$

where $k$ is Boltzmann's constant, $d_{12}$ is the equivalent hard sphere diameter for collisions between light and heavy gas molecules, and $m_{1}$ and $m_{2}$ are the masses of the light and heavy molecules. $M_{t p}$ is the actual tangential Mach number of the vortex at the jet entry radius. 


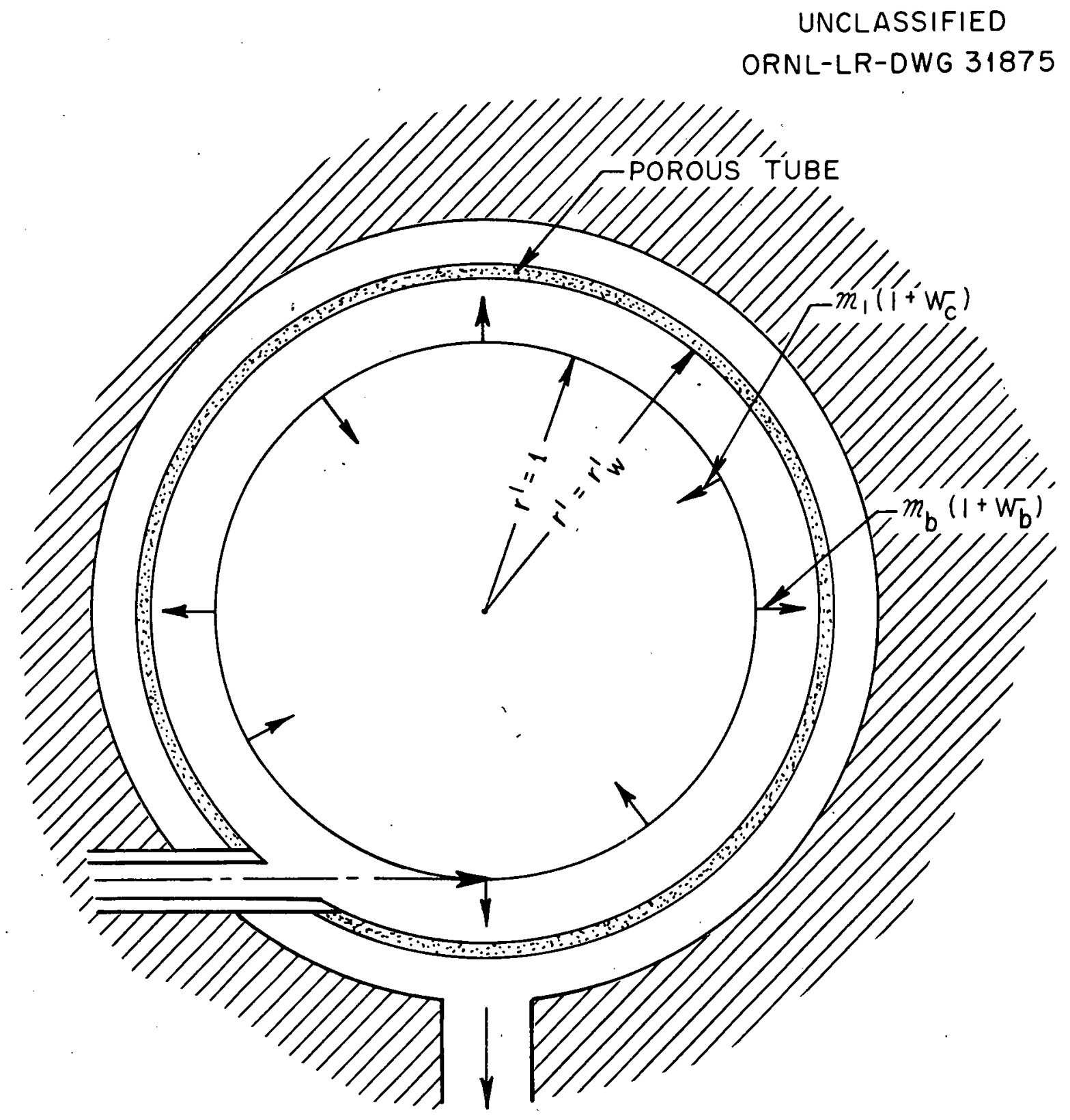

Fig. 5. Model Used for Calculation of Effect of Wall Bleed on Vortex Diffusion. 
We wish to Investigate the behavior of $w$ in a range of $r$ 'from unity to a value, $r_{w}^{\prime}$ slightly greater than unity. Because of the narrow range of $r^{\prime}$ to be considered, and the fact that $T^{\prime}$ varies quite slowly with $r^{\prime}$ in regions of the tube where $w$ is small, $T^{\prime}$ will be taken equal to unity. It is felt that it will be necessary to insist that $w$ be small near the tube wall if the bleed system is to be used, since otherwise large concentrations of fissionable material would enter the recirculation system. The dimensionless velocity $v_{0}^{\prime}$, is given by Eq. (3), so that for $T^{\prime}=1$, we have,

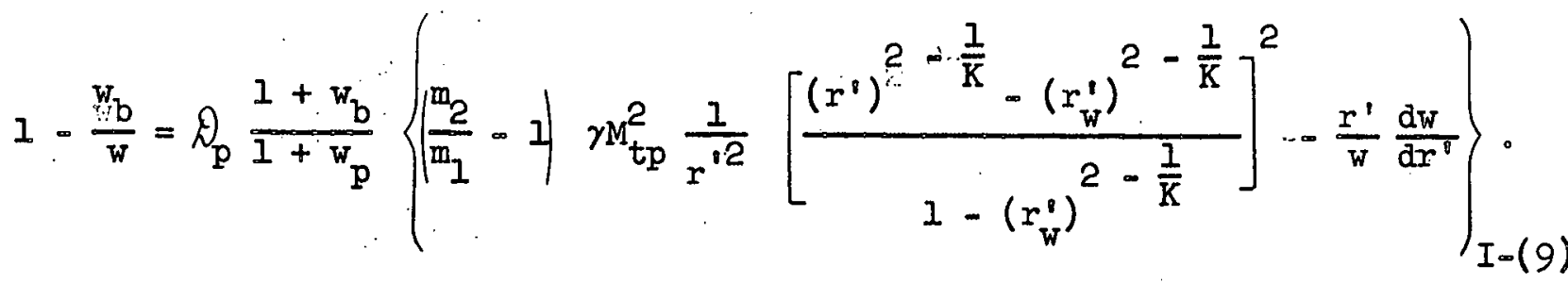

The quantity $\mathscr{D}_{p}$ shows the influence of the radial mass flow on the system. It can be written in terms of the characteristic parameters of the vortex core and the mass flow ratio, $m_{b} m_{1}$, as follows (see Eqs. (25) and (34), Ref.1)

$$
\partial_{\mathrm{p}} \frac{1+\mathrm{w}_{\mathrm{b}}}{I+\mathrm{w}_{\mathrm{p}}}=\mathrm{T}_{\mathrm{p}}^{* \frac{1}{2}} \frac{1-\mathrm{w}_{\mathrm{c}} / \mathrm{w}_{\mathrm{m}}}{\gamma \mathrm{M}_{\mathrm{tm}}^{2}\left(\frac{\mathrm{m}_{2}}{\mathrm{~m}_{1}}-1\right)} \frac{m_{1}}{m_{\mathrm{b}}} .
$$

Equation (9) may now be written in the following form:

$$
\begin{aligned}
& \frac{\mathrm{d}\left(\frac{\mathrm{w}}{\mathrm{w}_{\mathrm{b}}}\right)}{\mathrm{dr^{0 }}}=\frac{\gamma \mathrm{M}_{\mathrm{tm}}^{2}\left(\frac{\mathrm{m}_{2}}{\mathrm{~m}_{1}}-1\right)}{\left(1-\frac{\mathrm{w}_{\mathrm{c}}}{\mathrm{w}_{\mathrm{m}}}\right) \mathrm{T}_{\mathrm{p}}^{\frac{1}{\mathrm{~F}^{2}}}} \frac{m_{\mathrm{b}}}{m_{1}}\left(\frac{1-\frac{\mathrm{w}}{\mathrm{w}_{\mathrm{b}}}}{\mathrm{r}^{8}}\right)+ \\
& r M_{t p}^{2}\left(\frac{m_{2}}{m_{1}}-1\right) \cdot\left[\frac{\left(r^{1}\right)^{2-\frac{1}{K}}-\left(r_{w}^{0}\right)^{2-\frac{1}{K}}}{I-\left(r_{w}^{1}\right)^{2-\frac{1}{K}}}\right]^{2} \frac{\left.\mid \frac{w}{w_{b}}\right)^{3}}{r^{3}}
\end{aligned}
$$


This equation is linear, and hence integrable; however, the general solution is quite involved because the coefficient of $\mathrm{w} / \mathrm{w}_{\mathrm{b}}$ is complicated. On the other hand, it is expected that $\mathrm{w} / \mathrm{w}_{\mathrm{b}}$ will be close to unity in the cases of interest. In this case $\mathrm{w} / \mathrm{w}_{\mathrm{b}}$ may be taken as unity in the last term, to a first approximation. The integration is then easy and yields,

$$
\begin{aligned}
& 1-\frac{\mathrm{w}}{\mathrm{w}_{\mathrm{b}}}=\frac{\gamma \mathrm{M}_{\mathrm{tp}}^{2}\left(\frac{\mathrm{m}_{2}}{\mathrm{~m}_{1}}-1\right) \mathrm{r}_{\mathrm{w}}^{2-\frac{2}{\mathrm{~K}}}}{\left(1-\mathrm{r}_{\mathrm{w}}^{2}-\frac{1}{\mathrm{~K}}\right)^{2 !}}\left\{\frac{1}{\alpha+2-\frac{2}{\mathrm{~K}}}\left[\left|\frac{\mathrm{r}^{\prime}}{\mathrm{r}_{\mathrm{w}}^{\prime}}\right|^{-\alpha}-\mid \frac{\mathrm{r}^{\prime}}{\mathrm{r}_{\mathrm{w}}^{\prime}}\right)^{2-\frac{2}{\mathrm{~K}}}\right] \\
& \left.-\frac{2}{\alpha-\frac{1}{\mathrm{~K}}}\left[\left(\frac{r^{\prime}}{r_{\mathrm{W}}^{\prime}}\right)^{-\alpha}-\left(\frac{r^{\prime}}{r_{\mathrm{W}}^{\prime}}\right)^{-\frac{1}{\bar{K}}}\right]+\frac{1}{\alpha+2}\left[\left(\frac{r^{\prime}}{r_{\mathrm{W}}^{\prime}}\right)^{-\alpha}-\left(\frac{r^{\prime}}{r_{\mathrm{W}}^{\prime}}\right)^{-2}\right]\right\}
\end{aligned}
$$

where

$$
\alpha=\frac{\gamma M_{t m}^{2}\left(\frac{m_{2}}{m_{1}}-1\right)}{\left(1-\frac{w_{c}}{w_{m}}\right) T_{p}^{* 1 / 2}} \frac{m_{b}}{m_{1}}
$$

According to the estimates given in the previous sections, $K$ must be of order - 0.01 if the shear layer is to be stabilized, and this gives $m m_{b} / m_{1}=-0.67$, for the example quoted previously. Thus, for the cases considered in Ref. $1, \alpha$ is about -100 . Since $-\alpha$ and $-1 / \mathrm{K}$ are then large positive numbers, all terms of Eq. (12) except the last are negligible for $r^{\prime}$ appreciably less than $r_{\mathrm{w}}^{0}$. We therefore find,

$$
\left.I-\frac{w}{w_{b}} \approx\left(1-\frac{w_{c}}{w_{m}}\right)\left(\frac{M_{t p}}{M_{t m}}\right)^{2} T_{p}^{* 1 / 2} \frac{1}{r^{2}} \mid-\frac{M_{1}}{m_{m_{b}}}\right) .
$$


For the cases of interest (e.g. case 2, Table I, p.6I, Ref. I), the factor $\left(\mathrm{M}_{\mathrm{tp}} / \dot{\mathrm{M}}_{\mathrm{tm}}\right) \mathrm{P}_{\mathrm{p}}^{* 1 / 2}$ is about unity。Thus at $\mathrm{r}^{8}=I_{\mathrm{g}} \mathrm{w} / \mathrm{w}_{\mathrm{b}}$ is nearly equal to $1+m_{1} / m_{b}$. If $=m_{b} / m_{I}$ is $2, w_{b} / w_{p}$ is then about 2.5 . Replacing $\mathrm{w} / \mathrm{w}_{\mathrm{b}}$ by unity in the last term of $\mathrm{Eq}$. (17) results in an overestimate of $\mathrm{w}_{\mathrm{b}} / \mathrm{w}_{\mathrm{p}}$, since the last term is positive and would in fact be everywhere smaller than it has been assumed to be.

The analysis therefore indicates that the ratio of the wall density ratio to that at the free vortex periphery will be less than 2 , if $-m_{b} / m_{1}$ is 2 or more. A mass flow ratio of 2 should, according to the previous section, be sufficient to stabilize the shear layer, so that it seems sufficient to produce the desired vortex strength. Therefore in the following analysis of recirculation systems, a mass flow ratio of 2 will be regarded as a minimum which the recirculation system must allow to be satisfactory.

\section{Recirculation systems :}

The purpose of the recirculation system is to return the fluid bled through the porous tube wall to a condition such that it can be reintroduced to the vortices through the entrance nozzles. In passing through the wall shear layer and porous tube, the fluid will in general suffer a total pressure loss and a stagnation temperature increase, the latter because it contains fissionable material. Thus, the recirculation system must increase the total pressure of the fluid, and decrease its stagnation temperature.

The two devices which are to be proposed for this purpose are essentially heat engines, their energy source being in both cases the heat picked up by the bled fluid during its residence within the vortex tube, and their net work supplying the desired total pressure rise. Any heat engine must reject a considerable fraction of its input energy, as heat, at some temperature below that of its heat source. It will be assumed, for the present rocket application, that no external heat sink is available, so that all of

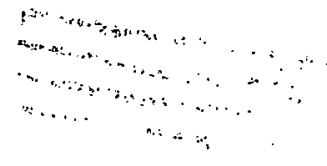


this heat must be rejected to the propellant. Since the propellant can only be raised to some temperature below that of the fluid entering the vortex tubes, its heat capacity is limited, and the total pressure rise which can be obtained is therefore also limited.

Gas turbine cycle:

The first device which will be considered is a rather conventional gas turbine cycle, shown schematically in Fig. 6. The fluid bled from the vortex tube expands through a turbine, which drives a compressor and a pump, then passes through a heat exchanger, where it rejects heat to the propellant. It is then compressed and re-enters the vortex tube. The propellant is raised from tank pressure to vortex entrance pressure by the pump, picks up heat from both the recirculated fluid and any solid parts of the reactor which must be cooled, then enters the vortex tube. The net flow into the system, which is handled by the pump, is equal to the net radial inflow through the vortex.

The following notation will be used:

$\mathrm{T}_{t} \equiv$ turbine inlet temperature

$T \equiv$ total temperature ratio

$\pi \equiv$ total pressure ratio

$\eta$ effi:ciency or effectiveness

$\Delta \mathrm{H}$. enthalpy rise of propellant, per unit mass

$-\left(1+w_{b}\right) m_{b} /\left(1+w_{c}\right) m_{1} \equiv$ ratio of recirculated to through mass flows $c_{p} \equiv$ specific heat at constant pressure of recirculating fluid $\gamma \equiv$ ratio of specific heats of recirculating fluid.

The values of $\tau, \pi, \eta_{9}$ and $\Delta \mathrm{B}$ for the various components of the cycle will be distinguished by subscripts as follows:
$t$, turbine
8 , reactor solids
C, compressor
$\mathrm{h}$, heat exchanger.
$v$, vortex tube 


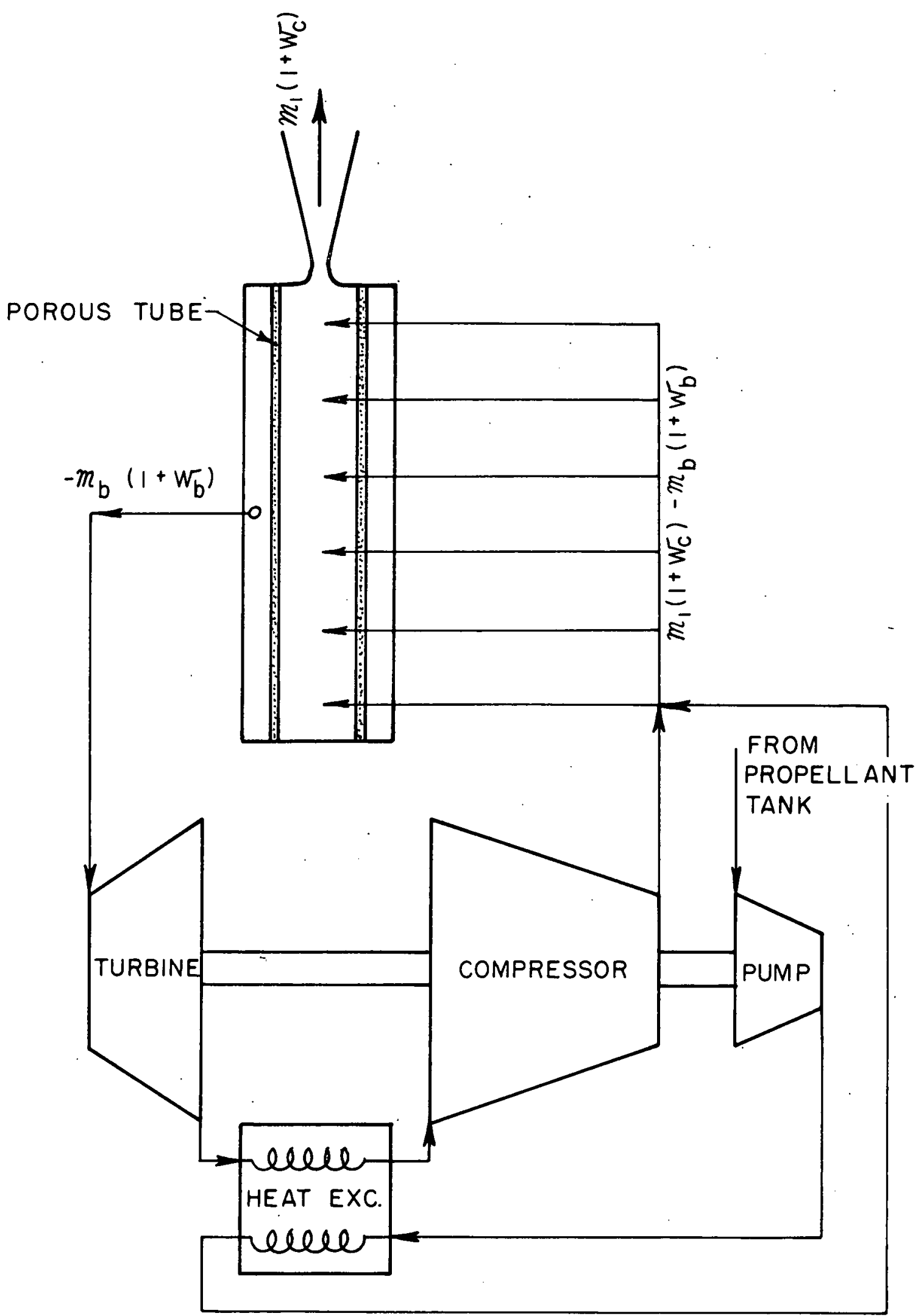

Fig. 6. Schematic of Gas-Turbine Driven Recirculation 
Since the fluid recirculates, it is necessary that

$$
\tau_{c} \tau_{v} \tau_{t} \tau_{h}=1
$$

and

$$
\pi_{c} \pi_{v} \pi_{t} \pi_{h}=1
$$

A work balance for the turbine, compressor, and pump gives,

$$
\tau_{t}=1-\tau_{t} \tau_{h}\left(\tau_{c}-1\right)+\frac{\left(1+w_{c}\right) m_{1}}{\left(1+w_{b}\right) m_{b}}\left(\frac{\Delta H_{p}}{c_{p} T_{t}}\right) .
$$

The energy balance for the heat exchanger gives,

$$
\tau_{h}=I+\frac{\left(I+w_{c}\right) m_{1}}{\left(I+w_{b}\right) m_{b}} \frac{I}{\tau_{t}}\left(\frac{\Delta H_{h}}{c_{p} T_{t}}\right) \text {. }
$$

According to the usual definitions of the efficiencies of the turbine and compressor, we have finolly,

$$
\tau_{c}=I+\frac{I}{\eta_{c}}\left(\pi_{c} \frac{\gamma-1}{\gamma}-1\right)
$$

and

$$
\tau_{t}=1-\eta_{t}\left(1-\pi_{t} \frac{\gamma-1}{\gamma}\right) .
$$

Straightforward manipulation of these equations yields the following expression for the mass flow ratio:

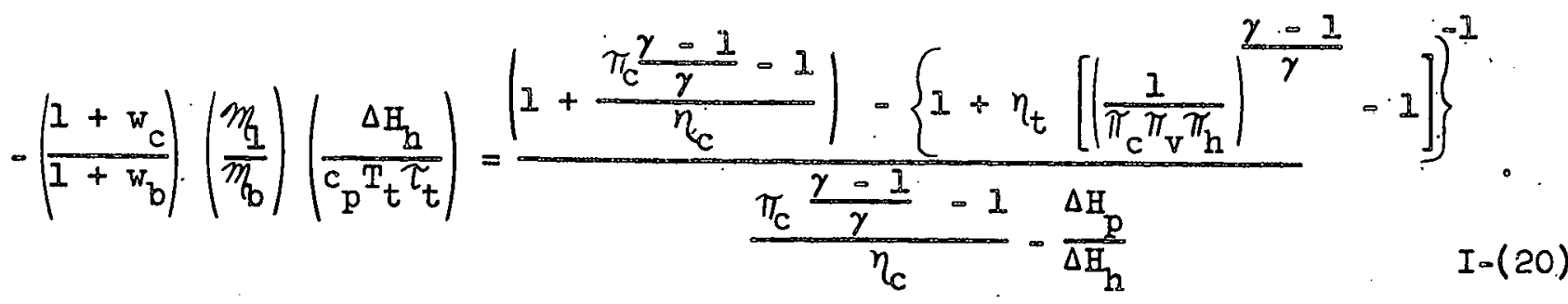

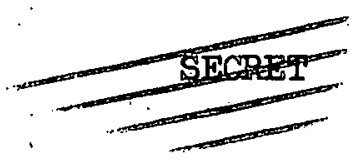


The factor $\Delta \mathrm{H}_{\mathrm{h}} / \mathrm{c}_{\mathrm{p}} \mathrm{T}_{t} \tau_{t}$ shows the limitation imposed on the mass flow ratio by the heat capacity of the propeliant. If the enthalpy rise of the propellant in the heat exchanger can be increased, the mass flow ratio can be increased, since a smaller amount of propellant can provide the required heat capacity. The right side of Eq. (20) is plotted in Fig. 7 , for $\Delta H_{p}=0$, as a function of $\pi_{v} \pi_{b}$ and. $\pi_{c}$.

It seems likely that $\pi_{\mathrm{v}} \pi_{\mathrm{h}}$ wijl be less than 0.5 , this being the value which corresponds to the ratio of static to total pressures at a Mach number of unity. Thus, the lowest obtainable value of the quantity plotted in Fig. 7 is about 0.65 .

The largest possible value of $\Delta \mathrm{H}_{h} / c_{p} T_{t} \tau_{t}$ is obtained when $\Delta H_{h}$ is the enthalpy rise of the propellant from tank conditions to the temperature $T_{t} \tau_{t}$. This value can be attained only if $\Delta \mathrm{H}_{\mathrm{p}}$ is negligible and the effectiveness of the heat exchanger is unity: however, it serves to establish an upper limit to the mass flow ratio. These maximum possible values of $\Delta \mathrm{H}_{\mathrm{n}} / \mathrm{c}_{\mathrm{p}} \mathrm{T}_{t} \tau_{t}$ are shown in Fig. 8 for hydrogen. The initial state has been taken as the liquid at its normal boiling point. Since the values of $\Delta \mathrm{H}_{\mathrm{h}} / \mathrm{c}_{\mathrm{p}} \mathrm{T}_{\mathrm{t}} \tau_{t}$ are very close to unity, a reasonable lower limit for a $\left(1+\mathrm{w}_{\mathrm{c}}\right) \mathrm{m}_{\mathrm{l}} /$ $\left(1+w_{b}\right) M_{b}$ is 0.65 or 0.70 , and the greatest obtainable mass flow ratio is 1.4 to 2.5. The gas turbine system is therefore at best marginal, according to the criteria established by the diffusion and boundary layer stabilization processes, which require mass flow ratios of two and unity, respectively.

In order that the cycle operate at a point on Fig. 7 , a certain amount of heat must be supplied to it. This heat input may be expressed in terms of the temperature ratio across the vortex tube, $\tau_{v^{\circ}}$ : From Eqs. (14) to (19),

$$
\tau_{v}=\frac{I}{I+\left(\frac{1+w_{c}}{I+w_{b}}\right)\left(\frac{m_{I}}{m_{b}}\right) \frac{\Delta H_{b}}{c_{p} T_{t} t}\left\{I+\eta_{t}\left[\left(\frac{1}{\pi_{c} \pi_{v} \pi_{b}}\right)^{\frac{\gamma}{\gamma}}-1\right]\right\}\left(1+\frac{\Delta H_{p}}{\Delta H_{h}}\right)}
$$

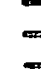




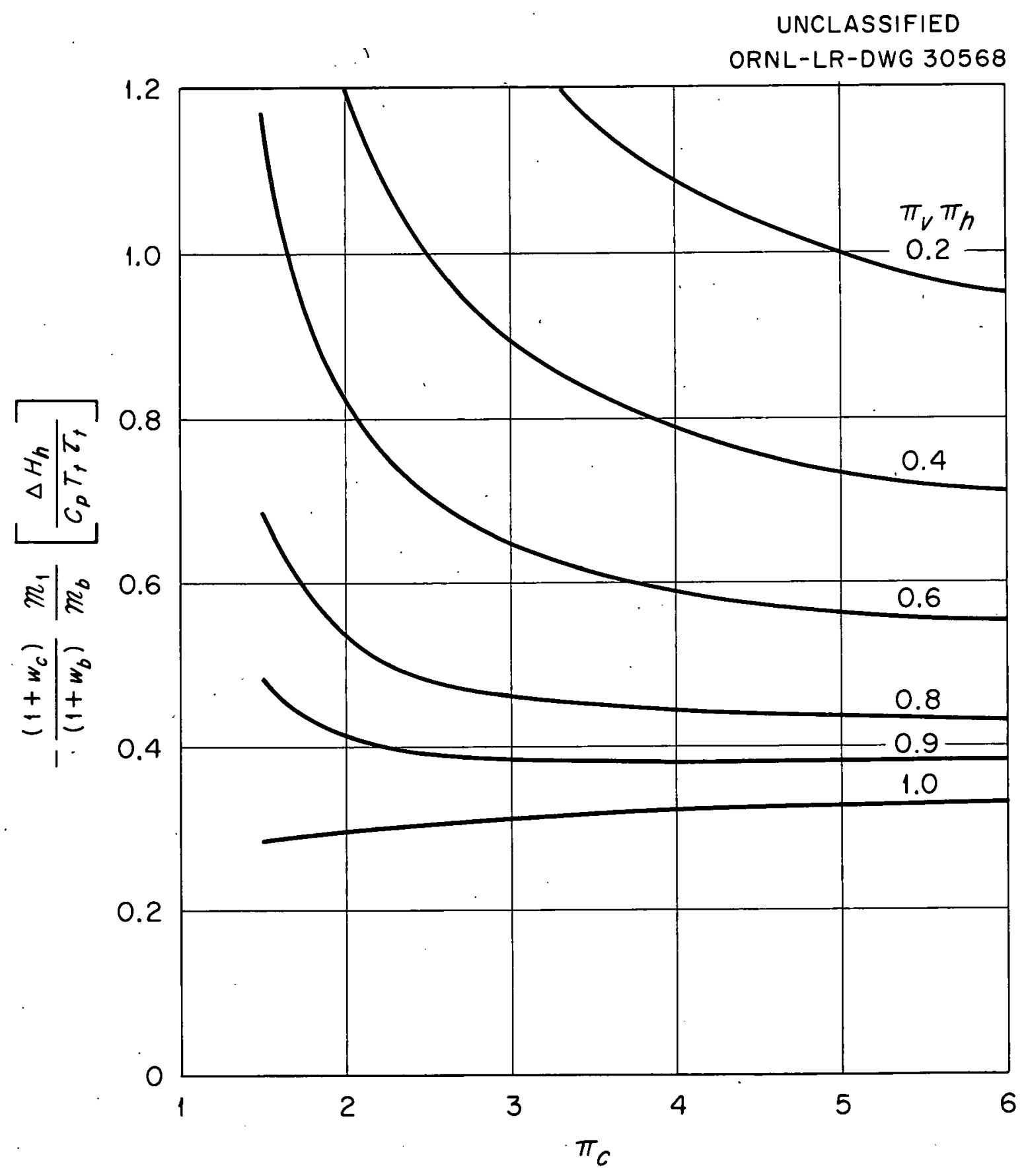

Fig. 7. Permissible Mass Flow Ratios for Gas-Turbine Recirculation System, as Function of Compressor Pressure Ratio and Total Pressure Loss Ratio. 


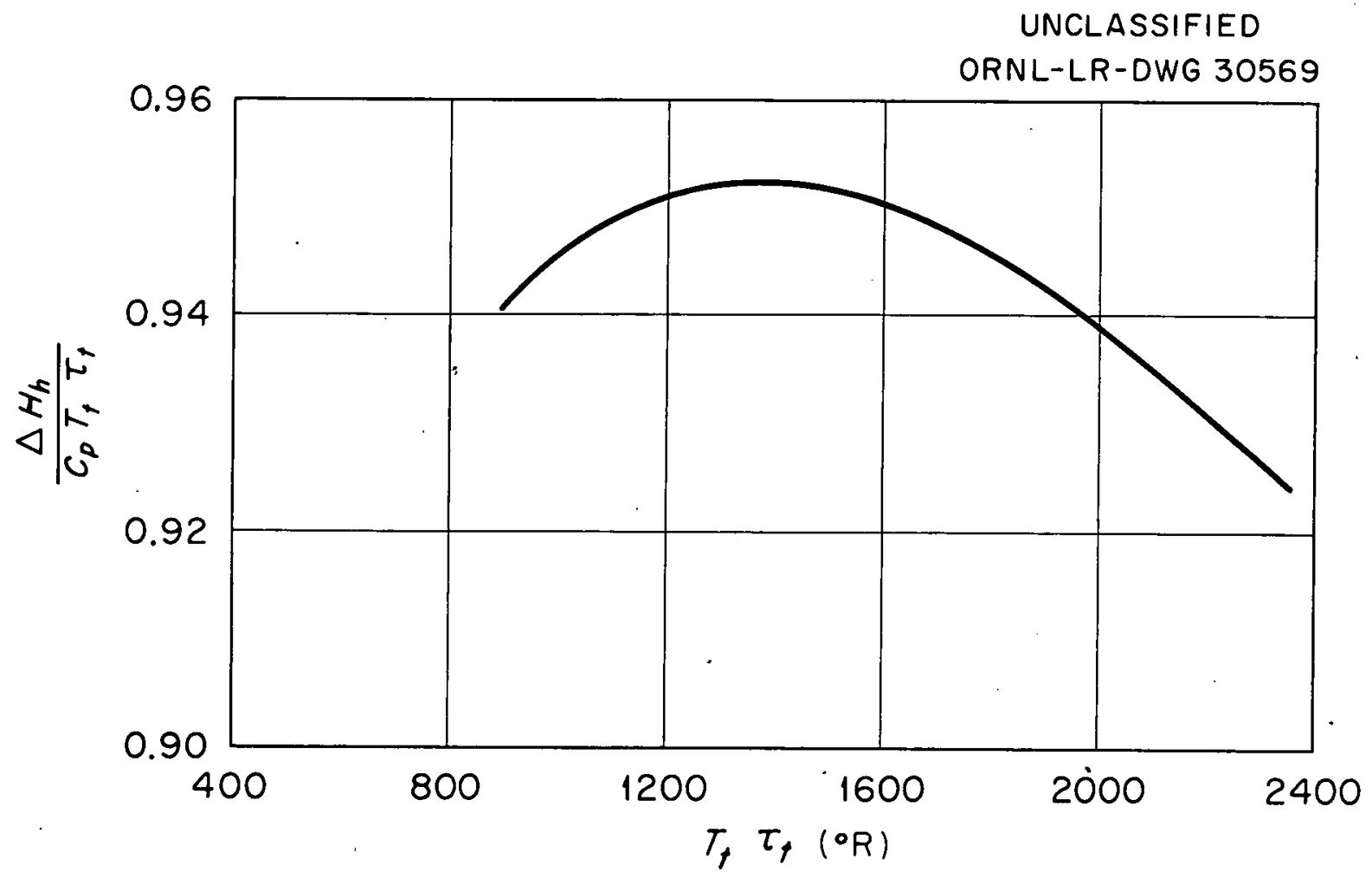

Fig. 8. 'Variation of Maximum Dimensionless Heat Exchanger Enthalpy Rise with Turbine Outlet Temperature, for Hydrogen. 
As is shown in Fig. 9, the temperature ratio required for the mass flow ratios from 1.4 to 1.5 is about 2.0. This figure does not impose an important limitation on the system unless it is so low that it becomes impossible to circulate the mixture of propellant and fissionable material through the vortex tube without its temperature ratio exceeding the indicated value.

Propellant turbine cycle:

The second cycle which will be considered is one in which only the through flow of propellant passes through the turbine. Such a scheme is shown in Fig. 10. The propellant is pressurized by a pump, picks up heat from the circulating fluid, then expands through the turbine and passes into the vortex tubes. The recirculating fluid passes through the heat. exchanger and compressor only.

Using the same notation as for the gas turbine cycle, we must have,

$$
\begin{aligned}
& \tau_{c} \tau_{v} \tau_{h}=1 \\
& \pi_{c} \pi_{v} \pi_{h}=1 .
\end{aligned}
$$

The energy balance for the pump, turbine, and compressor is

$$
-\frac{m_{1}\left(1+w_{c}\right)}{m_{b}\left(1+w_{b}\right)}\left(\Delta H_{t}-\Delta H_{p}\right) \equiv c_{p} T_{h} \tau_{h}\left(\tau_{c}-1\right),
$$

where $T_{h}$ is the temperature of the circulating fluid entering the heat exchanger. The energy balance for the heat exchanger gives,

$$
-\frac{m_{1}\left(1+w_{c}\right)}{m_{b}\left(1+w_{b}\right)} \Delta H_{h}=c_{p} T_{h}\left(1-\tau_{h}\right)
$$


UNCLASSIFIED

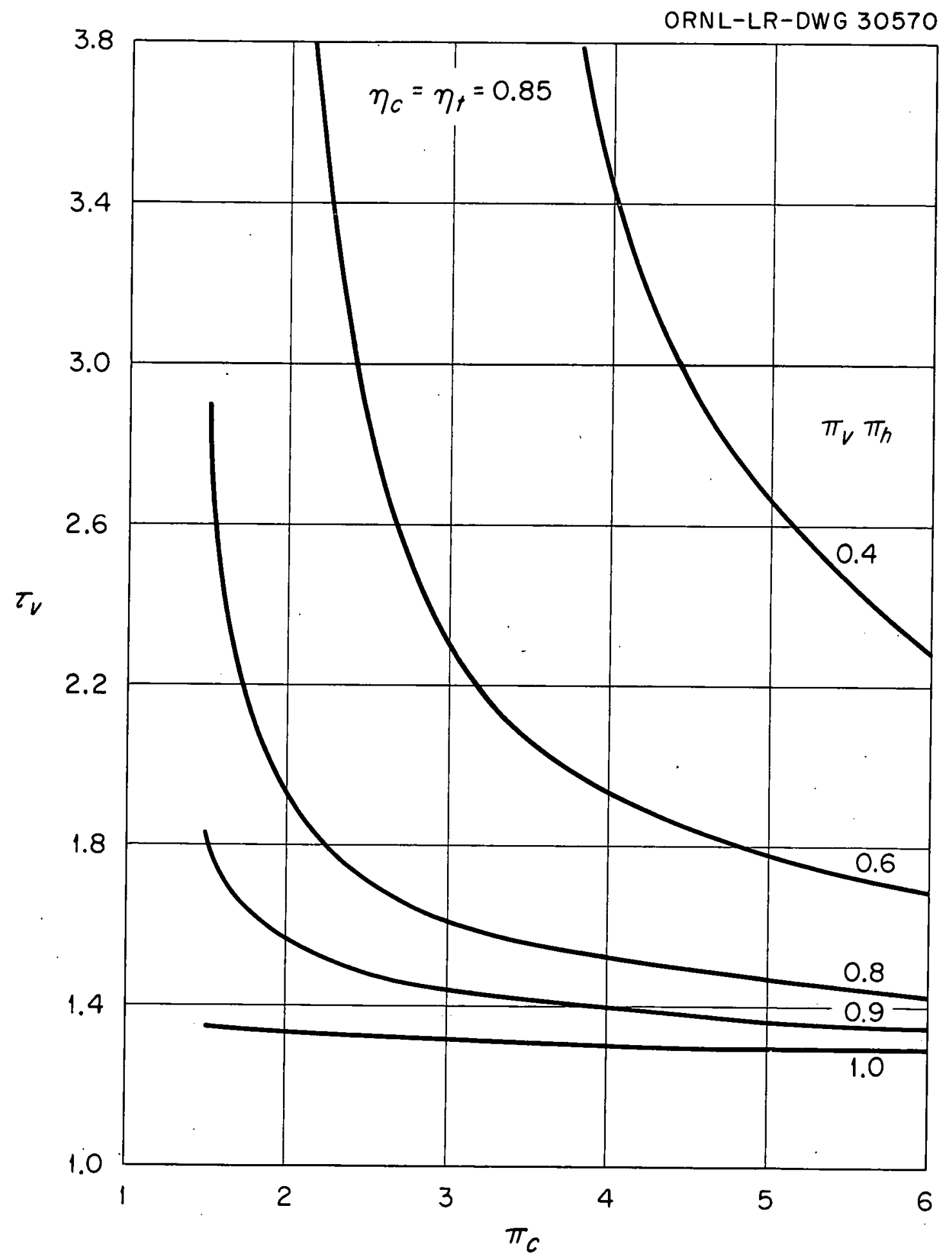

Fig.9. Vortex Tube Temperature Ratios Required by Gas-Turbine Recirculation Systems.

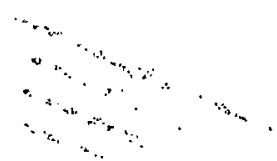



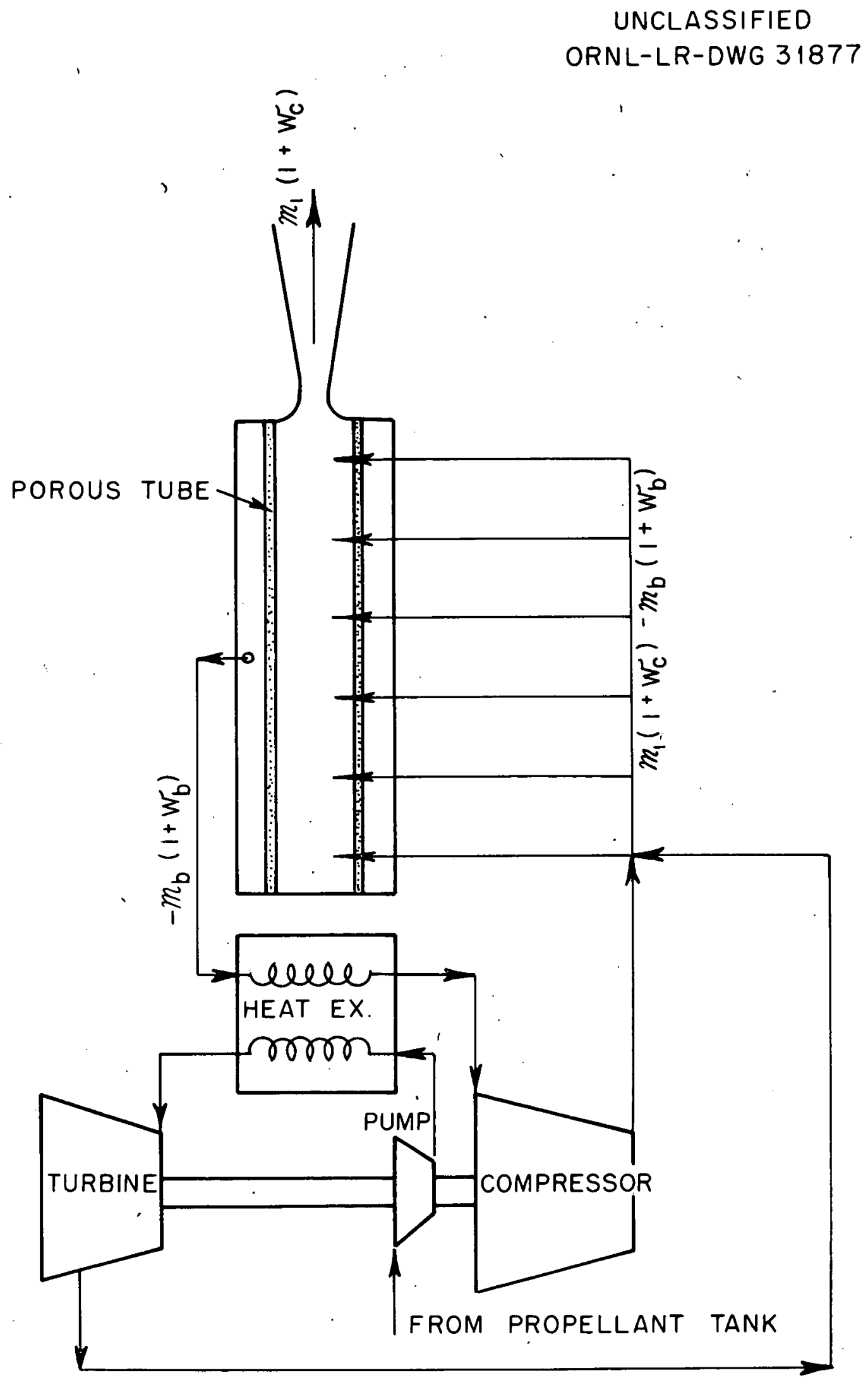

Fig. 10. Schematic of Propellant-Turbine Driven Recirculation System. 
From these equations, it is readily shown that,

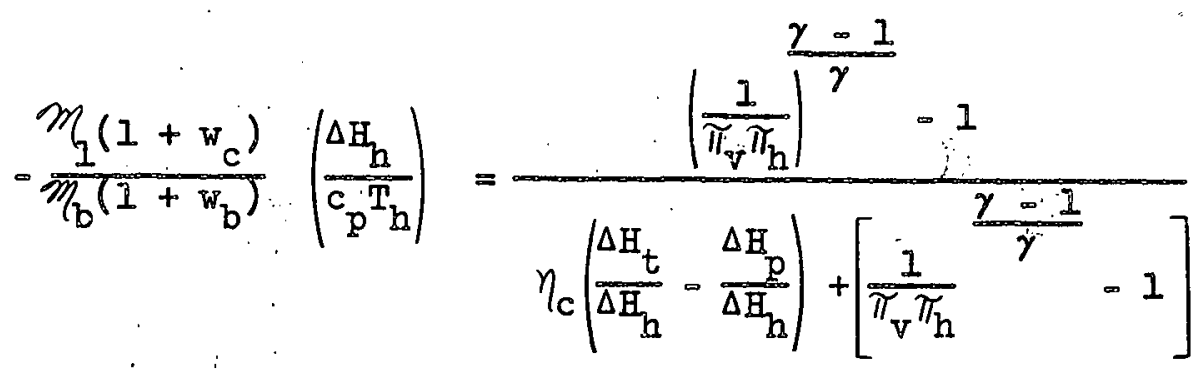

It is clear that $\Delta \mathrm{H}_{\mathrm{h}} / c_{\mathrm{p}} \mathrm{T}_{\mathrm{h}}$ plays the same role for this cycle that $\Delta \mathrm{H}_{\mathrm{h}} \mathrm{c}_{\mathrm{p}} \mathrm{T}_{\mathrm{t}} \tau_{\mathrm{t}}$ does for the gas turbine cycle, i.e., it shows the limitation of the mass flow ratio by the propeliant heat capacity.

The right side of Eq. (26) is shown in Fig. 11 as a function of $\Delta \mathrm{H}_{\mathrm{t}} / \Delta \mathrm{H}_{\mathrm{h}}$ and $\pi_{\mathrm{v}} \pi_{\mathrm{h}}$. Ratber large mass flow ratios, are obtainable for $\Delta \mathrm{H}_{t} / \Delta \dot{\mathrm{H}}_{\mathrm{h}}$ equal to 0.5 or more. However, such large values of $\Delta \mathrm{H}_{t} / \Delta \mathrm{H}_{\mathrm{h}}$ imply small values of $\pi_{t}$, since

$$
\pi_{t}=\left[1-\left(\frac{\Delta \mathrm{H}_{t}}{\Delta \mathrm{H}_{h}}\right)\left(\frac{\Delta \mathrm{H}_{\mathrm{h}}}{\mathrm{c}_{\mathrm{p}}^{\mathrm{T}} \mathrm{T}_{\mathrm{h}}}\right)\left(\frac{\mathrm{T}_{\mathrm{h}}}{\mathrm{T}_{t}}\right)\right]^{\frac{\gamma^{\prime}}{\gamma^{\prime}-1}},
$$

where $c_{p}^{0}$ and $\gamma^{\circ}$ are values for the pure propellant. If, for example, $\Delta \mathrm{H}_{\mathrm{h}} / \mathrm{c}^{\prime} \mathrm{p}_{\mathrm{h}}$ and $\mathrm{T}_{\mathrm{h}} / \mathrm{T}_{\mathrm{t}}$ are both unity, and $\Delta \mathrm{H}_{t} / \Delta \mathrm{H}_{\mathrm{h}}$ is $0.5, \pi_{t}$ is about 0.09 . Such low values of $\pi_{t}$ cannot be tolerated, since the vortex feed pressure is already very high(I).

For $\pi_{v} \pi_{h}=0.5$, and the minimum satisfactory value of $=m_{b}\left(1+w_{b}\right) /$ $m_{1}\left(1+w_{c}\right)$, i.e., 2.0, we find $\Delta \mathrm{H}_{t} / \Delta \mathrm{H}_{h}=0.25$ and $\pi_{t}=0.37$. Thus, even to obtain a mass fllow ratio of 2.0 , the pumping pressure must be increased by a factor of about 2.7 .

The temperature ratio required for operation under the conditions implied by Fig. 13 is given by,

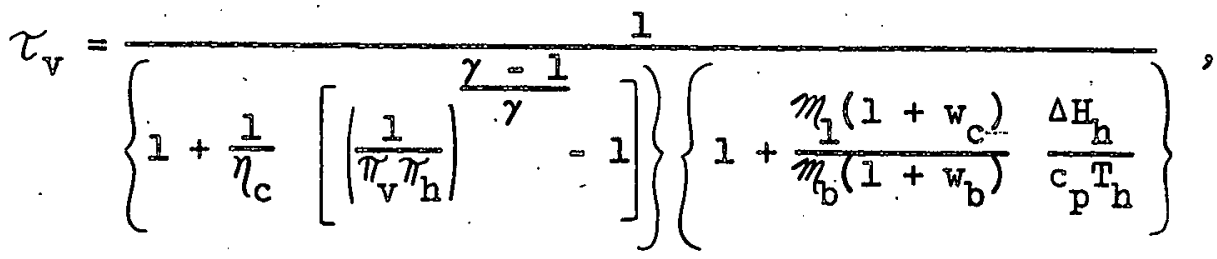




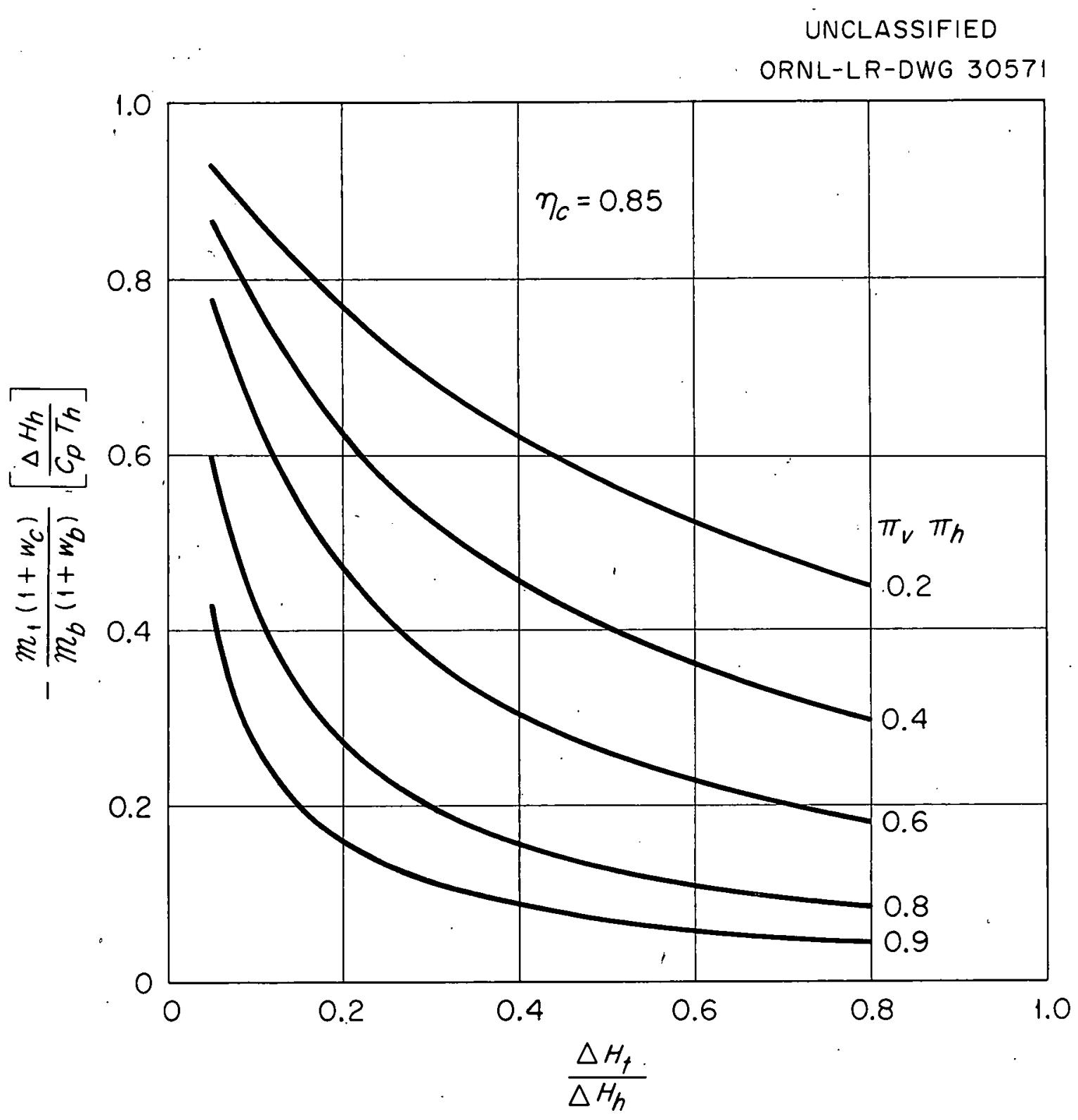

Fig. 11. Permissible Mass Flow Ratios for Propellant-Turbine Recirculation System, as Function of Ratio of Turbine and Heat Exchanger Enthalpy Changes and Total Pressure Loss Ratio. 
and is shown in Fig. 12. As for the gas turbine cycle, the value of $\tau_{v}$ does not constitute a limitation on the cycle unless it is so small that the fluid cannot be circulated through the vortex tubes without its temperature ratio exceeding $\tau_{v}$.

\section{Conclusions:}

On the basis of the preceding analyses, the following conclusions seem warranted.

1. Laminar vortices having tangential velocities greater than onehalf the inviscid value can be generated by providing uniform wall suction, with ratios of bled mass flow to radial mass flow of unity or higher.

2. The tendency of the radial outflow through the tube wall to sweep the heavy gas from the vortex is reduced as the above mentioned mass flow rate increases. For a mass flow ratio of 2 , the heavy to light gas density ratio at the tube wall is less than twice that at the vortex periphery.

3. A gas turbine cycle operating with the recirculating fluid as a working medium is capable of recirculating the fluid at mass flow ratios up to 1.5 if the total pressure ratio across the vortex tube is 0.5 .

4. A propellant turbine cycle is capable of producing a mass flow ratio of 2.0 at the total pressure ratio of 0.5 , if the pumping pressure can be increased to 2.7 times the vortex feed pressure.

5. From the above four conclusions, it is probable that a recirculation system can be devised, which will enable laminar vortices, of sufficient strength for separation, to be produced. 


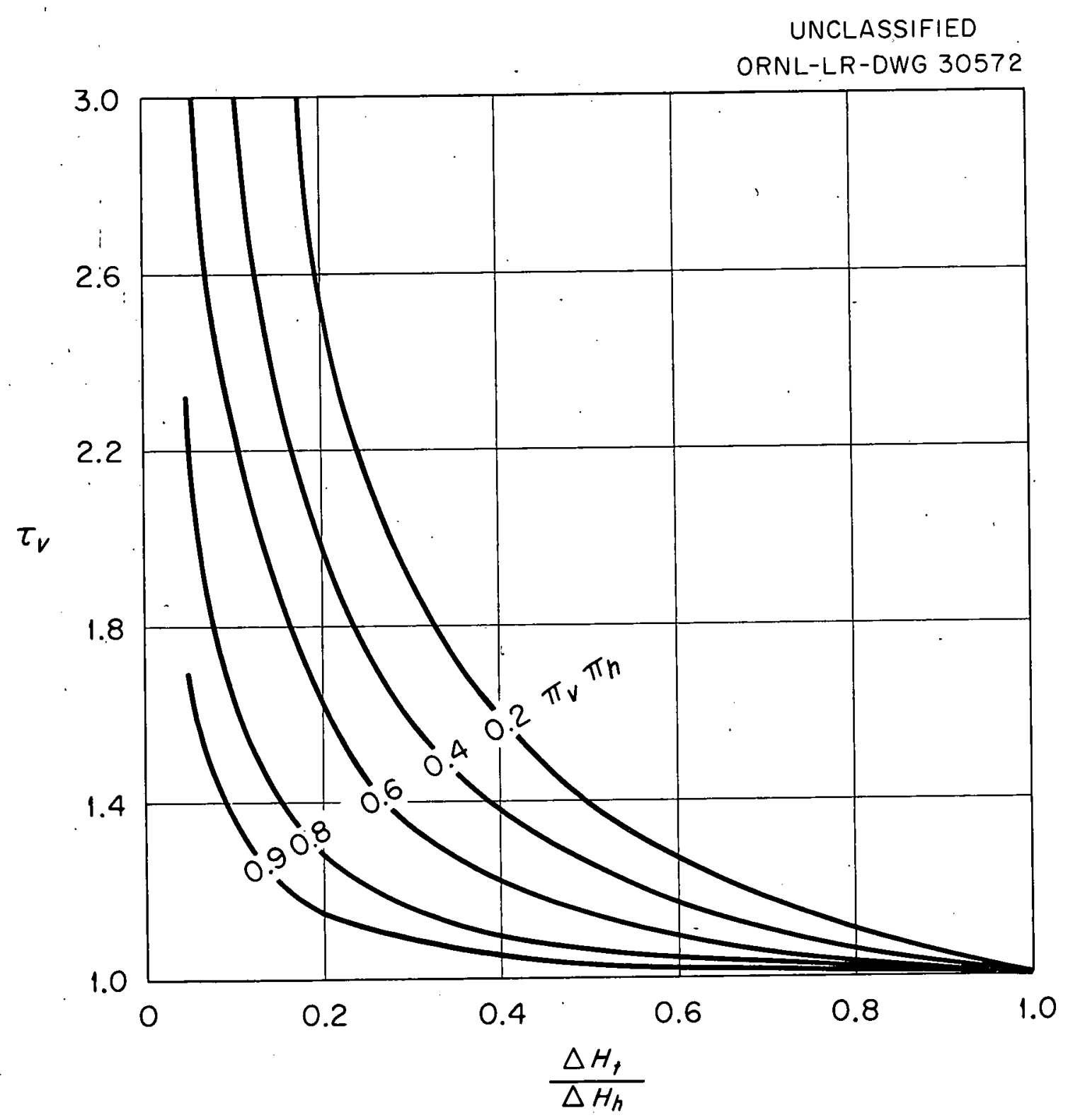

Fig. 12. Vortex Tube Temperature Ratios Required by Propellant-Turbine Recirculation System. 
SECTION II

Criticality

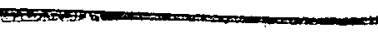

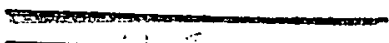

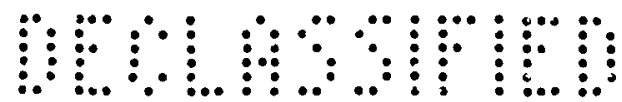

SECRET 
Introduction:

The criticality problem for vortex reactors is unusual in that the reactor weight is of extreme importance. In addition to' its influence on the performance of a rocket vehicle through the thrust to weight ratio of the rocket reactor, the criticality requirement in a sense determines the size of vehicle to which a given rocket reactor is applicable. Thus, vortex reactors are not scaleable in the usual sense. A characteristic length has been introduced by the neutron transport processes.

Because of the rather low fissionable material concentrations allowed by the vortex-separation process, the sizes and weights of vortex reactors tend to be large, in the sense that the vortex reactor is suitable for very large rocket vehicles. The fuel concentration can be increased, and the reactor weight reduced, by increasing the pressure in the vortex tubes, but the containment problem.is then aggravated. It appears that, for a given vortex tube design, it will generally be desirable to select the reactor configuration so as to minimize the reactor weight. Thus, the approach taken in the present calculations is to minimize the reactor weight, by varying the reactor configuration, for fixed vortex tube designs. The vortex tube designs which have been selected as examples are those given in Table I, p. 61, of Ref. I.

Since the calculations are exploratory, hence parametric in nature, a simple two-group, two-region nuclear model is used.. The reactor core is assumed to be a cylindrical matrix of vortex tubes in pure moderator, of diameter equal to the length of the tubes. A beryllium reflector of uniform thickness surrounds the core on all sides. Thus, for a given vortex tube design, the characteristics of the reactor are determined by the reflector thickness and the ratio of tube volume to total core volume, which will be called the moderator void fraction.

Derivation of Nuclear Constants from Separation Calculation:

Representative nuclear constants for the two-group, two-region criticality calculations were derived from the examples of Ref. $I$, Table $I$, as follows. 
Thermal average fission and absorption cross sections were computed for reactor cores consisting of either graphite, hydrogen, and plutonium or beryllium, hydrogen, and plutonium. The concentrations of hydrogen and plutonium in the vortex tubes were determined for each vortex tube design, from the data given in Ref. 1 , Table $I$. Then for an assumed moderator void fraction, the cross sections were computed for a homogenized, uniform core. It was assumed, in computing the thermal average cross sections, that the thermal neutrons were distributed in energy according to a Maxwell-Boltzmann distribution at the temperature of the moderator, which in turn was taken as the vortex tube entrance temperature.

Examples were given in Ref. I of vortex configurations capable of producing two different temperature ratios. The first three examples were for vortex entrance and exit temperatures of 4500 and $7020^{\circ} \mathrm{R}$, while the last three were for entrance and exit temperatures of 2420 and $10,000 \mathrm{R}$. The three cases for each temperature ratio were for values of $w_{m}$ equal to 0.5 , 1.0 and 4.0 , where $w_{m}$ is the maximum value of the ratio of fissionable gas density to hydrogen density occurring in the tube.

It was found that for all these cases, the macroscopic fission cross section of the homogenized reactor core depended on the product of $w_{m}$ and the vortex exit pressure, $p_{o c^{2}}$ in the simple way shown in Fig. 13. For a given moderator void fraction the dependence of $\Sigma_{f}$ on $w_{m}$ is small for $w_{m}$ between zero and unity, but becomes appreciable for $\mathrm{w}_{\mathrm{m}}$ equal to four. The variation of the infinite medium multiplication constant, $k_{\infty}$, with $\Sigma_{f}$ is shown in Fig. 14 for the same cases. By. combining Figs. 13 and $14, k_{\infty}$ could be given as a function of $\mathrm{p}_{\mathrm{oc}} \mathrm{w}_{\mathrm{m}}$ also.

For the two group a two region calculations, representative cases were selected for the two moderators as indicated by the points in Fig. 14 .

A moderator void fraction of 0.6 was assumed in Figs. 13 and 14. To determine the influence of the void fraction, reactors with a fixed vortex design, (case 5 of Ref。I, Table I, with $p_{o c}=200 \mathrm{~atm}$ ) and various void fractions, were also computed.

The neutron diffusion coefficient for the thermal group was taken as the moderator diffusion coefficient, corrected for the moderator void fraction.

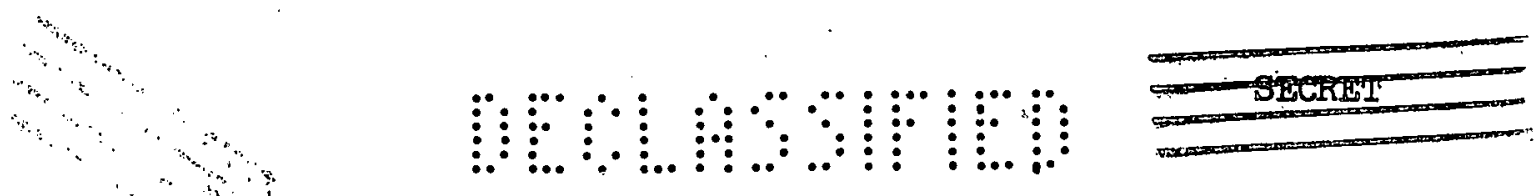




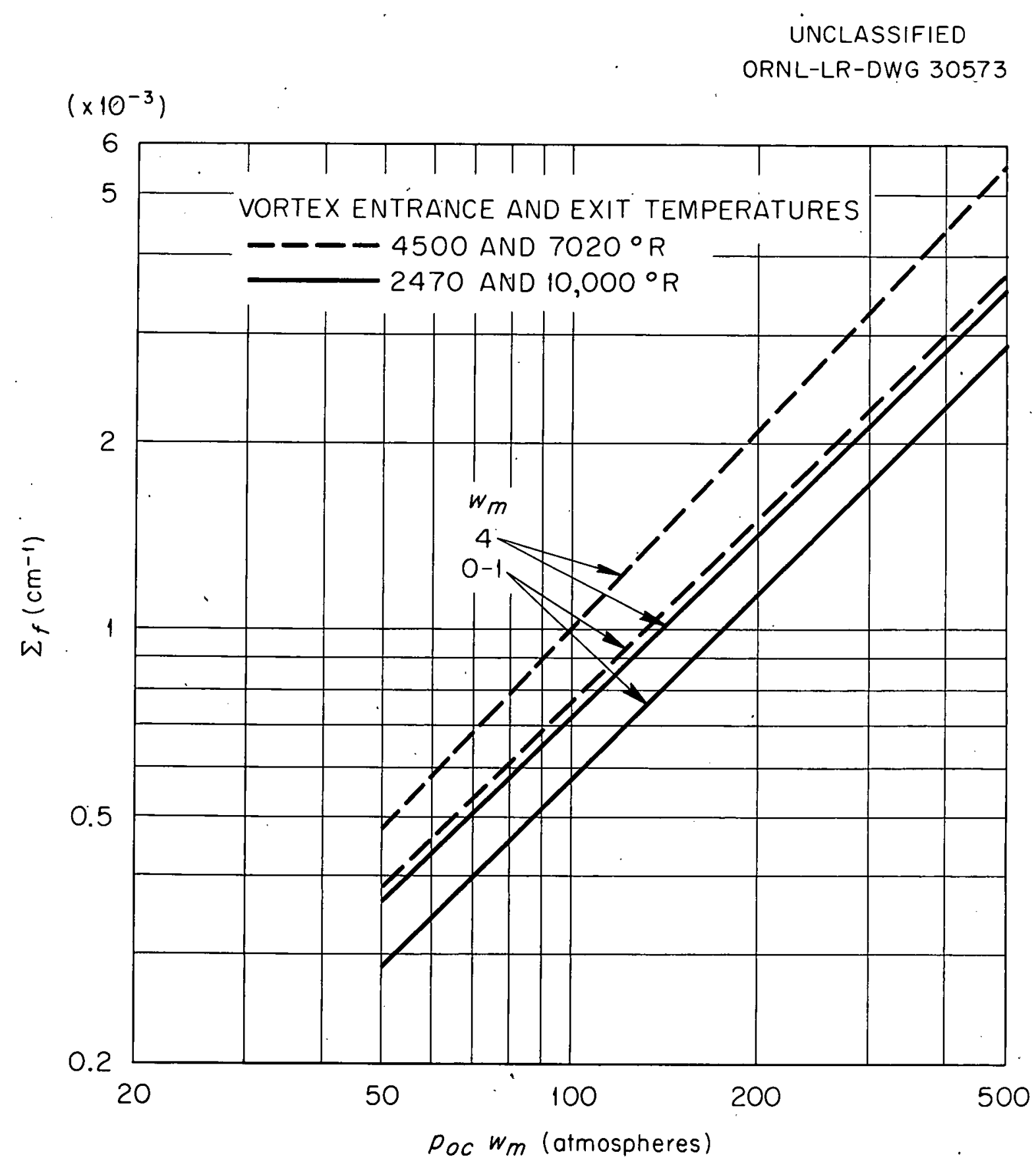

Fig. 13. Variation of Macroscopic Fission CrossSection with Product of Vortex Outlet Pressure and Maximum Value of Ratio of Fuel Density to Propellant Density, for Typical Vortex Reactors. 
UNCLASSIFIED

ORNL-LR-DWG 30574

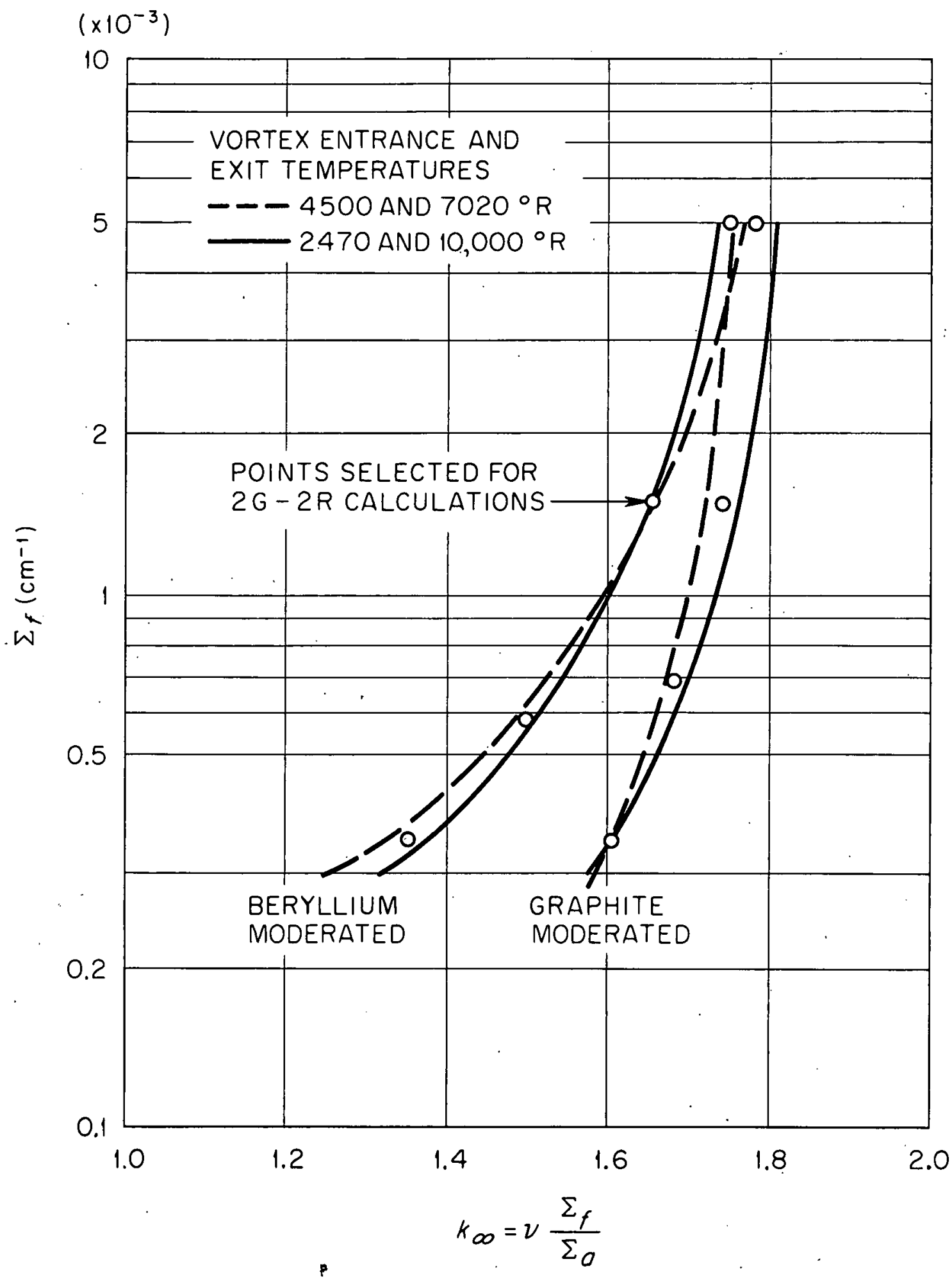

Fig. 14. Variation of Infinite Medium Multipli cation Constant with Macroscopic Fission Cross-Section for Typical Vortex Reactors. 
In choosing the nuclear constants for the fast neutron group, several simplifying assumptions were made. The resonance escape probability was taken as unity, and fast fission was neglected. The cross section for removal of neutrons from the fast group to the thermal group was taken as the diffusion coefficient divided by the Fermi age to Indium resonance. The age to Indium resonance was selected because of the high thermal neutron temperatures envisioned. The fast diffusion coefficient and the age were assumed to be those for pure moderator, corrected for the void fraction.

\section{Reactor code:}

The code used for computing the fully reflected, cylindrical reactors, consists of a three group, three region, one difensional code, modified to two-groups and two-regions for this case, and a three-dimensional reflector savings program. The three-group, three region code has been described in Ref. 3. Since a description of the reflector savings program is not available in the literature, it will be briefly described here.

Multiplication constants are computed.for two series of reactors, one series consisting of side reflected cylinders with bare ends, the other of end reflected cylinders with bare sides. In each case the cross section in the reflected dimension is the same as that of the fully reflected reactor for which the multiplication is to be found. By an iterative procedure, the code determines the height and diameter, respectively, of the side and end reflected cylinders of the two series which bave the same multiplication constant as a bare reactor with this same height and diameter. The multiplio cation constant which is common to the bare cylinder, end reflected cylinder and side reflected cyllnder is then taken as the multiplication constant for the fully reflected cylinder.

The iterative procedure is as follows. A height is assumed for the side reflected cylinder, and its multiplication constant computed. The diameter of a bare reactor with the same height and multiplication is then found. The multiplication is then computed for an end reflected reactor with this diameter. Finally, the height of a bare reactor with the same diameter and multiplication 
is found. This height is then taken as an improved estimate for the height of the side reflected cylinder, and the procedure is repeated until the multiplication constants for the end and side reflected reactors agree.

\section{Results:}

The variation of reactor core plus reflector weight with reflector thickness is shown in Fig. 15 for each of the core compositions indicated by points on Fig. 14; and for a moderator void fraction of 0.6 . For given core composition, the minimum weight occurs for reflector thicknessea of about $20 \mathrm{~cm}$ for the graphite cores and about $10 \mathrm{~cm}$ for the beryllium cores. For each value of " $\Sigma_{f}$ ' the minimum weight beryliium core reactor is considerably lighter than the minimum weight graphite reactor. This difference is due to the better neutron moderating properties of beryllium as compared to graphite.

Critical core radii are shown in Fig. 16 for the same cases shown in Fig. 15. From a comparison of the two figures it is clear that the minimum reactor weight is attained for a reflector thickness considerably below the value which is effectively infinite. This is due it part to the fact that the core density is only about 0.4 of the reflector density for the beryllium cores, and even less for the graphite cores.

That the higher: values of $\Sigma_{f}$, and the lower reactor weights, shown in Fig. 15, correspond: to very high vortex tube pressures can be seen from Fig. 13. The lowest reactor weight shown; $4800 \mathrm{lbs}$, requires that $\mathrm{p}_{\mathrm{oc}} \mathrm{w}_{\mathrm{m}}$ be equal to about 500 atm. It was pointed out in Ref。 I that, for $m=4$, this, pressure level in the tubes would require a pumping pressure of about 1000:a.tm.

Critical masse äre given in Fig. 17 for the minimum weight: reactors from Fig. 25. The masses are quite low, as a result of two effects. First, the reactor core has been assumed to be free of structural poisons. Second, the fission cross section of plutonium actualiy increases with neutron temperaw ture, up to about $1600^{\circ} \mathrm{K}$, while the absorption cróss sections of graphite, beryllium, and hydrogen decrease.

The effects of vold fraction on reactor core plus reflector weight and core radius are shown in Figs. 18 and 19, for a core composition which gives $\Sigma_{f} \approx 1.15 \times 10^{-3}$ and $\dot{k}_{\infty}=1.74$ and 1.62 respectively for graphite and beryllium

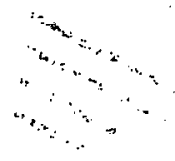


UNCLASSIFIED

ORNL-LR-DWG 30575

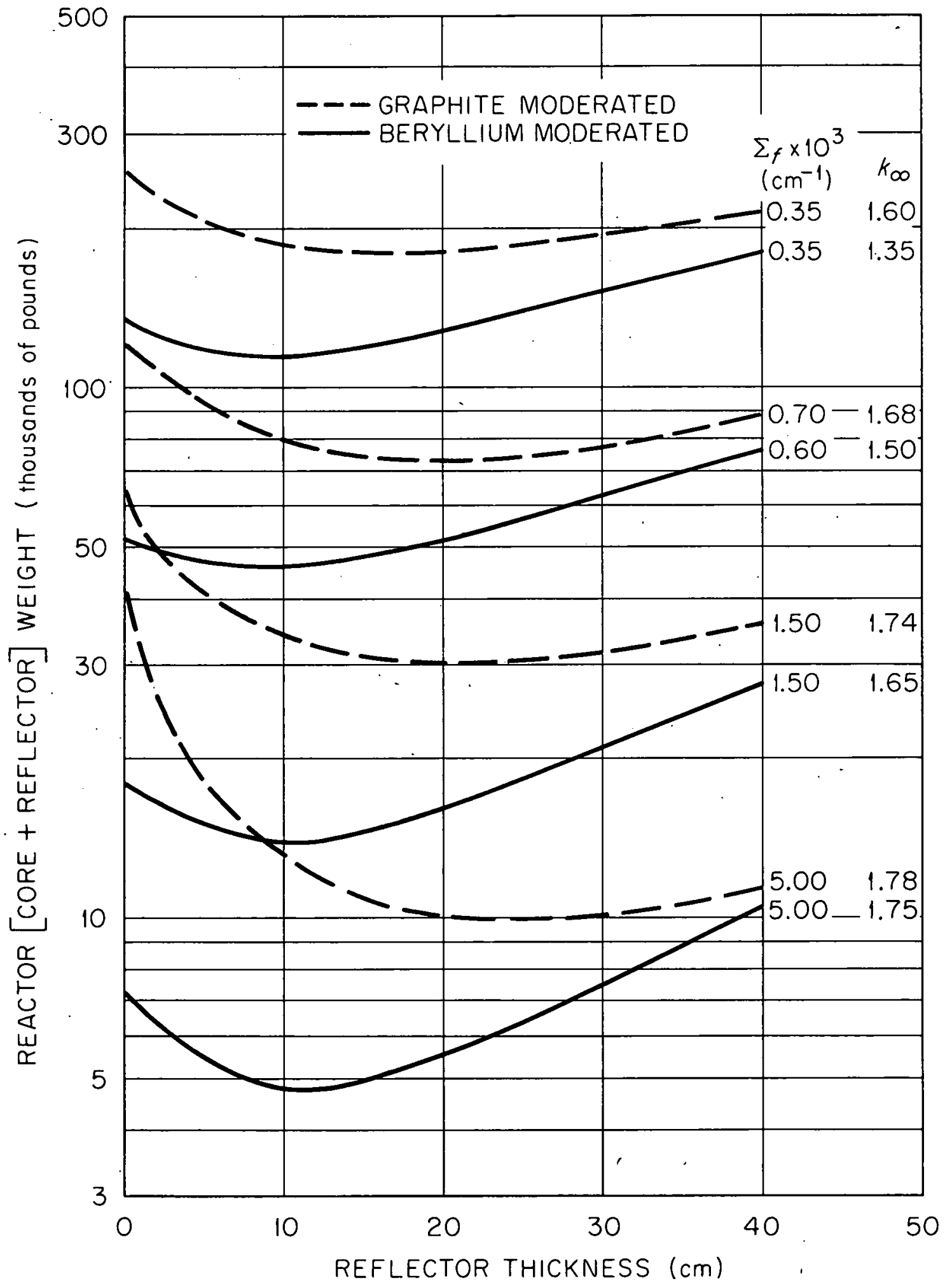

Fig. 15. Variation of Reactór (Core plus Reflector) Weight with Reflector Thickness for Typical Grophite and Beryllium Moderated Reactors. 
UNCLASSIFIED

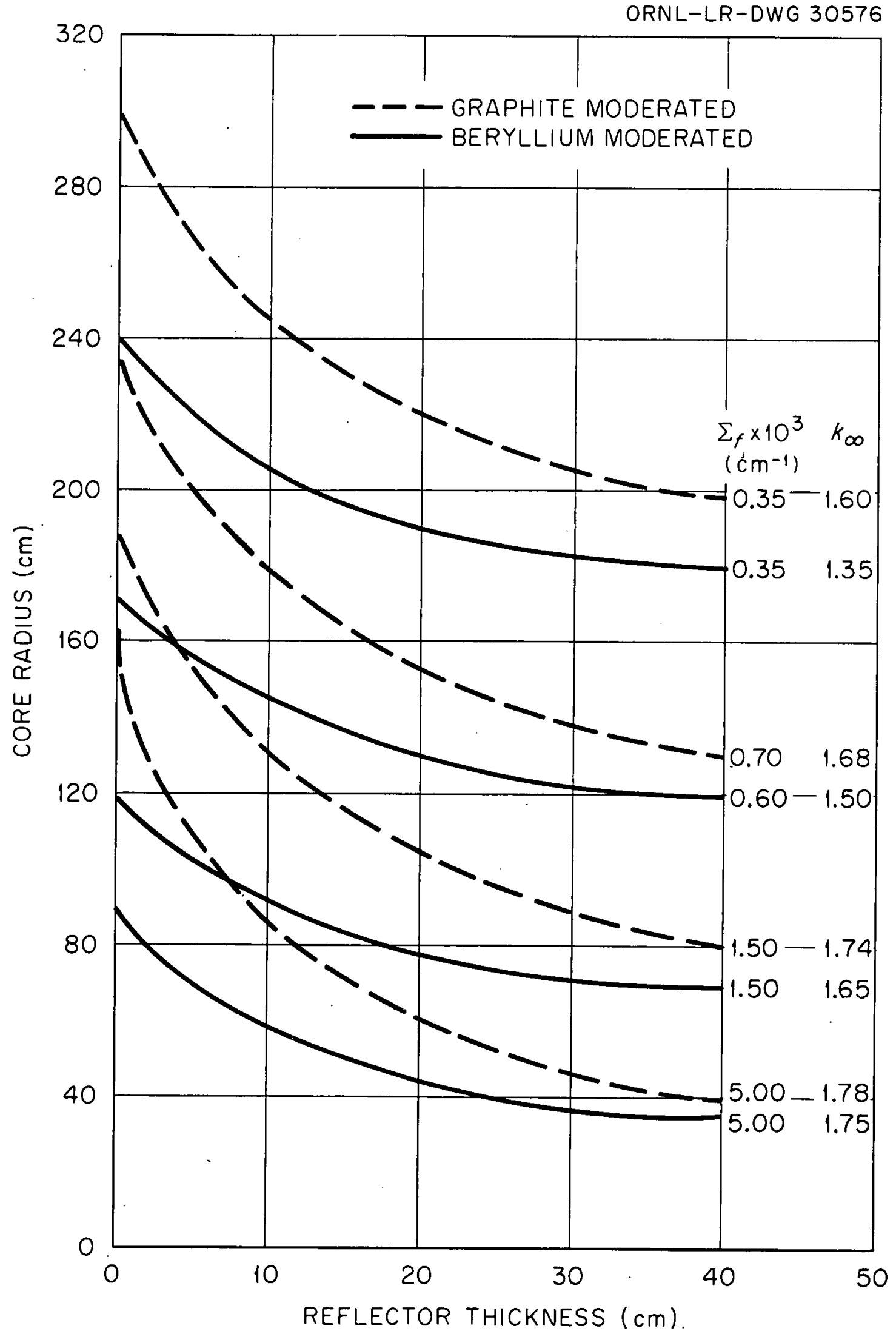

Fig. 16. Variation of Core Rodius with Reflector Thickness for 


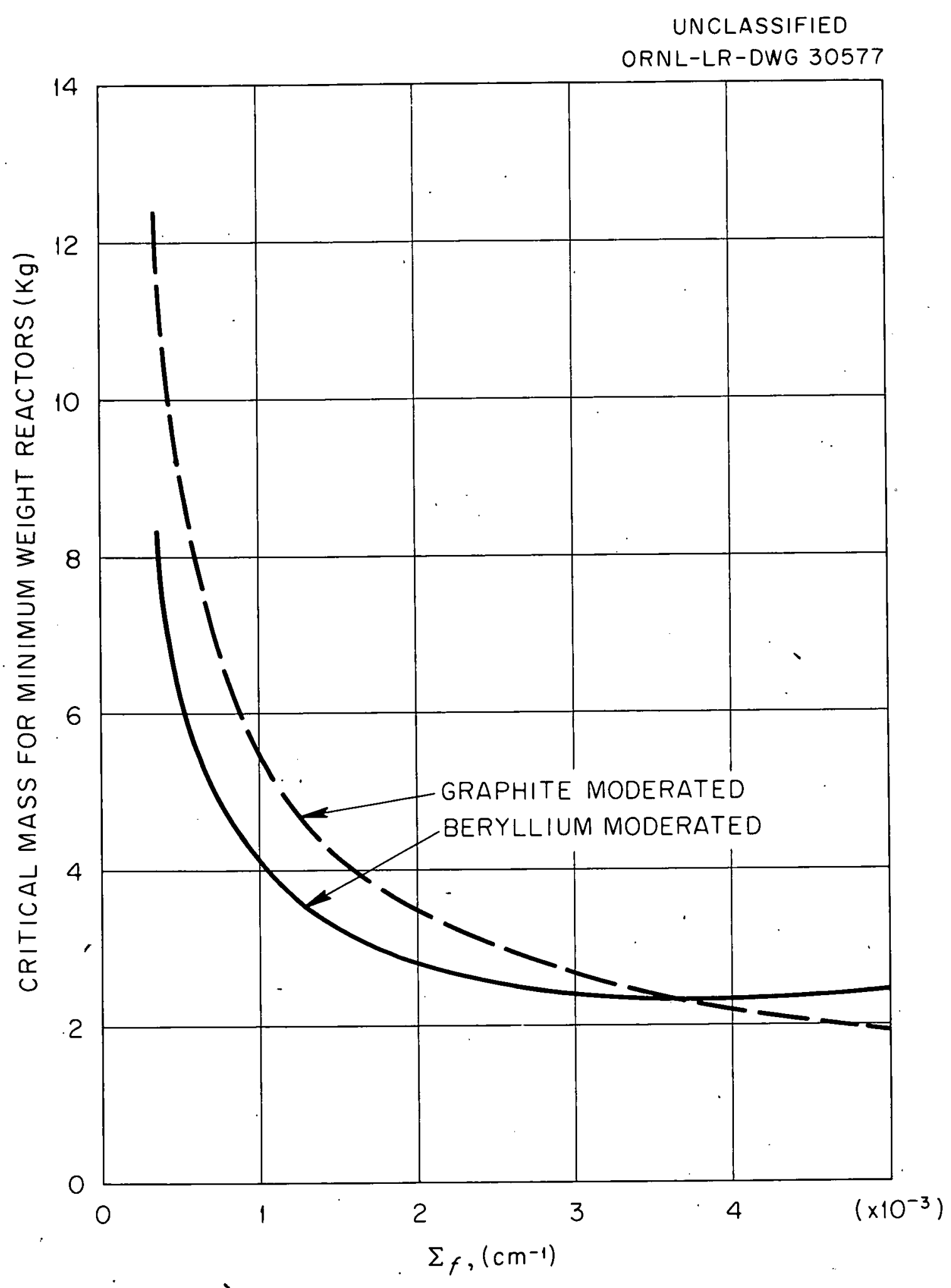

Fig. 17. Variation of Critical Mass with Macroscopic Fission Cross Section for Minimum Weight Reactors. 
UNCLASSIFIED

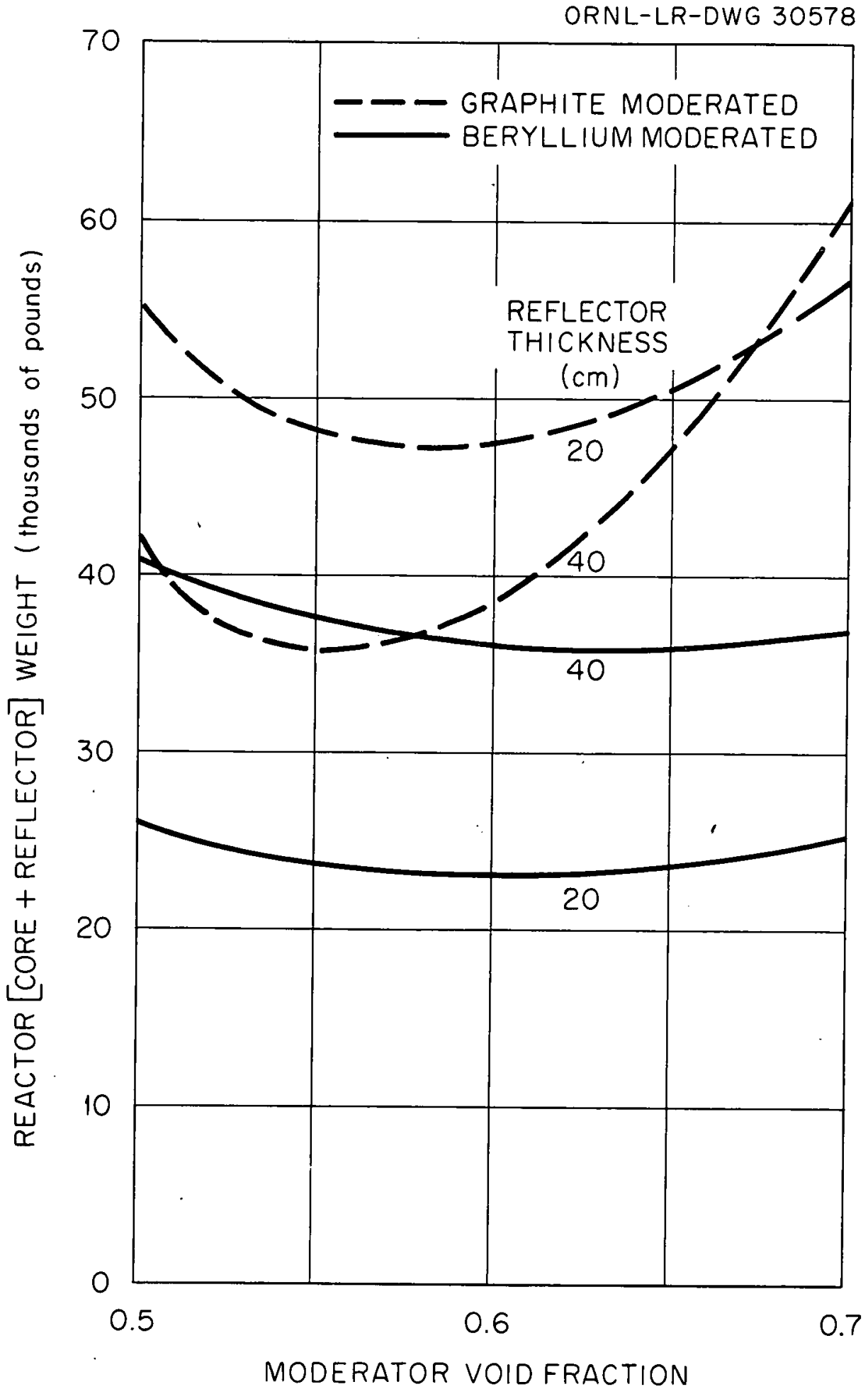

Fig. 18. Variation of Reactor (Core plus Reflector) Weight with Moderator Void Fraction for Typical Reactors. 
UNCLASSIFIED

ORNL-LR-DWG 30579

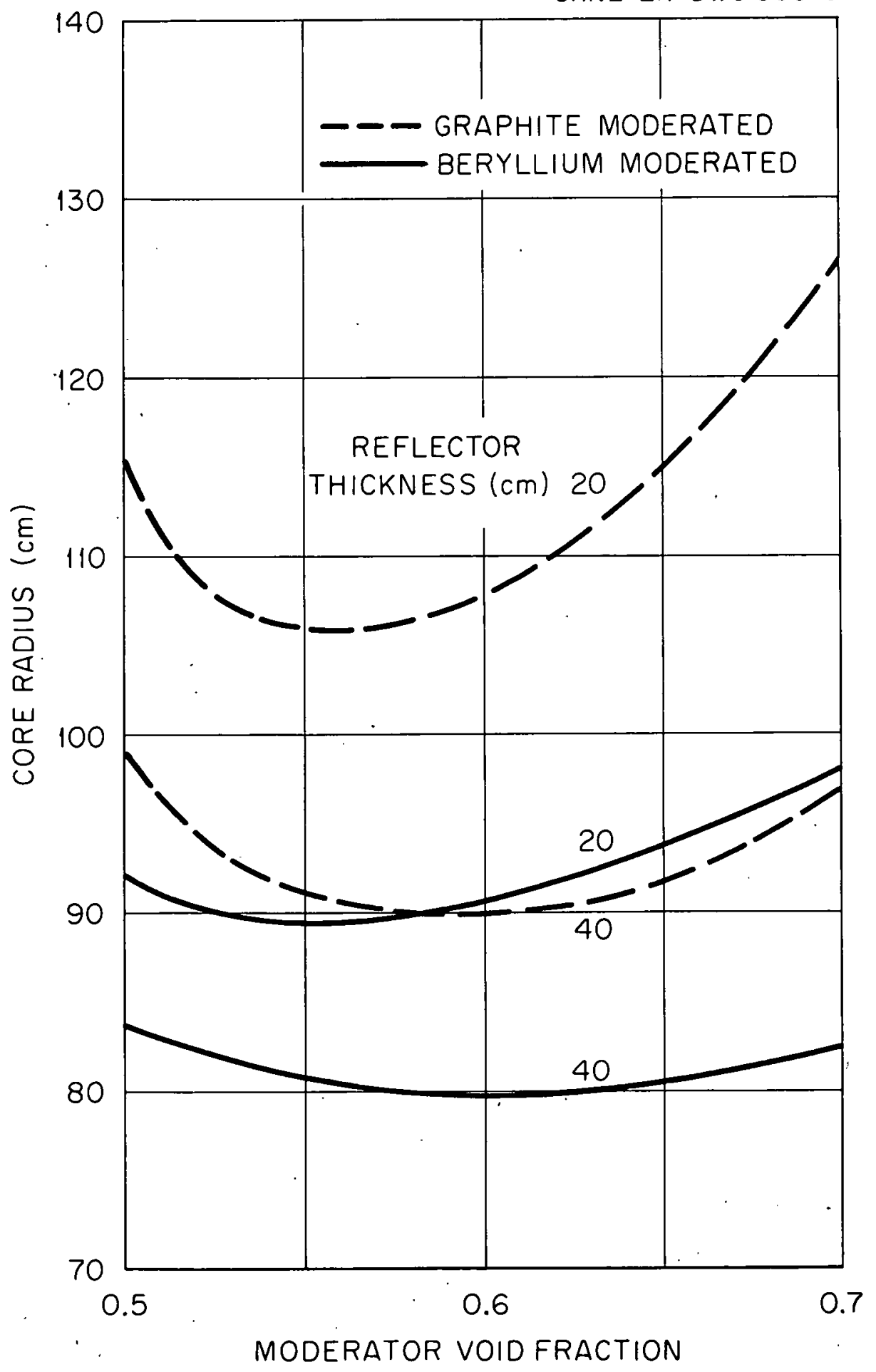

b)

$\infty$

Fig. 19. Variation of Core Radius With Moderator Void Fraction for Typical Reactors. 
moderators and a void fraction of 0.6 . Neither the weight nor the core radius are very sensitive to the void fraction for the cases shown. They would be somewhat more sensitive for thinner reflectors, however.

\section{Conclusions:}

The principgs conclusion to be drawn from these simplified criticality calculations is that vortex reactors of reasonable size and weight can be obtained if the pressure and maximum fuel to hydrogen density ratio in the tubes are such thit $\mathrm{p}_{\mathrm{OC}} \mathrm{W}_{\mathrm{m}}$ is greater than about 100 , and if the core is free of structural poisons. Under these conditions, reflector thicknesses of about 20 and $10 \mathrm{~cm}$ give the lowest reactor weights for graphite and beryllium cores. The optimum moderator void fraction is between 0.5 and 0.6 for both moderators. 


\section{SECTION III}

Gaseous Fissionable Compounds

for Vortex Reactors. 


\section{Introduction:}

It was implicitly assumed in Ref. I that some compound of plutonium, or uranium, could be found, which it would be possible to hold in gaseous form under the desired conditions. Rather high concentrations of fission. able material must be held at very bigh temperatures and under reducing conditions, if hydrogen is to be used as propellant. There is some doubt as to whether any material can be found which will satisfy these require. ments, since the compounds of uranium and plutonium which are stable at high temperatures are neither very volatile nor very resistant to reduction by hydrogen.

If there is any appreciable tendency toward. reduction of the fissionable material by hydrogen; this tendency will be increased by the separative effect of the vortex field, which will tend to separate the products of the reduction from the reactants. A quantitative description of this effect involves a yery complicated multi-component diffusion problem, with chemical reactions between the components, and will not be attempted at the present time. Rather, the requirement of chemical equilibrium rill be indicated by giving the concentrations of reduction products which must be maintained, in order that the reduction be restricted to the desired extent.

\section{Possible fuel carriers:}

Of the many compounds of plutonium and uranium, only a few appear to be promising for the present application. These are the oxides, halides, the metals themselves, and possibly the hydrides. The hydrides are eliminated immediately on the basis of instability at high temperatures. The decomposition pressure of $\mathrm{PuH}_{2}$ at $2000^{\circ} \mathrm{K}$ is about $5000 \mathrm{~atm}^{(4)}$. The halides and oxides of plutonium and uranium are quite similar in bebavior, but plutonium has nuclear characteristics somewhat superior to those of uranium. Furthermore, the volatility of metallic plutonium is much higher than that of metallic uranium, so it seems sufficient to consider metallic plutonium, the plutonium balides, and plutonium oxides as the most promising fuel carriers. since the higher halides are quite readily reduced to the tri-halides by hydrogen at only slightly elevated temperatures $\left(225.600^{\circ} \mathrm{C} \text { for } \mathrm{PuF}_{4}\right)^{(5)}$, only the tri-balides will be considered.

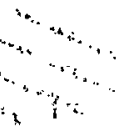




\section{Volatility:}

The concentrations at saturation are shown as functions of temperature in Fig. 20, for the interesting fuel carriers. The curve for $\mathrm{Pu} \mathrm{CI}_{3}$ would lie between those for $\mathrm{PuF}_{3}$ and $\mathrm{PuBr}_{3}$, but has been omitted because of the high neutron absorption cross section of chlorine.

- These curves have been computed from the Clausius-Clapeyron equation,

$$
\log p=-\frac{L_{0}}{R T}+c
$$

where $\mathrm{L}_{0}$ is the latent heat of vaporization. The empirical values of $\mathrm{L}_{0}$ and $\mathrm{c}$ for $\mathrm{PuF}_{3}$ and $\mathrm{PuBr}_{3}$, were obtained over temperature ranges of 1440 to 1770 and 929 to $1100 \mathrm{~K}_{\mathrm{K}}(6)$, respectively, and have not been corrected for the temperature dependence of $\mathrm{L}_{0}{ }^{\circ}$ The data for $\mathrm{PuO}_{2}$ are for the vapor in equilibrium with solid (7), at temperatures up to $1800^{\circ} \mathrm{C}$, hence, the vapor pressure at the higher temperatures is probably overestimated for $\mathrm{PuO}_{2}$. The range of applicability of the data for Pu was not given in Ref. 8 . Criticality calculations $(1)$ have indicated that fissionable material concentrations of at least $0.5 \times 10^{18} \mathrm{~cm}^{-3}$ are necessary in the low tempera. ture regions of the vortex tube: Thus, if a metallic tube structure is to be used, $\mathrm{PuBr}_{3}$ is probably the only fuel carrier with sufficient volatility. If the lowest temperature in the tube is of the order of $2100^{\circ} \mathrm{K}$ or above, $\mathrm{PuF}_{3}$ is sufficiently volatile; however, $3000 \mathrm{~K}$ is necessary to aliow the desired concentration if metallic $\mathrm{Pu}$ is the fissionable gas.

\section{Chemical equilibrium:}

If the reaction of the fuel carrier with hydrogen,

$$
2 \mathrm{PuX}_{3}(\mathrm{~g})+3 \mathrm{H}_{2} \leftrightarrows 2 \mathrm{Pu}(\mathrm{g})+6 \mathrm{HX},
$$

proceeds so far toward the right that the concentration of $\mathrm{Pu}(\mathrm{g})$ exceeds that corresponding to the plutonium vapor pressure at the existing temperature, the plutonium will condense. Thus, an upper limit is placed on the permissible concentration of $\mathrm{Pu}$ by its vapor pressure. The permissible concentration of $\mathrm{PuX}_{3}$ is related to the concentrations of $\mathrm{Pu}, \mathrm{HX}$, and $\mathrm{H}_{2}$ by the equilibrium constant,

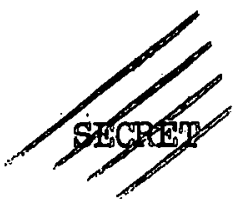


$-51-$

UNCLASSIFIED

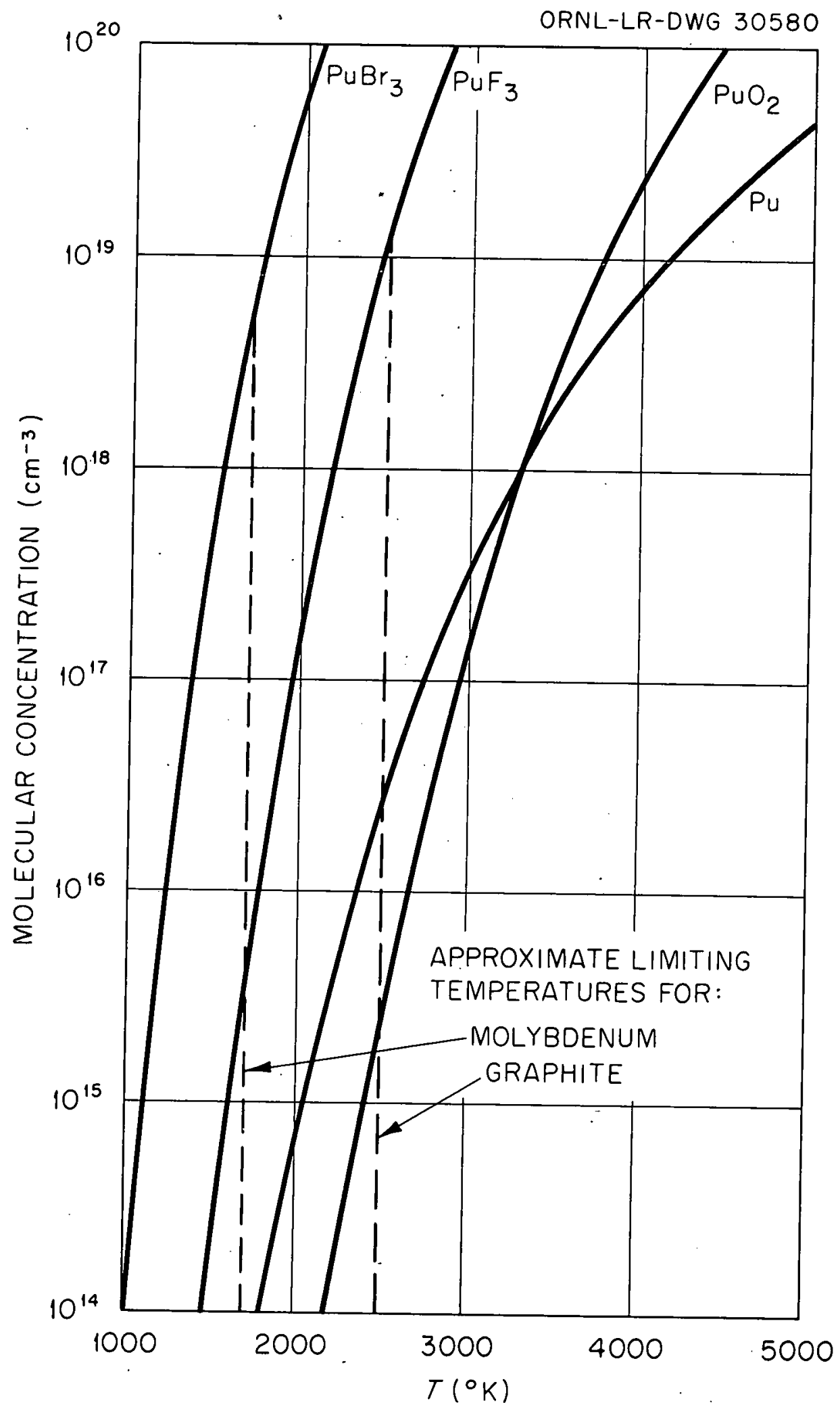

Fig. 20. Vapor Pressure Limited Concentrations for Possible Fuel Carriers. 


$$
K_{p}=\frac{(P u)^{2}(\mathrm{HX})^{6}}{\left(\mathrm{PuX}_{3}\right)^{2}\left(\mathrm{H}_{2}\right)^{3}}
$$

where $(X)$ is the partial pressure of $X$, in atmospheres. Equation (2) may be re-written as,

$$
\frac{(\mathrm{HX})^{2}}{\left(\mathrm{H}_{2}\right)}=\mathrm{K}_{\mathrm{p}}^{1 / 3}\left(\frac{\mathrm{nux}_{3}}{\mathrm{Pu}_{\mathrm{Pu}}}\right)^{2 / 3} .
$$

If $n_{2}$ is the total fissionable material concentration, and $n_{P u, v}$ is the concentration of plutonium at saturation, then we must have

$$
\frac{(\mathrm{HX})^{2}}{\left(\mathrm{H}_{2}\right.} \geq \mathrm{K}_{\mathrm{p}}^{1 / 3}\left|\frac{\mathrm{n}_{2}}{\mathrm{n}_{\mathrm{Pu}, \mathrm{v}}}-\mathrm{I}\right|^{2 / 3},
$$

in order that the plutonium shall not condense. Since $\mathrm{n}_{\mathrm{Pu}, \mathrm{v}}$ is only dependent on the temperature, the equilibrium problem can be described in terms of the value of $(\mathrm{HX})^{2} /\left(\mathrm{H}_{2}\right)$ which is necessary in order to maintain a given total fuel concentration, $n_{2}$, at a given temperature.

The equilibrium constant is related to the free energy change of the reaction, Eq. (1), by,

$$
\log \mathrm{K}_{\mathrm{p}}=-\Delta \mathrm{F}^{\mathrm{O}} / \mathrm{RT}
$$

Values of $\Delta \mathrm{F}^{\circ}$ have been given at $298.16^{\circ} \mathrm{K}$ for the reaction,

$$
2 \mathrm{Pu}(\mathrm{s})+3 \mathrm{x}_{2}(\mathrm{~g}) \rightarrow 2 \mathrm{Pux} \mathrm{x}_{3}(\mathrm{~s})
$$

They are: - $712 \mathrm{~K}$ cal for $\mathrm{PuF}_{3}$ and $-367 \mathrm{~K}$ cal for $\mathrm{PuBr}_{3}$ (9)

We have also the following data at $298.16^{\circ} \mathrm{K}$,

$$
\begin{array}{lll}
\mathrm{PuF}_{3}(\mathrm{~s}) \rightarrow \mathrm{PuF}_{3}(\mathrm{~g}) & \quad \Delta F^{\circ}=91.94 \mathrm{~K} \mathrm{cal}(9) \\
\operatorname{PuBr}_{3}(\mathrm{~s}) \rightarrow \mathrm{PuBr}_{3}(\mathrm{~g}) & ; & \Delta F^{\circ}=59.89 \mathrm{~K} \mathrm{cal} \\
\mathrm{Pu}(\mathrm{s}) \rightarrow \mathrm{Pu}(\mathrm{g}) & \Delta F^{\circ}=74 \mathrm{~K} \mathrm{cal}(*) \\
\frac{1}{2} \mathrm{H}_{2}(\mathrm{~g})+\frac{1}{2} \mathrm{~F}_{2}(\mathrm{~g}) \rightarrow \mathrm{HF} ; & \Delta F^{\circ}=-64.7 \mathrm{~K} \mathrm{cal}(10) \\
\frac{1}{2} \mathrm{H}_{2}(\mathrm{~g})+\frac{1}{2} \mathrm{Br}_{2}(\mathrm{~g}) \rightarrow \mathrm{HBr}: & \Delta F^{\circ}=-13.10 \mathrm{~K} \mathrm{cal}(10)
\end{array}
$$

*Estimated from vapor pressure data 
Thus, the free energy changes for Eq. (1) are,

$$
\begin{aligned}
& \mathrm{PuF}_{3}: \\
& \Delta \mathrm{F}_{298}^{\circ}=+712-2(91.94)+2(74)+6(-64.7)=288 \mathrm{~K} \mathrm{cal} \\
& \mathrm{PuBr}_{3}: \\
& \Delta \mathrm{F}_{298}^{\circ}=367-2(59 \cdot 89)+2(74)+6(-13.10)=3.17 \mathrm{~K} \mathrm{cal}
\end{aligned}
$$

At $298^{\circ} \mathrm{K}, \mathrm{PuBr}_{3}$ is evidently somewhat more stable in hydrogen than $\mathrm{PuF}_{3}$, because the free energy of formation of $\mathrm{BBr}$ is so much less than that of $\mathrm{HF}$ 。

In order to compute the free energy change, $\Delta \mathrm{F}^{\circ}$, at elevated temperatures, it is necessary to estimate the free energy changes of the products and reactants of $\mathrm{Eq}$. (1). The free energies are available for $\mathrm{H}_{2}$ and $\mathrm{EF}$ or $\mathrm{HBr}$. They must be computed for $\mathrm{PuF}_{3}(\mathrm{~g}), \mathrm{PuBr}_{3}(\mathrm{~g})$ and: $\mathrm{Pu}(\mathrm{g})$.

\section{Calculation of free energies:}

Since $\mathrm{Pu}(\mathrm{g})$. is monatomic, its free energy can be computed quite readily unless its electronic degrees of freedom are excited. It will be assumed for present purposes that they are not. For the $\mathrm{PuF}_{3}$ and $\mathrm{PuBr}_{3}$ a knowledge of the vibrational frequencies of the molecule is needed for computing the free energy. Such information is not available for the $\mathrm{PuBr}_{3}$, and only rough estimates (from data on $\mathrm{PuF}_{6}$ ) are available for $\mathrm{PuF}_{3}$. Accordingly the following equilibrium estimates will be restricted to the $\mathrm{PuF}_{3}$ system.

The free energy of a perfect gas with internal degrees of freedom is given by (II),

$$
F=R T\left\{\log \left[\frac{h^{3}}{(2 \pi m k T)^{3 / 2}}\left(\frac{p}{k T I}\right)\right]-\log Q_{\text {int }}\right\},
$$

where $Q_{\text {int }}$ is the internal partition function, and the other notation is conventional. 
In the case of gaseous $\mathrm{Pu}$, without electronic excitation, the free energy is given by the first term of Eq. (7). After substitution of the appropriate values, the expression becomes,

$$
\mathrm{F}^{\mathrm{O}} / \mathrm{RT}=\log \left(0.0105 / \mathrm{T}^{5 / 2}\right), \mathrm{T}=\mathrm{O}_{\mathrm{K}}, \mathrm{Pu}(\mathrm{g})
$$

In the case of $\mathrm{PuF}_{3}$ it is necessary to evaluate the internal partition function. In the absence of rotational-vibrational inter actions and electronic excitation,

$$
Q_{\text {int }}=Q_{\text {rot }} Q_{\text {vib }}
$$

It will be assumed in evaluating the rotatianal partition function,

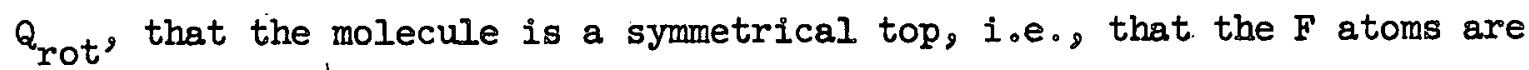
arranged with 120 degree separation in a plane. The rotational partition function is then $(11)$,

$$
Q_{\text {rot }}=\frac{8 \pi^{2}(2 \pi k t)^{3 / 2} I_{1} I_{2}^{1 / 2}}{6 h^{3}}
$$

where $I_{l}$ is the moment of inertia about an axis perpendicular to the plane of the molecule, and $I_{2}$ is the moment of inertia about an axis in the plane. To evaluate $Q_{\text {rot }}$, we need the interatomic distance. Following Hawkins et al (12), we take this distance as $1.97 \mathrm{~A}^{\circ}$. The rotational partition function then becomes,

$$
Q_{\text {rot }}=5.77 \mathrm{~T}^{3 / 2}, \mathrm{~T}=\mathrm{o}_{\mathrm{K}}
$$

For the purpose of computing the vibrational partition function, the molecule may be replaced by a set of six harmonic oscillators, in which case $^{(11)}$

$$
Q_{v i b}=\prod_{i=1}^{6}\left[\frac{1}{1-\exp \left(-u_{i}\right)}\right]
$$

where $u_{i}=h \nu_{i} / k T$ and $\nu_{i}$ is the frequency of the $i^{\text {th }}$ vibrational mode。 
There is no precise information on the vibrational frequencies of the $\mathrm{PuF}_{3}$ molecule: however, the wave numbers $(13)$ and degeneracies $(14)$ for $\mathrm{PuF}_{6}$ are as follows:

\begin{tabular}{|c|c|c|}
\hline$\omega_{2} \mathrm{~cm}^{-1}$ & & degeneracy \\
\hline 631 & : & 1 \\
\hline 523 & & 2 \\
\hline 202 & & 3 \\
\hline 173 & & 3 \\
\hline 210 & & 3 \\
\hline 615 & & 3 \\
\hline
\end{tabular}

It seems reasonable to asaign the higher of these frequencies to "stretching" vibrations, and the lower to "bending" vibrations for the $\mathrm{Pu} F$ bond. Then for the average stretching frequency we get, $[(1)(631)+2(523)+3(615)] / 6=587 \mathrm{~cm}^{-1}$, and for the bending frequency; $[(3)(202)+(3)(210)+3(173)] / 9=195 \mathrm{~cm}^{-1}$. since the heat of formation of $\mathrm{PuF}_{3}$, per $\mathrm{F}$ atom, is considerably higher than that of $\mathrm{PuF} 6$, it is to be expected that the "stretching" frequencies for $\mathrm{PuF}_{3}$ will be higher than those for $\mathrm{PuF}_{6}$. The heats of formation are $\Delta \mathrm{H}_{298}=-125$ and $-76 \mathrm{~K}$ caI per mole of $F$.

If the interatomic force law can be approximated by a Morse potential,

$$
U\left(r-r_{e}\right)=D_{e}\left[1-e^{-\beta\left(r-r_{e}\right)}\right]^{2},
$$

the frequency of osciliation about the equilibrium point, $r_{e}$, is $\nu=\left(2 \mathrm{p}_{\mathrm{e}} \beta^{2} / \mathrm{m}\right)^{1 / 2}$, where $\mathrm{m}$ is the reduced mass for the mode in question. For lack of information, $\beta$ and $r_{e}$ will be assumed to be the same for the $\mathrm{Pu} \times \mathrm{F}$ bonds in $\mathrm{PuF}_{3}$ and $\mathrm{PuF}_{6}$, when

$$
v_{\mathrm{PuF}_{3}}=\left(\frac{\mathrm{e}_{2} \mathrm{PuF}_{3}}{\mathrm{D}_{\mathrm{e}, \mathrm{PuF}}}\right)^{\mathrm{D} / 2} \nu_{\mathrm{PuF}_{6}}
$$

and if $\mathrm{D}_{e} \propto-\Delta \mathrm{H}_{298}$ as given above, then

$$
\nu_{\mathrm{PuF}_{3}} \approx 1.28 \nu_{\mathrm{PuF}_{6}}
$$

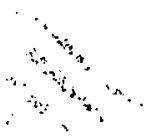


Applying this correction to the "stretching" frequency found for PuF $\sigma^{8}$ we have the following frequencies for Pif $3^{\circ}$

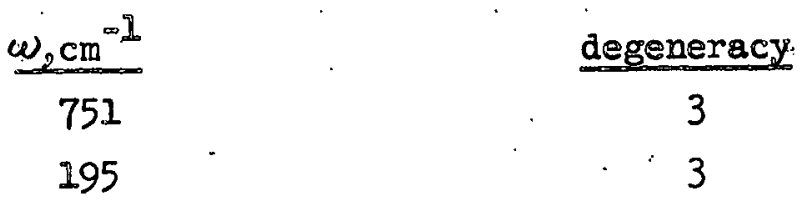

Toe vibrational partition function is now,

$$
Q_{\text {vib }}=I /\left[1-e^{-u_{1}}\right]^{3}\left[1-e^{-u_{2}}\right]^{3}
$$

where

$$
\begin{aligned}
& u_{y_{2}}=1.08 \times 10^{3} / \mathrm{T}, T={ }^{O} \mathrm{~K} \\
& u_{2}=0.281 \times 10^{3} / \mathrm{T}, \quad \mathrm{T}={ }^{\mathrm{o}_{\mathrm{K}}} .
\end{aligned}
$$

Substituting Eqs. (11) and (13) into Eq. (7); we find for the PuF $3^{8}$

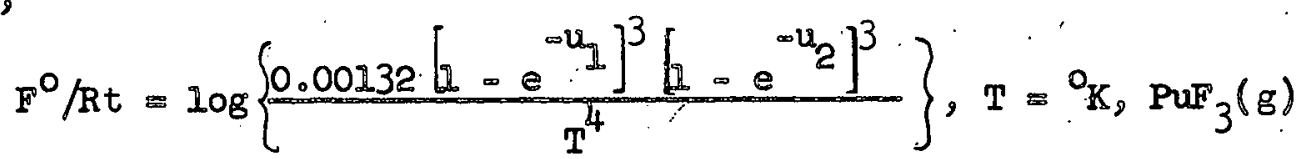

With Eqs. (8) and (14) for the free energies of Pu(sg) and PuF $3(g)$, and tabulated values for and $\mathrm{K}_{2}$, the value of $\Delta \mathrm{F}_{\mathrm{T}}^{\mathrm{O}}$ for $\mathrm{Eq}$. (I) may be computed according to?

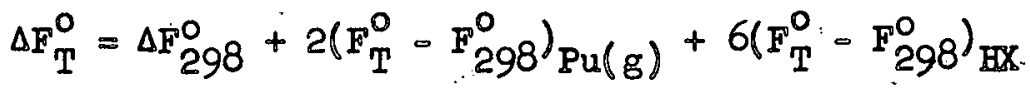

$$
\begin{aligned}
& \therefore 2\left(\mathrm{~F}_{\mathrm{T}}^{\mathrm{O}}-\mathrm{F}_{298}^{\mathrm{O}}\right)_{\mathrm{PuF}_{3}(g)}=3\left(\mathrm{~F}_{\mathrm{T}}^{\mathrm{O}}-\mathrm{F}_{298}^{\mathrm{O}}\right)_{\mathrm{H}_{2}}
\end{aligned}
$$

The results are shown in Fig. 21, together with $\log \mathrm{K}_{\mathrm{p}}$ computed from Eq. (4). It is clear that as the temperature rises the reaction tends more and more. to proceed to the right would be expected. The values of $F_{T}^{0}-F_{298}^{0}$ used in the calculation of Fig. 21 are shown in Fig. 22. 
UNCLASSIFIED

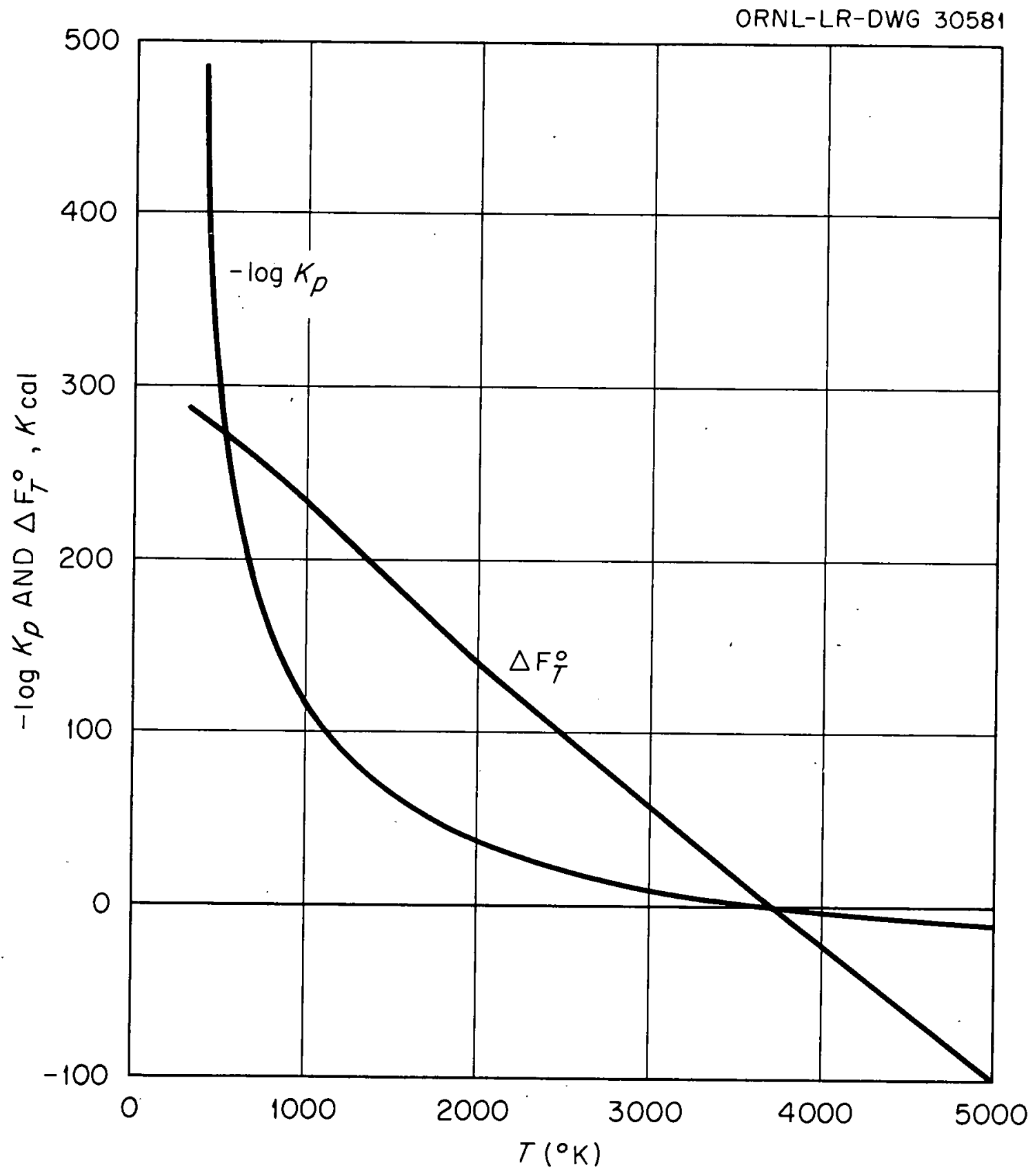

Fig. 21. Free Energy Change and Equilibrium Constant for the Reaction of Gaseous $\mathrm{PuF}_{3}$ and $\mathrm{H}_{2}$ to Form Gaseous Pu and HF. 


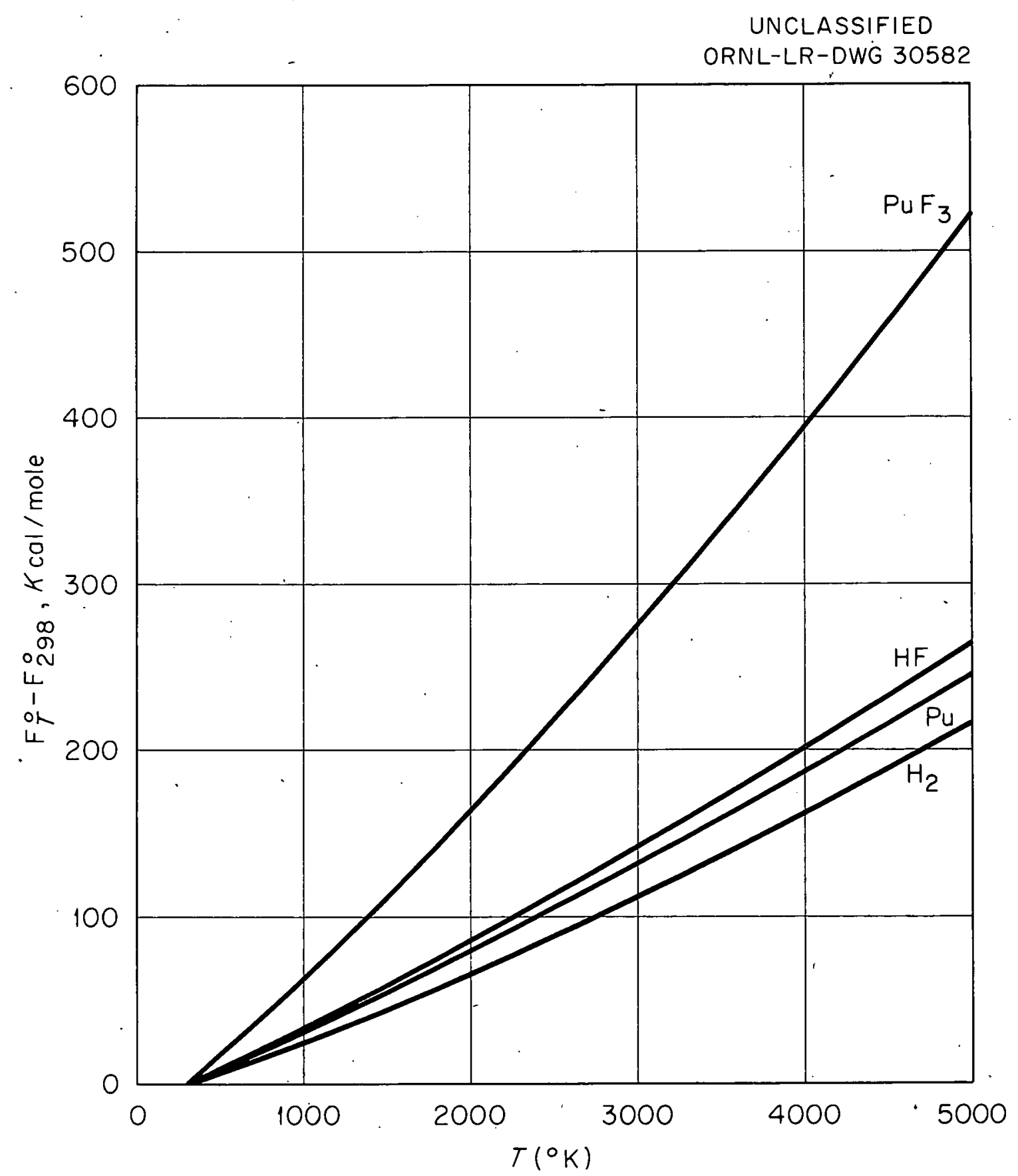

Fig. 22. Free Energy Changes for $\mathrm{PuF}_{3}, \mathrm{Pu}, \mathrm{HF}$, and $\mathrm{H}_{2}$. 
2. In order to stabilize either $\mathrm{PuF}_{3}$ or $\mathrm{PuBr}_{3}$ against reduction by hydrogen at the temperatures of interest, appreciable concentrations of the reduction products ( $\mathrm{HF}$ or $\mathrm{HBr}$ ) must be maintained in the vortex tube. The attendant loss in specific impulse, due to dilution of the exhaust gas with HF or $\mathrm{HBr}$, may be more than 20 percent for PuF ${ }_{3}$, if the average fuel concentration is $10^{18} \mathrm{~cm}^{-1}$, and will increase if the fuel concentration is increased. 
Requirements imposed by vapor pressure and equilibrium:

The ratio of the square of the partial pressure of HF to the partial pressure of $\mathrm{H}_{2}$, required to prevent condensation of $\mathrm{Pu}$, may be estimated from the vapor pressure data of Fig. 20 and the values of $\mathrm{K}_{\mathrm{p}}$ estimated above. It is clear that $\mathrm{Eq}$. (3) has no meaning if $\mathrm{n}_{2}<\mathrm{n}_{\mathrm{Pu}, \mathrm{v}}$, since then all of the fissionable material may exist as gaseous $\mathrm{Pu}_{3}$ and no $\mathrm{PuF}_{3}$ need be stabilized: ( $\mathrm{HF}$ ) is then zero. On the other hand, if $\mathrm{n}_{2}>\mathrm{n}_{\mathrm{Pu}, \mathrm{v}}$, some $\mathrm{PuF}_{3}$ must be held in gaseous form, and $\mathrm{Eq}$. (3) gives the ratio $(\mathrm{HF})^{2} /\left(\mathrm{H}_{2}\right)$ required to stabilize this concentration of $\mathrm{PuF}_{3}$ against reduction. These results are shown in Fig. 23.

Curves of concentration versus temperature are shown for two typical vortex configurations. EQch requires a maximum value of $\log _{10}\left[(\mathrm{HF})^{2} /\left(\mathrm{H}_{2}\right)\right]$ of about $=0.6$, hence $(\mathrm{HF})^{2} /\left(\mathrm{H}_{2}\right) \geq 0.25$. Now if $\left(\mathrm{H}_{2}\right)$ is $100 \mathrm{~atm},(\mathrm{HF})$ is $5 \mathrm{~atm}$, and a mole fraction of $\mathrm{HF}$ of 0.05 is required to stabilize the $\mathrm{PuF}_{3^{\circ}}$. The average molecular weight of the propellant is then $\overline{\mathrm{M}}=(0.95)(2)$ $+(0.05)(20)=2.90$. The specific impulse is thus reduced by about 20 percent.

It must be borne in mind in considering the above examples that the influence of the vortex field, in separating products and reactants of the reduction, will tend to increase the required concentrations of HF. Also, higher concentrations will be required if the average fissionable material concentration, $\bar{n}_{2}$, is to be increased beyond $10^{18} \mathrm{~cm}^{-3}$.

\section{Conclusions:}

On the basis of the preceding analysis, the following tentative conclusions seem justified. They sbould be reviewed if more exact thermo chemical data becomes available.

1. To provide the gaseous fuel concentrations necessary for vortex reactors, a polyatomic compound of plutonium is necessary, since metallic plutonium has insufficient volatility. The most promising compounds appear to be $\mathrm{PuF}_{3}$ and $\mathrm{PuBr}_{3}$. 


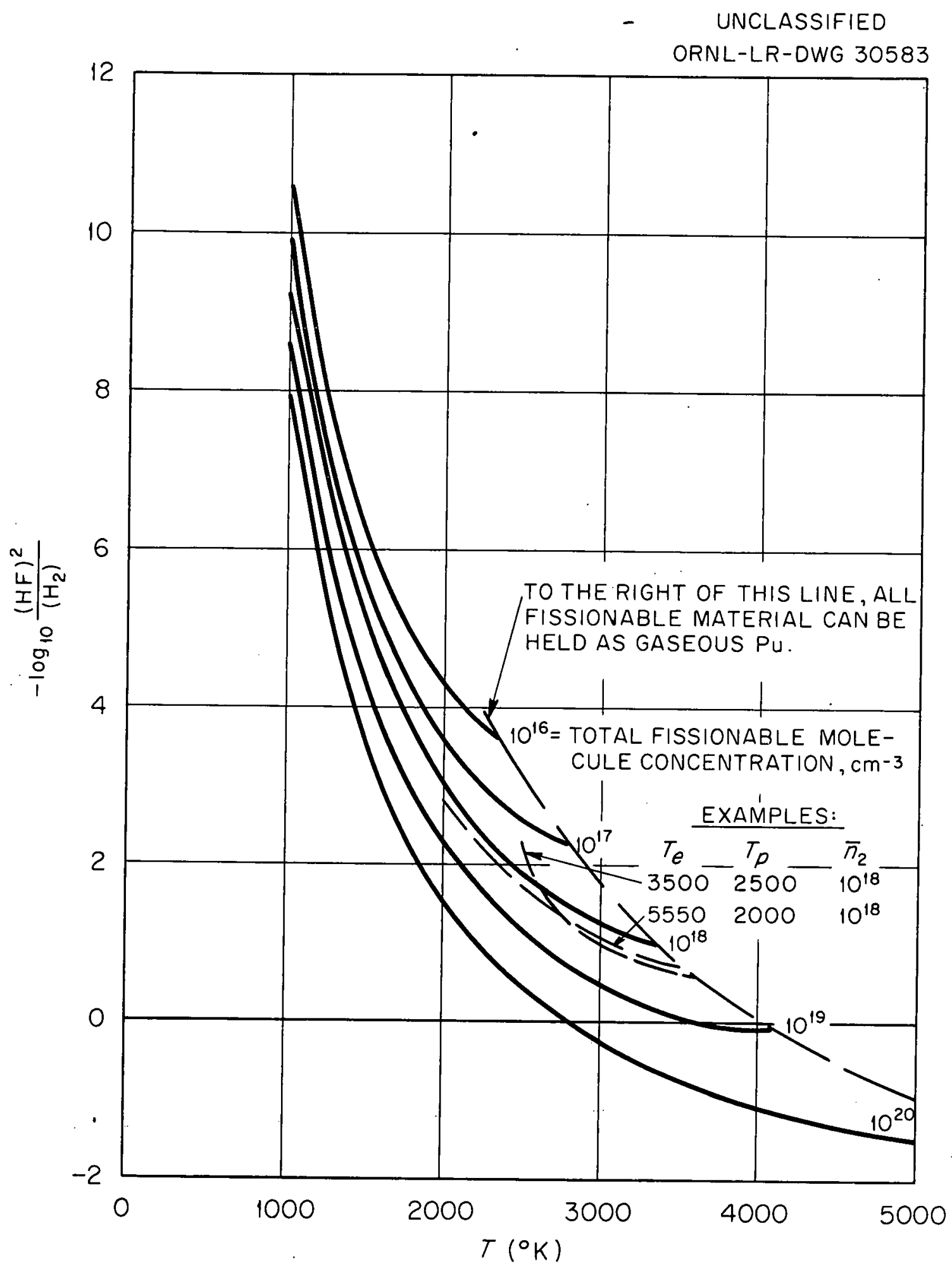

Fig. 23. Concentrations of HF Required to Maintain Given Total Fissionable Material Concentration, as Function of Temperature. 
SECTION IV

Fission Product Retention 
Introduction:

In five minutes operating time a 300,000 lb thrust vortex reactor with a specific impulse of 1400 will produce one fifteenth the contamination of a Hiroshima-type bomb, if all of the fission products are released to the atmosphere. It is therefore important to determine to what extent fission fragments produced within the vortex tubes will be contained by the vortex field.

Fission fragments having a range of masses will be produced locally in the vortex tube at a rate proportional to the fissionable material concen tration, and will diffuse toward the vortex tube exit under the combined influences of the vortex field and radial flow. The distribution of fission fragments within the tube will start from zero initially and grow to an equilibrium distribution at some later time. After this equilibrium distribution has been attained, the rate of loss of fission fragments will equal the generation rate within the vortex tube. Thus; the rate of loss of fission fragments will increase from zero initially to the maximum possible value when the distribution bas attained equilibrium. The objective of the following analysis is to determine the variation of the loss rate with time.

Each fission will be assumed to result in two fission fragments, having half the mass of a fissile atom, deposited as neutral particles at the point of fission. Since the concentration of the fragments will be small compared to that of the propellant and that of the fissionable material, the latter concentrations will not be effected by the fission fragments. Thus, the pressure, the temperature, and the densities of propellant and fissionable material will be those given by the analysis of Ref. 1. The variables describing the behavior of the fission fragments are then reduced to the fission fragment concentration and defusion velocity.

In the following sections, the differential equations governing these variables will be given, and their solution presented for an example selected from Ref。1.
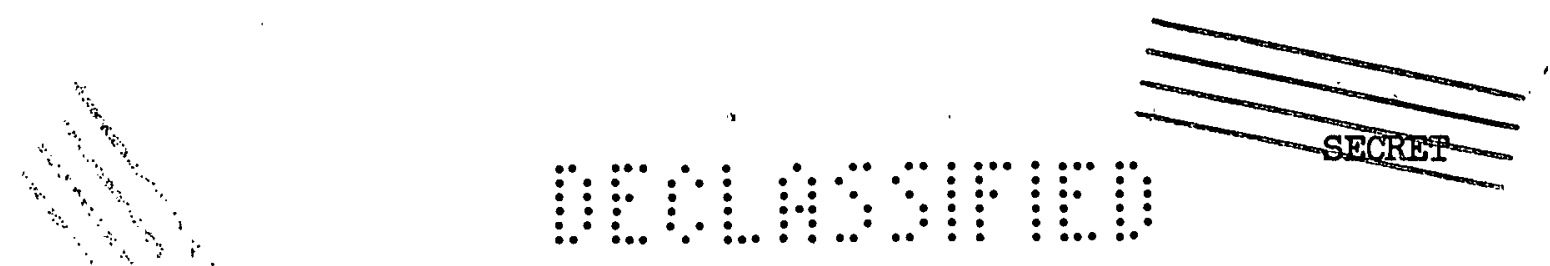


\section{Nomenclature:}

The principle notation used in the analysis is as follows:-

$d_{12}$ : effective hard sphere diameter for collisions between Pissionable and propellant molecules.

$d_{13} \equiv$ effective hard sphere diameter for collisions between fission fragments and propellant molecules.

$D$ a diffusion parameter (Eq. (5)).

$\mathrm{k} \equiv$ Boltzmann's constant.

$\mathrm{m}_{1} \equiv$ mass of propellant molecule.

$\mathrm{m}_{2} \equiv$ mass of fissionable molecule.

$m_{3} \equiv$ mean mass of fission fragment.

$\mathrm{M}_{t} \equiv$ tangential Mach number, based on speed of sound in light gas.

$\eta_{1}=$ mass flow rate of propellant per unit length of vortex tube.

$n_{1}$ molecular concentration of propellant.

$\mathrm{n}_{2}$ molecular concentration of fissionable gas:

$\mathrm{n}_{3}$ molecular concentration of fission fragments.

$\mathrm{n}_{0}$ total molecular concentration.

$\mathrm{p}_{0} \equiv$ total pressure.

r $\mathbf{m}$ radial coordinate.

$\mathrm{T} \quad \mathbf{\Xi}$ gas temperature.

$u_{1} \equiv$ diffusion velocity of propellant.

$\mathrm{u}_{2} \equiv$ diffusion velocity of fissionable gas

$u_{3} \equiv$ diffusion velocity of fission fragments.

$u_{0} \equiv$ mass averaged velocity。

$\mathrm{w} \equiv$ ratio of densities of fissionable and propellant gases. 


\section{Nomenclature (cont)}

$\gamma \equiv$ ratio of specific heats for propellant.

$\rho_{0} \equiv$ total density of gas mixture.

$\varnothing \quad$ neutron track length.

Subscripts :

On independent variable ( $r$ or $r^{*}$ ),

c - exit from tube

$p$ - periphery of tube

$m$ - point of maximum $w$

On dependent variables;

0 - value for gas mixture

1 - value for propellant

2 - value for fissionable gas

3 value for fission fragments.

Superscripts:

* - quantity divided by its value at point of maximum w.

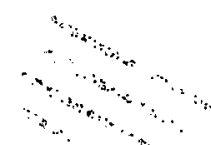




\section{Differential equations:}

If $n_{3}$ is the concentration of fission fragments, $v_{3}$. their diffusion velocity, $u_{0}$ the massaveraged velocity, $r$ the radial coordinate and $s$ the rate of generation of fission fragments per unit volume, the continuity equation for the fission fragments is,

$$
r \frac{\partial n_{3}}{\partial t}+\frac{\partial}{\partial r} \quad\left[r n_{3}\left(u_{0}+u_{3}\right)\right]=r S
$$

By making use of the facts that the fissionable material concentration, $\mathrm{n}_{2}$, and the fission fragment concentration are much smaller than the propellant concentration, the equation connecting the diffusion velocities of the fission fragments and propellant may be written as follows, (15)

$$
u_{3}-u_{1}=-D_{13} \frac{n_{0}}{n_{3}}\left[\frac{\partial}{\partial r}\left(\frac{n_{3}}{n_{0}}\right)+\left(\frac{n_{3}}{n_{0}}-\frac{n_{3} m_{3}}{\rho_{0}}\right) \frac{1}{p_{0}} \frac{d p_{0}}{d r}\right] .
$$

Here $D_{13}$ is the binary diffusion coefficient for fission fragments and propellant, $n_{0}$ is the total molecular concentration, $m_{3}$ is the fission fragment mass, and $p_{0}$ and $p_{0}$ are the total density and pressure. The source of fission fragments, $S$, is given by

$$
s=2 \sigma_{f} \phi n_{2},
$$

where $\sigma_{f}$ and $\emptyset$ are the fission cross section and neutron flux.

Equations (1), (2) and (3) are sufficient to solve for the concentration, $n_{3}$, if proper boundary conditions are specified. These will be given later. It is convenient to reduce the equations to a dimensionless form before attempting their solution. All of the quantities given by Ref. I will be nondimensionalized as they were in Ref. 1 , by dividing them by their values at the point in the tube where $w=n_{2} m_{2} / n_{1} m_{1}$ bas its maximum value. These dimensionless quantities are indicated by an asterisk. If $u_{0 m}$ and $r_{m}$ are the mass averaged velocity and radius at the point of maximum $w$, we may then write $\mathrm{Eq}$. (2) as, 


$$
\frac{u_{3}-u_{1}}{u_{O m}}=-\frac{D_{13}}{r_{m} u_{O m}}\left[\frac{1}{n_{3}} \frac{\partial n_{3}}{\partial r^{*}}=\frac{1}{n_{1}^{*}} \frac{\partial n_{1}^{*}}{\partial r^{*}}+\left(1-\frac{m_{3} / m_{1}}{1+w}\right) \frac{1}{p_{0}^{*}} \frac{d p_{0}^{*}}{d r^{*}}\right] .
$$

Now $u_{1} / u_{0 m}$ is found from Ref. 1 to be

$$
\frac{u_{1}}{u_{O m}}=u_{0}^{*} w\left(\frac{I-w_{c} / w}{1+w_{c}}\right),
$$

where $w_{c}$ is the value of $w$ at the vortex exit. Also,

$$
\frac{1}{n_{1}^{*}} \frac{d n_{1}^{*}}{d r^{*}}=\frac{1}{p_{0}^{*}} \frac{d p_{0}^{*}}{d r^{*}} \cdot \frac{i}{T^{*}} \frac{d T^{*}}{d r^{*}}
$$

and using Eq. (10) of Ref.1, we find,

$$
\frac{u_{3}}{u_{O m}}=u_{0}^{*} \quad w\left(\frac{1-w_{c} / w}{1+w_{c}}\right)=\frac{D_{13}}{r_{m} u_{O m}}\left[\frac{1}{n_{3}} \frac{\partial n_{3}}{\partial r^{*}}+\frac{1}{T^{*}} \frac{d T^{*}}{d r^{*}}-\gamma M_{t m}^{2} \frac{m_{3}}{m_{1}} \frac{1}{r^{* 3}} T^{*}\right] \cdot I V-(4)
$$

Here $M_{t m}$ is the tangential Mach number in the vortex at the point of maximum $\mathrm{w}$.

By analogy to Eq. (24) of Ref. 1, we take

$$
\frac{D_{13}}{r_{m} u_{0 m}}=-D_{m 3} \frac{T * 3 / 2}{p_{0}^{*}} \text {, }
$$

where

$$
\theta_{i \text { in }}=-\frac{3(2 \pi)^{1 / 2}}{8}\left(\frac{k^{1 / 2} m_{I}^{I / 2}}{a_{13}^{2}}\right)\left(1+\frac{m_{1}}{m_{3}}\right)^{1 / 2}\left(\frac{i+w_{m}}{I+w_{c}}\right)_{\frac{m}{m_{1}}}^{1 / 2}
$$

and $M_{1}$ is the mass flow rate of propellant, per unit of tube length. $a_{13}$ is the effective hard-sphere diameter for collisions between fission 
fragments and propellant. Now if $\mathscr{D}_{\mathrm{m} 2}$ is the quantity defined by Eq. (24) of Ref. 1, then

$$
\theta_{m 3}=\left(\frac{m_{1}}{1+\frac{m_{3}}{m_{1}}}\right)^{1 / 2}\left(\frac{d_{12}}{d_{13}}\right)^{2} \cdot \theta_{m 2},
$$

! but from Eq. (34), Ref. 1,

$$
\partial_{\mathrm{m} 2}=\frac{\left(1-\mathrm{w}_{\mathrm{c}} / \mathrm{w}_{\mathrm{m}}\right)\left(1+\mathrm{w}_{\mathrm{m}}\right)}{\gamma \mathrm{M}_{\mathrm{tm}}^{2}\left(\frac{\mathrm{m}_{2}}{\mathrm{~m}_{1}}-1\right)\left(1+\mathrm{w}_{\mathrm{c}}\right)},
$$

and

$$
\partial_{m 3}=\frac{\left(1-w_{c} / w_{m}\right)\left(1+w_{m}\right)}{\gamma M_{t m}^{2}\left(\frac{m_{2}}{m_{1}}-1\right)\left(1+w_{c}\right)}\left(\frac{1+\frac{m_{1}}{m_{3}}}{1+\frac{m_{1}}{m_{2}}}\right)^{1 / 2}\left(\frac{d_{12}}{d_{13}}\right)^{2} .
$$

The continuity equation, Eq. (2), may also be written in dimensionless form,

$$
r^{*} \frac{\partial n_{3}}{\partial t}+\frac{u_{0 m}}{r_{m}} \frac{\partial}{\partial r^{*}}\left[r * n_{3}\left(u_{0}^{*}+\frac{u_{3}}{u_{0 m}}\right)\right]=r * s .
$$

Eliminating $u_{3} / u_{0 m}$ from this equation with Eq. (4), we find

$$
r^{*} \frac{\partial n_{3}}{\partial t}+\frac{u_{0 m}}{r_{m}} \frac{\partial}{\partial r^{*}}\left[a\left(r^{*}\right) n_{3}+b\left(r^{*}\right) \frac{\partial n_{3}}{\partial r^{*}}\right]=r^{*} s
$$


where

$$
a\left(r^{*}\right)=r^{*} u_{0}^{*}\left(\frac{1+w}{1+w_{c}}\right)+D_{m 3^{*}} r^{*} \frac{T^{*} / 2}{p_{0}^{*}}\left(\frac{1}{T^{*}} \frac{d^{*}}{d r^{*}}-\gamma M_{t m}^{2} \frac{m_{3}}{m_{1}} \frac{1}{r^{*} T^{*}}\right)
$$

and

$$
b(r *)=D_{m 3} r * \frac{\mathrm{T}^{* 3 / 2}}{\mathrm{p}_{0}^{*}}
$$

Carrying out the indicated differentiation,

$$
\begin{gathered}
r^{*} \frac{\partial n_{3}}{\partial t}+\frac{u_{0 m}}{r_{m}} b\left(r^{*}\right) \frac{\partial^{2} n_{3}}{\partial r^{* 2}}+\frac{u_{0 m}}{r_{m}}\left[a\left(r^{*}\right)+\frac{d b\left(r^{*}\right)}{d r^{*}}\right] \frac{\partial n_{3}}{\partial r^{*}} \\
\pm \frac{u_{O m}}{r_{m}} \frac{d a\left(r^{*}\right)}{d r^{*}} n_{3}=r^{* S}
\end{gathered}
$$

Now $S$ is given by $\mathrm{Eq} \cdot(3)$. We define a mean lifetime, $\tau_{2}$, for a fissionable atom as

$$
\tau_{2} \equiv \frac{1}{\sigma_{f} \phi}
$$

and write $\mathbf{S}$ as

$$
s=\frac{2 n_{2 m}}{\tau_{2}} n_{2}^{*}
$$

A quantity which is characteristic of the fluid residence time in the tube may be defined as,

$$
\tau_{1} \equiv-\frac{r_{m}}{u_{O m}}
$$

We then find that if a new variable, $\eta$, is defined as

$$
\eta \frac{n_{3}}{2 n_{2 m}} \frac{\tau_{2}}{\tau_{1}}
$$


and a new time variable is defined as

$$
\xi \equiv t / \tau_{1}
$$

the differential equation takes the final form,

$$
\frac{\partial \eta}{\partial \xi}-f\left(r^{*}\right) \frac{\partial^{2} \eta}{\partial r^{* 2}}-g\left(r^{*}\right) \frac{\partial \eta}{\partial r^{*}}-h\left(r^{*}\right) \eta=n_{2}^{*}
$$

where

$$
\begin{gathered}
f\left(r^{*}\right)=\frac{b\left(r^{*}\right)}{r^{*}}=D_{m 3} \frac{T^{* 3 / 2}}{p_{0}^{*}} \\
g\left(r^{*}\right)=u_{0}^{*}\left(\frac{1+w^{\prime}}{1+w_{c}}\right)+f\left(r^{*}\right)\left[\frac{1}{r^{*}}+\frac{5}{2} \frac{1}{T^{*}} \frac{d T^{*}}{d r^{*}}-r M_{t m}^{2}\left|\frac{m_{3}}{m_{1}}+1_{1}+w\right| \frac{1}{r^{*} T^{*}}\right] \\
h\left(r^{*}\right)=\frac{1}{r^{*}} \frac{d}{d r^{*}}\left[a\left(r^{*}\right)\right]
\end{gathered}
$$

The particular advantage of this form is that all of the coefficients in the equation are of order unity, since all the quantities with asterisks are unity at at least one point in the tube.

\section{Boundary conditions:}

The region of interest extends from the tube exit, at $r_{c}^{*}$, to its periphery, at $r_{p}^{*}$. At the periphery, the physical boundary condition is that the mass flow of fission fragments must be zero. This requires that $n_{3} m_{3}\left(u_{0}+u_{3}\right)$ be zero at $r_{p}^{*}$. Since $n_{3}$ will in general not be zero at $r_{p}^{*}$, we find from Eqs. (4), (6), and (7)

$$
\left.\frac{1}{\eta} \frac{\partial \eta}{\partial r^{*}}\right|_{r_{p}^{*}}=-\frac{a\left(r_{p}^{*}\right)}{b\left(r_{p}^{*}\right)}
$$


At the tube exit, the playsical boundary condition is that the gas mixture is rapidiy swept from the tube. This is equivalent to saying that at that point $u_{3}$ is small compared to $u_{0}$. We therefore put $u_{3}$ equal to zero at $r_{c}^{*}$. From Eqs. (4), (6) and (7) again,

$$
\left.\frac{1}{\eta} \frac{\partial \eta}{\partial r^{*}}\right|_{r_{c}^{*}}=\frac{a\left(r_{c}^{*}\right)-r_{c}^{*} u_{0}^{*} \cdot\left(r_{c}^{*}\right)}{b\left(r_{c}^{*}\right)}
$$

With the initial condition that $\eta\left(r^{*}, 0\right)=0$, the problem is then completely defined.

For complete consistency it is necessary that the value $\mathrm{r}_{\mathrm{c}}^{*}$, which is taken as the inaer boundary of the flow, be the same as that prescribed for a given case in Ref。 $1,1_{0} e_{0}$, the value of $r^{*}$ at which $w$ is reduced to some specified value, $w_{c}$. However, it was show in Ref. 1 that the value of $\mathrm{w}_{c}$ which was chosen, namely 0.0001 , resulted in vortex tubes of very small diameter. It seems likely that an increase in tube diameter from the values computed in Ref。 1 , and a corresponding decrease in $r_{c}^{*}$, will be necessary in an actual vortex reactor. Accordingly, in the numerical example which will be given later, the fission product leakage rate will be computed for values of $r_{c}^{*}$ less than the value specified by Ref。 I for $w_{c}=0.0001$.

\section{Leakage rate:}

In accordance with the above boundary condition at $r_{c}^{*}$, the rate of

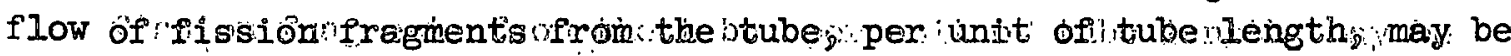
written as,

$$
\mathscr{L}=2 \pi r_{c} n_{3}\left(r_{c} t\right) u_{0}\left(r_{c}, t\right)
$$

In terms of the dimensionless quantities,

$$
\mathcal{L}(\xi)=2 \frac{\tau_{I}}{\tau_{2}} \frac{1}{m_{2}} \frac{w_{m}}{I+w_{m}} m_{I}\left(I+w_{c}\right) r_{c}^{*} u_{O c}^{*} \eta\left(r_{c}^{*}, \xi\right)
$$

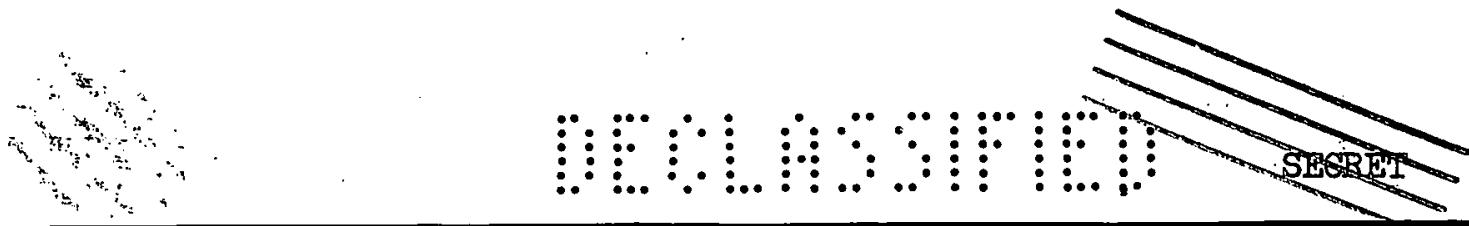


$\mathcal{L}$ is the loss rate in particles per unit time, and use has been made of the relation

$$
\mathscr{M}_{1}\left(1+w_{c}\right)=2 \pi_{r_{m}} \rho_{O m} u_{O m}
$$

For large values of $\xi$, after the equilibrium distribution is attained, we must have

$$
\mathcal{L}(\infty)=2 \pi r_{p}^{2} \bar{n}_{2} \sigma_{f} \phi,
$$

where $\bar{n}_{2}$ is the mean fissionable material concentration in the tube. Combining this with $\mathrm{Eq}_{0}(19)$, we find as the asymptotic value of $\eta\left(r_{c}^{*}\right)$,

$$
\eta\left(r_{c}^{*}, \infty\right)=\frac{r_{p}^{*}}{2 u_{0}^{*} r_{c}^{*}} \quad\left(\frac{\bar{w}}{w_{m}}\right)\left(\frac{\bar{\rho}_{l}}{\rho_{l p}}\right)\left(\frac{p_{0 p}^{*}}{\frac{T_{p}^{*}}{p}}\right)
$$

This relation gives a useful check on the integration of Eq. (13).

\section{Numerical example:}

A machine code has been prepared for ORACLE ${ }^{(16)}$, to solve the gene ral linear, time dependent diffusion equation, as typified by Eq. (13):。 With this code Eq. (13) has been integrated for an example relected from

\begin{tabular}{|c|c|c|c|}
\hline$M_{t m}$ & 0.7 & $\mathbb{M}_{t p}$ & 0.640 \\
\hline $\mathrm{W}_{\mathrm{m}}$ & 1.0 & & 0.599 \\
\hline$g_{m} / g_{m}\left(\max x_{0}\right)$ & 0.338 & $\mathrm{p}: \mathrm{oc}$ & 0.575 \\
\hline$r_{p}^{*}$ & 1.24 & & 1.22 \\
\hline
\end{tabular}
Ref. 1. Some pertinent data for this example are summarized in Table $1_{0}$

\section{TABLE I - Data Por Numerical Example}

* The authors are indebted to F. Jo Witt for preparing this program [Ref:o( 16$)]$; and carrying gout the machine calculations. 


$$
\begin{array}{llll}
r_{c}^{*} & 0.725 & T_{p}^{*} & 0.7794 \\
u_{o c}^{*} & 4.1 .13 & & \\
T_{c}^{*} / T_{p} & 1.35 & & \\
w^{*} / w_{m} & 0.361 & &
\end{array}
$$

The coefficients, $f(r), g(r *)$, and $h(r *)$ have been computed from Eqs. (14), (15) and (16), and are tabulated in Table 2 , along with $n_{2}^{*}$.

Table 2 - Coefficients for Eq. (13)

$\begin{array}{llllc}r^{*} & f(f 2 *) & g\left(r^{*}\right) & h(r *) & n_{2}^{*}\left(r^{*}\right) \\ 1.245 & 0.01475 & 0.6402 & 0.1925 & 0.1530 \\ 1.205 & 0.01529 & 0.6482 & 0.0505 & 0.2704 \\ 1.165 & 0.01628 & 0.6634 & -0.2400 & 0.4609 \\ 1.125 & 0.01779 & 0.6914 & -0.6086 & 0.6870 \\ 1.085 & 0.01993 & 0.7347 & -1.0219 & 0.8947 \\ 1.045 & 0.02268 & 0.8053 & -1.3200 & 1.0195 \\ 1.005 & 0.02594 & 0.8876 & -1.3100 & 1.0115 \\ 0.065 & 0.02917 & 0.9798 & -0.07305 & 0.8576 \\ 0.925 & 0.03223 & 1.0473 & 0.4222 & 0.5964 \\ 0.885 & 0.03451 & 1.0719 & 2.0747 & 0.3175 \\ 0.845 & 0.03617 & 1.0190 & -3.9093 & 0.1169 \\ 0.805 & 0.03746 & 0.8799 & 5.8188 & 0.0260 \\ 0.765 & 0.03873 & 0.6473 & 7.9166 & 0.0029 \\ 0.725 & 0.04022 & 0.2961 & 10.9466 & 0.0001 \\ 0.685 & 0.04199 & -0.1728 & 15.3106 & 0 \\ 0.645 & 0.04424 & -1.0213 & 22.37 .05 & 0 \\ 0.605 & 0.4717 & -2.02569 & 34.0764 & 0 \\ 0.565 & 0.05110 & -4.02530 & 54.6482 & 0 \\ 0.525 & 0.05656 & -7.6432 & 93.5514 & 0\end{array}$


In the range of $r^{*}$ from 1.24 to 0.725 the data were taken directly from the results of Ref. 1. In the range from 0.725 to 0.525 , the functions were computed by assuming $w=0$ and an isentropic expension. As a first approximation, $a_{12} / d_{13}$ was taken as unity.

The time dependence of $\eta$ is shown in Fig. (24) for $r_{c}^{*}=0.725$, the value which led to a ratio of heavy gas mass flow to light gas mass flow of 0.0001 in the solution of Ref. 1. The solution grows from a shape similar to that of $n_{2}^{*}$ to a shape peaked at a somewhat smaller value of $r^{*}$. This inward shift is of course due to the fact that the fission fragments are only one half as heavy as the fissionable molecules.

The variation of $\eta\left(r_{c}^{*} \xi\right)$ with $\xi i s$ shown in Fig. (25) for this same case: It will be reealled from Eq. (19) that the fission fragment loss rate is. proportional to $\eta\left(r_{c}^{*}, \xi\right)$. The most important fact to be gained from Fig. (25) is that, for $\mathrm{r}_{\mathrm{C}}^{*}=0.725$, the maximum loss rate is approached in an interval of time corresponding approximately to $\xi=1$. Recalling the definition of $\xi\left[\mathrm{Eq}_{0}(12)\right]$, we see that the relaxation time is for this case of the order of the fluid residence time in the vortex tube. It is then clear that for $r_{c}^{*}=0.725$, no appreciable storage of fission fragments occurs. After the first small fraction of a second of operating time they leak out as fast as they are generated.

It is then reasonable to ask what will happen if the inner boundary of -the flow is moved inward, to a smaller radius than that required for containment of the fissionable material. The effect of so reducing the core diameter on the asymptotic fission fragment distribution is shown in Fig. (26). The quantity of fission fragments which can be retained increases very rapidiy. The steady astate solutions could not be computed for values of $r_{c}^{*}$ less than 
UNCLASSIFIED

$-3$

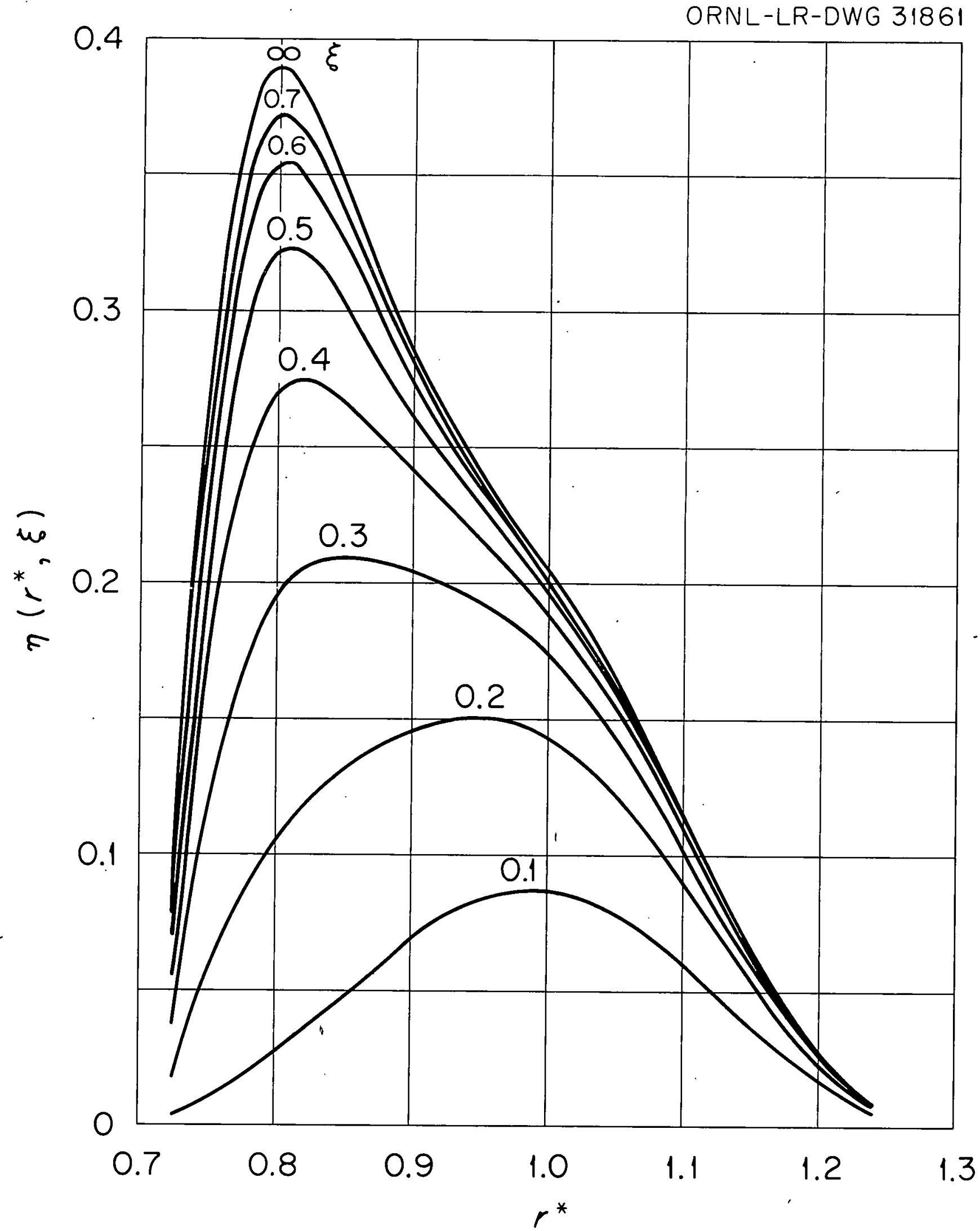

Fig. 24. Development of Dimensionless Fission

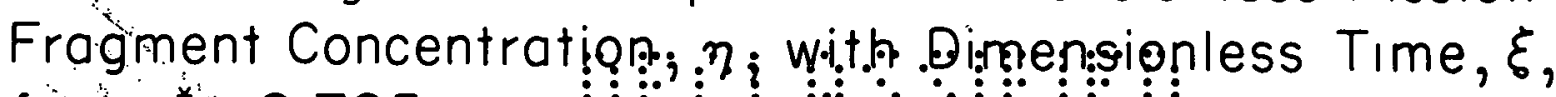
for $r_{c}^{*}=0.725$. 品 


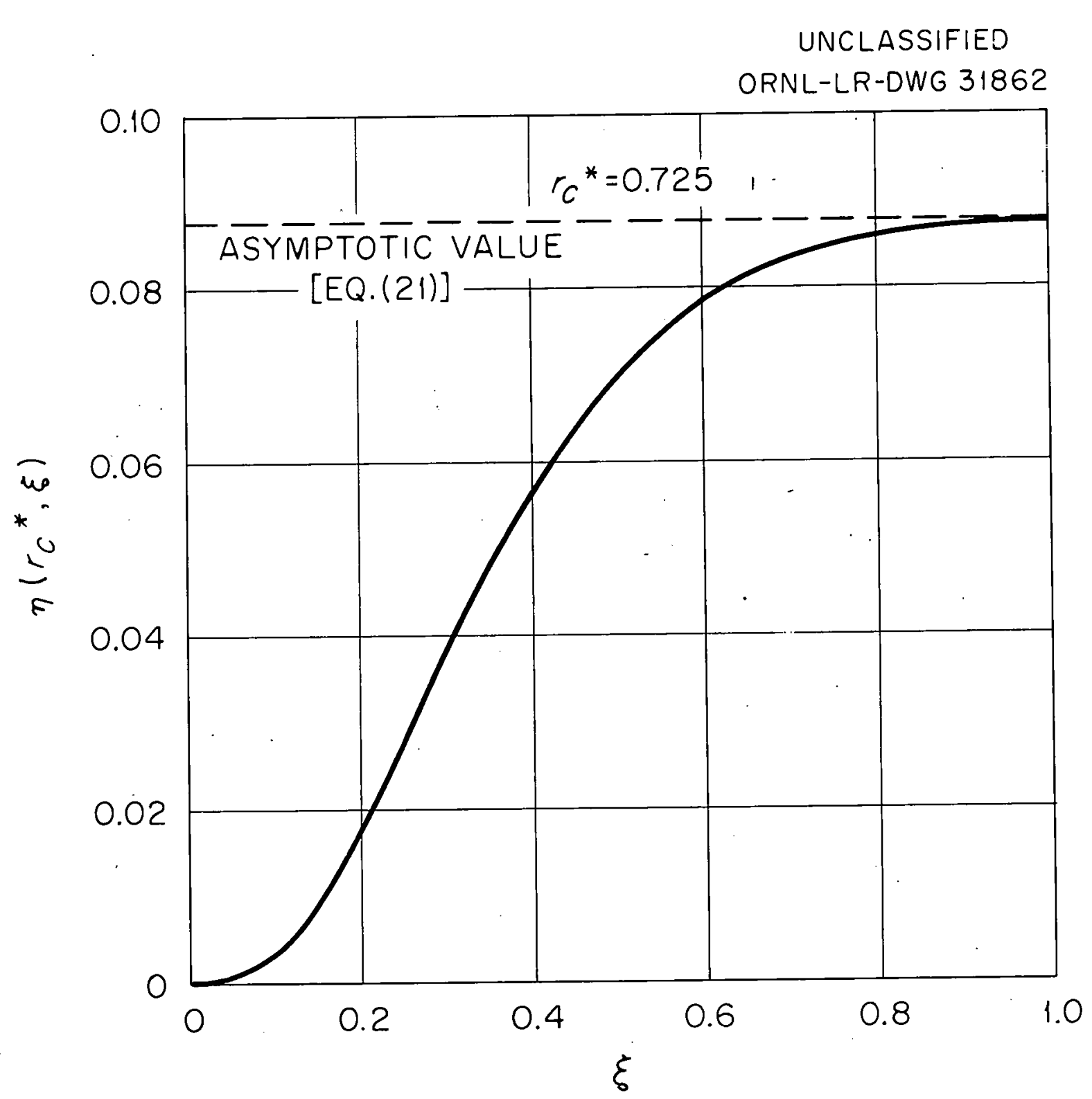

Fig. 25. Variation of Dimensionless Concentration at Inner Boundary $\left[\eta\left(r_{c}{ }^{*}\right)\right]$, with Dimensionless Time, $\xi$, for $r_{c}{ }^{*}=0.725$. 
$-77-$

UNCLASSIFIED ORNL-LR-DWG 31863

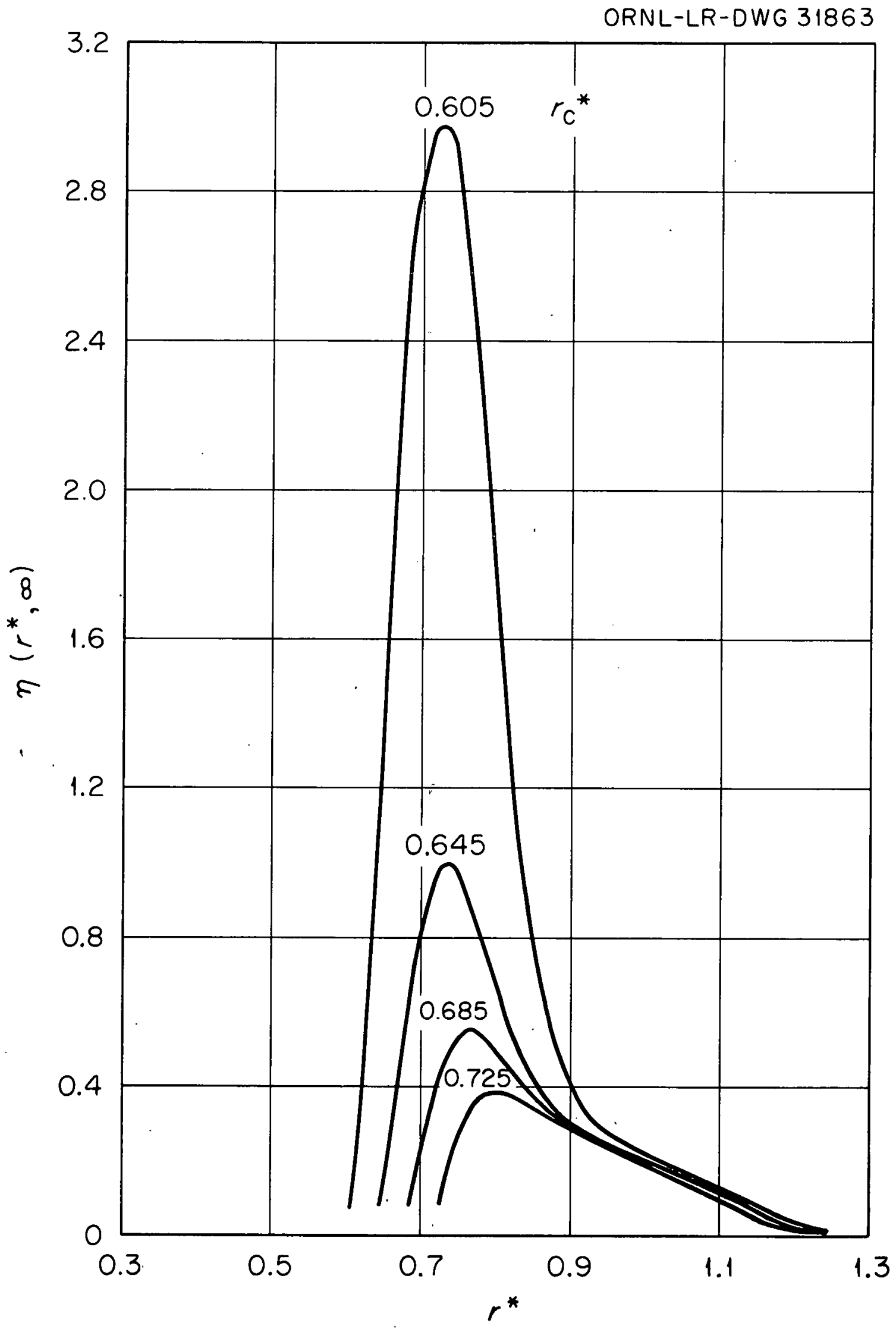

Fig. 26. Dependence of Asymptotic

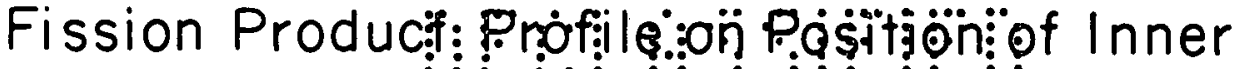

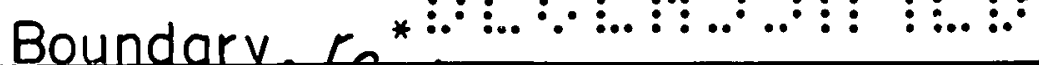


0.605 because of machine difficulties, however the transient solution is shown in Fig. (27) for $r_{c}^{*}=0.525$. For this value of $r_{c}^{*}$ the quantity of fission fragments which is stored is more than one hundred times as large as for $r_{c}^{*}=0.725$. As would be expected, the time required for the loss rate to reach its maximum value is also more than one hundred times as large: This is shown in Fig. (28)。

For a typical vortex tube as described in Ref。 1 , the value of $\tau_{1}$, is about 0.1 seconds. Thus, the time required to attain the maximum fission product loss rate, for $r_{c}^{*}=0.525$, is about 10 seconds. While this is still a small time compared to the burning time of a typical large rocket, it seems clear that by reducing $r_{c}^{*}$ to a value somewhat smaller than 0.525 , the relaxaw tion time could be increased to 100 seconds or longer.

\section{Conclusions:}

It is therefore concluded that, by reducing $r_{c}^{*}$ to a value approximately onemalf of that required for adequate retention of the fissionable material. the rate of loss of fission fragments can be reduced to a small fraction of their rate of generation, at least during the first portion of the rocket?s flight。'

Because of the complexity of the problem and the large number of independent variables, it does not seem feasible to make this statement more quantitative at the present time. However, the method outlined should be capable of yielding a fairly precise estimatecof fission product loss rates for a specific reactor design, should such an estimate be desired.

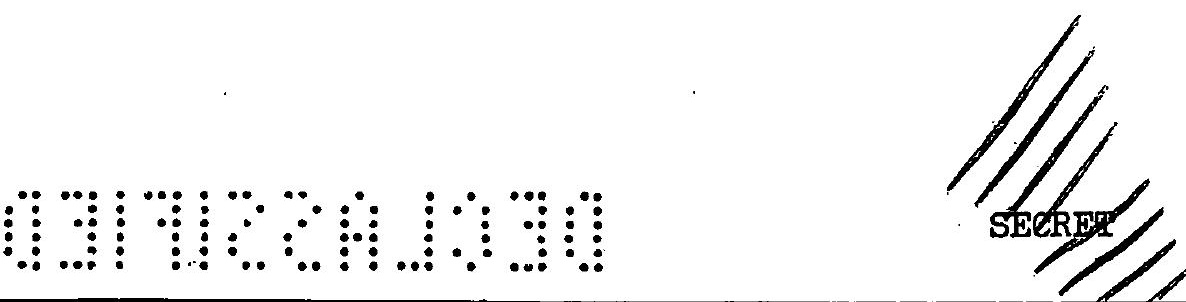




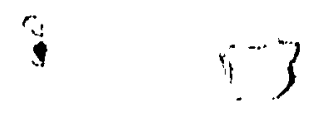

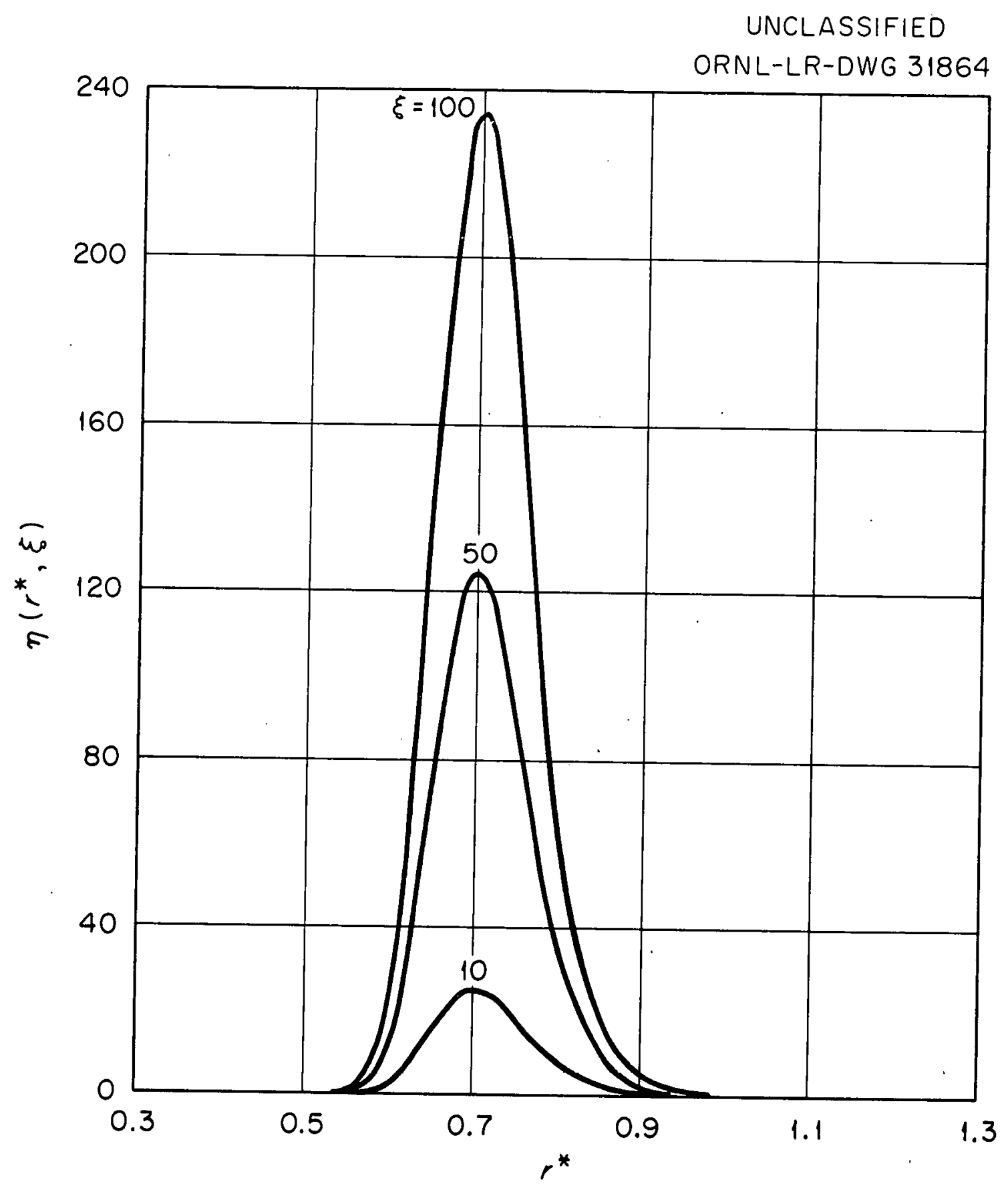

Fig. 27. Development of Dimensionless Fission Fragment Concentration, $\eta$, with Dimensionless Time, $\xi$, for $r_{c}^{*}=0.525$. 


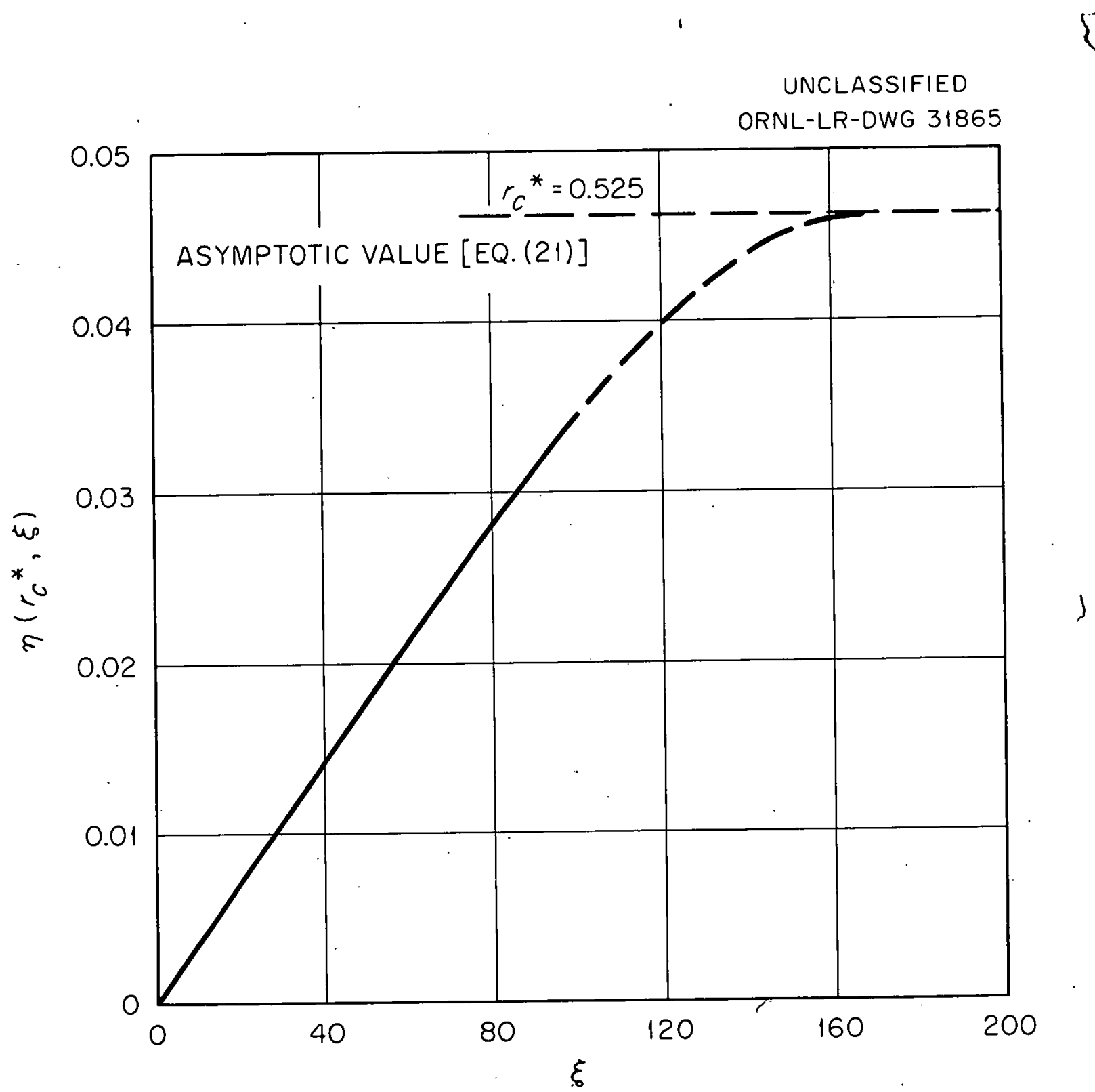

Fig. 28. Variation of Dimensionless Concentration at Inner Boundary $\left[\eta\left(r_{c}{ }^{*}\right)\right]$, with Dimensionless Time, $\xi$, for $r_{c}^{*}=0.525$. 


\section{REFERENCES}

1. J. I. Kerrebrock and R. V. Meghreblian, An Analysis of Vortex Tubes for Combined Gas Phase Fission-Heating and Separation of the Fissionable Material, ORNL CF 57-11.03, Rev。 1, April 11, 1958.

2. Pai, Viscous Flow Theory, p. 346, D. Van Nostrand, 1956.

3. R. R. Bate, I. T. Einstein and W.E.Kinney, Description and Operating Manual for the Three Group, Three Region Reactor Code for ORACLE, ORNL CF 55-1-76, January 13, 1955.

4. R. N.R.Mulford and G. E. Sturdy, "Dissociation Pressures for PuH ${ }^{\prime \prime}$, J.Am。Chem。Soc., 77 , p. 3449 (1955).

5. S. Fried and $N$. R. Davidson, "Studies in the Dry Chemistry of Plutonium Fluorides", N.N.E.S。 Div。IV, I4B, p。784, McGraw ${ }^{\text {HIII }}$ Book Co。

6. T. E. Phipps, G.W. Sears, R. L. Seifert and O.C. Simpson, "The Vapor Pressure of Plutonium Ealides", NoN。E。S。Div。IV, 14B, p.682, McGraw=Hill Book Co。

7. T. E. Phipps, G.W. Sears and O. E. Simpsōn, "The Volatility of Plutonium Dioxide", NoN.E.S. Div。 IV, I4B, p.704, McGraw Hill Book Co.

8. Reactor Handbook, 3, p. 237 .

9. L. Brewer, L. Bromley, P.W Gilles and N. I. Lofgren, "The Thermodynamic Properties and Equilibria at High Temperatures of the Compounds of Plutonium", N.N.E.S. Div。IV, I4B, p. 861, McGraw-Hill Book Co。

10. F。D.Rossini, D. D. Wagman, W.H. Evans, S. Levine and I。 Jaffe, Selected Values of Chemical Thermodynamic Properties, National Bureaú of Standards Circular 500 . 
11. R. Fowler and E. A. Guggenheim, Statistical Thermodynamics, Cambridge University Press.

12. N. Jo Hawkins, H. C. Mattraw and W.W. Sabol, Infrared Spectrum and Thermodynamic Properties of PuF 6 , KAPL-1007, May 24, 1954.

13. John G.MaIm and Bernard Weinstock, Argonne Plutonium Hexafluoride Program, ANL -5366 (Secret)。

14. J. J. Katz and E. Rabinowitch, "The Chemistry of Uranium", N.N.E.S. Div, VIII, 2, p. 436 .

15. F. D. Rossini, The Thermodynamics and Physics of Matter, Princeton University Press, p. 345 .

16. "Fo Joef Witt, "SOL: An Oracle Code for the Solutioxir of Certain Second Order Linear Partial Differential Equations" " ORNL Beport Number 2585. 


\section{ILIST OFF FIGURES}

(1) Withdrawal of fluid through porous palil.

(2) Variation of effectiveness of vortex formation, $v_{0}(I) / \mathrm{v}_{\mathrm{g}}$. With bleed to radial mass flow ratio, $M_{\text {od }} / m_{I}$, and dimensionless tube radius, $x_{W}^{\circ}$

(3) Comparison of rortex tube shear layer velocity profile with Blasius and asympitic flat plate suction profiles.

(4) Variation of ratio of shear lajer displacement thickneas to tube radius, $\delta * / r_{W}$, with bleed mass flow rate and dimensionless tube radius.

(5) Model used for calculation of effectiof wall bleed on vortex diffusion.

(6) Schematic of gasoturbine driven recirculation system.

(7) Permissible mass flow ratios for gas-tuibine recircuration system, as function of compressor presisure ratio and total pressure loss ratio.

(8) Variation of maximn dimensionless heat exchanger enthalpy rise with turbine outilet tempergture, for hyarogen.

(9) Vortex tube temperature ratios requifed by gasmturbine recirculation systems.

(10) Schematic of propellast-turibine ariven recirculation system.

(11) Permissible mass Plow sotios for propellant-turbine recirculation system, as function of ratio of throbse and heat exchanger enthalpy changes and. total pressure loss ratio.

(12) Vortex tube temperature ratios required by propeltantaturbine recirculation system.

(13) Varistion of macroscople f'ission cross section with product or vortex outlet pressure añ maximam value of ratio of fuel density to propellant deasity, for typical vortex reactors.

(14) Variation of inflaite medium muliiplication constant with macroscopic fission cross section for typical vortex reactors.

(15) Variation of reactor (core plui reflector) weight with reflector thickness for typical grapartendaberylium moderated reactos.

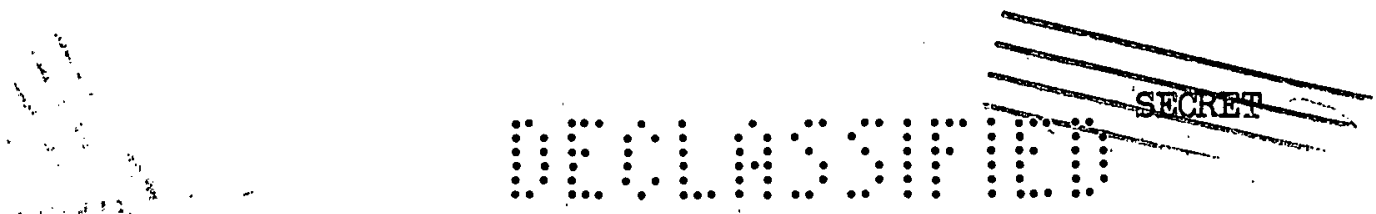


(16) Variation of core radius with reflector thickness for typical reactors.

(17) Variation of critical mass with macroscopic fission cross section for minimum wieight reactors.

(18) Variation of reactor (core plus reflector) weight with moderator void fraction for typical reactors.

(19) Variation of core radius with moderator woid fraction for typical reactors.

(20) Vapor pressure limited concentrations for possible fuel carrièrs.

(2i) Free energy change and equilibrium constant for the reaction of gaseous $\mathrm{PuF}_{3}$ and $\mathrm{H}_{2}$ to form gaseous $\mathrm{Pu}$ and $\mathrm{HF}_{0}$

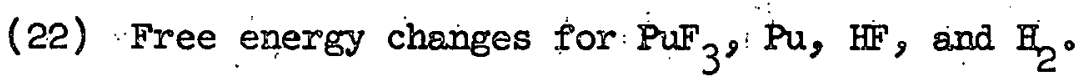

(23) Concentrations of HF required to maintain given total fissionable material concentration; as function of temperature.

(24) Development of dimensionless fission fragment concentration, $\eta$, with dimen. sionless time, $\xi$, for $r_{c}^{*}=0.725$.

(25) Variation of dimensionless concentration at inner boundary $\left[n_{c}\left(r_{c}^{*}\right)\right]$, with dimensionless time; $\xi$, for $\mathrm{r}_{\mathrm{c}}^{*}=0.725$.

(26) Dependence of asymptotic fission product profile on position of inner boundary, rete $^{*}$

(27) Development of dimensionless fission fragment concentration, $ף$, with dimensionless time, $\xi$ for r $=0.525$.

(28) Variation of dimensioniess concentration at inner boundary $[\eta($ ro $)]$, with dimensiontess time, $\xi$, for $r_{c}^{*}=0.525$. 

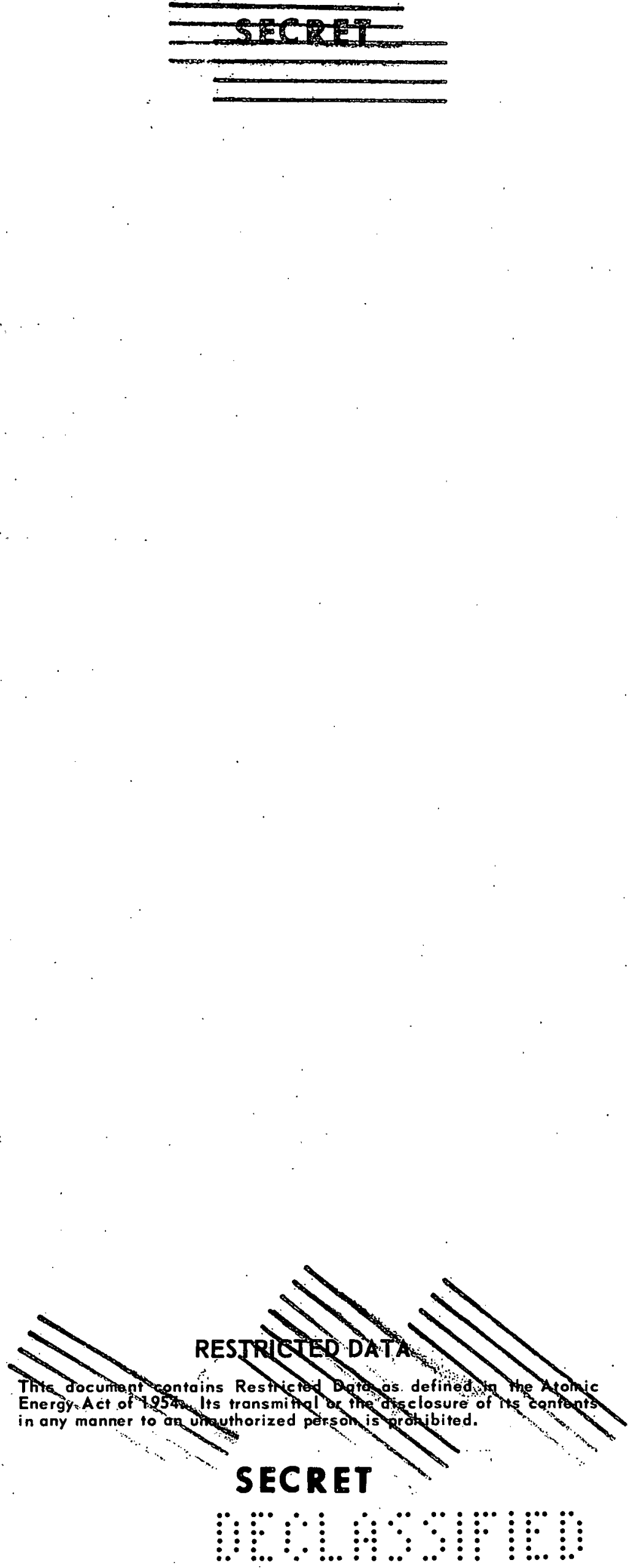